Portland State University

PDXScholar

Winter 3-14-2018

\title{
A Spatial Analysis of Ceramics in Northwestern Alaska: Studying Pre-Contact Gendered Use of Space
}

Katelyn Elizabeth Braymer-Hayes

Portland State University

Follow this and additional works at: https://pdxscholar.library.pdx.edu/open_access_etds

Part of the Anthropology Commons

Let us know how access to this document benefits you.

\section{Recommended Citation}

Braymer-Hayes, Katelyn Elizabeth, "A Spatial Analysis of Ceramics in Northwestern Alaska: Studying PreContact Gendered Use of Space" (2018). Dissertations and Theses. Paper 4357.

https://doi.org/10.15760/etd. 6250

This Thesis is brought to you for free and open access. It has been accepted for inclusion in Dissertations and Theses by an authorized administrator of PDXScholar. Please contact us if we can make this document more accessible: pdxscholar@pdx.edu. 
A Spatial Analysis of Ceramics in Northwestern Alaska:

Studying Pre-Contact Gendered Use of Space

by

Katelyn Elizabeth Braymer-Hayes

A thesis submitted in partial fulfillment of the requirements for the degree of

Master of Science

in

Anthropology

Thesis Committee:

Shelby L. Anderson, Chair

Virginia L. Butler

Douglas C. Wilson

Portland State University

2018 


\section{Abstract}

Activities and production among ethnographic Arctic peoples were primarily divided by gender. This gendered division of labor also extended to a spatial segregated pattern of the household in some Arctic cultures. Other cultures had a more gender-integrated spatial pattern of the household. There have been very few archaeological studies of gender in the Arctic, and even fewer studies of gendered use of space.

In this thesis, I evaluated the existence of this gendered use of space in pre-contact Northwest Alaska. I also evaluated the existence of discrete activity spaces. I drew from both ethnoarchaeology and gender/feminist archaeology to both construct my hypotheses and interpret my results. I used ceramics, which were likely primarily made by and used by women, as a proxy for women's movement within the house. Ceramics are abundant and well-preserved in many Northwestern Alaskan sites, and are well suited for a robust spatial analysis. In addition to ceramics, I also evaluated the spatial density of other female artifacts, like ulus or scrapers, and male artifacts, like harpoon points or adzes, in order to further test the existence of gender specific use of space.

I tested this using the HDBSCAN (Hierarchical Density Based Spatial Clustering of Applications with Noise) algorithm in Python, a programming language. HDBSCAN identifies discrete clusters of artifacts, as well as the persistence, or stability, of the cluster. Birnirk and Thule era (1300-150 BP) house features from Cape Espenberg, Alaska, were used to test these expectations.

Based on the results of my spatial analysis, I did not find any evidence of gender specific use of space, nor did I find specific activity areas within the house. My findings 
are not necessarily an indication that gender-segregated use of space does not exist among pre-contact Northwest Alaskan people: I just did not find evidence supporting it. This could be, in part, due to issues of sample size, house size, and the role of secondary and post deposition processes in shaping the ceramic assemblage and distribution. While ceramics did cluster, they mostly clustered in the entrance tunnel of the house. This is likely the result of cleaning, storage, or other depositional processes. When ceramics did cluster in the main rooms, clustering was idiosyncratic. Male and female artifacts were not spatially segregated. Female artifacts were slightly more likely to cluster than male artifacts. Both sets of artifacts were generally in the same area as the ceramic clusters. While this study did not find evidence of gendered use of space, it still is an important contribution of addressing questions of gender in the Arctic. In addition, it is a valuable methodological contribution, using a clustering algorithm that previously has not been frequently used by archaeologists. 


\section{Acknowledgments}

First and foremost, I'd like to thank my advisor, Shelby Anderson, for her continuing support and unwavering dedication throughout this thesis process. Words aren't enough to express how grateful I am for your guidance during my graduate school career. Thank you to my committee, Virginia Butler and Doug Wilson, for their extremely valuable input on this project.

This work could have never been completed without the wonderful people involved in the Cape Espenberg Project, and the Cape Espenberg Birnirk Project. I would like to thank all of those involved for your work on the site and excavations. Thank you to Christyann and John Darwent for the use of the maps and field drawings, and the use of the catalog in this thesis. Thank you to Lauren Norman, for your work on Feature 87 and your invaluable help with all of my questions. Thank you to Pat Reed for your help on the final ceramic counts and the volume.

I am so grateful for all of my fellow grad students. Thank you for your friendship. It means more to me than you know. Thank you to my parents, Jon and Mary, for their constant support.

Finally, thank you to my husband, Matt Braymer-Hayes. It's not hyperbole to say I couldn't have done this without you. Thank you for teaching me Python and questioning my methods (I appreciate it now). Thank you for your absolute faith in me, even when I didn't have faith in myself. Thank you for telling me I could finish this, doing more than your fair share of housework, and pouring me glasses of wine when you knew I needed them. 


\section{Table of Contents}

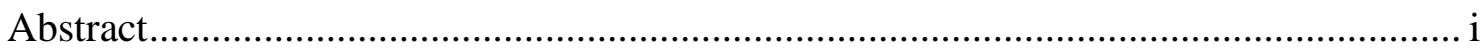

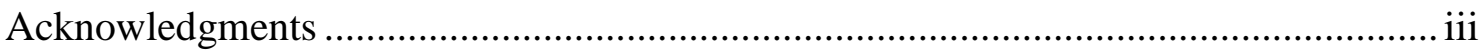

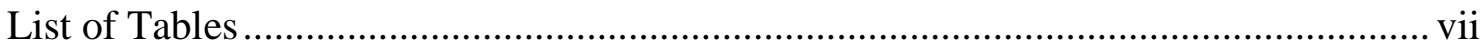

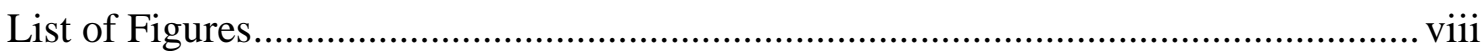

Chapter 1: Gender, Ethnographic Analogy and Use of Space in Northern Alaska......... 1

Theoretical Perspectives .................................................................................. 3

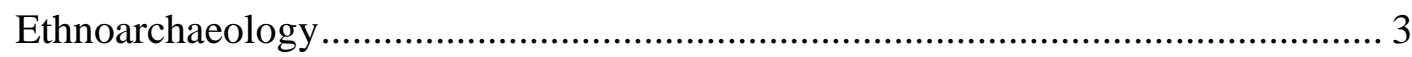

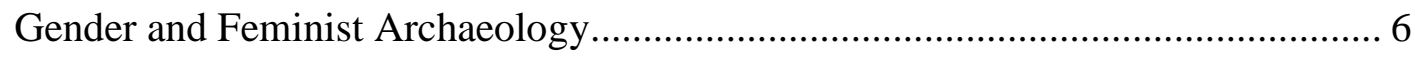

Gender, Space, and the Ethnographic Roles of Alaskan Women.............................. 9

Conceptualization of Gender Roles among the Historic Iñupiat ........................... 9

Hypotheses and Expectations ..................................................................... 12

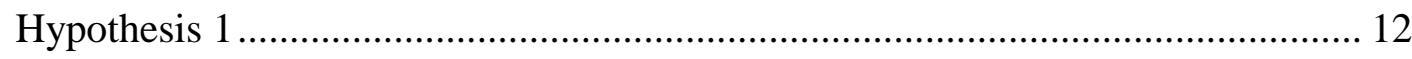

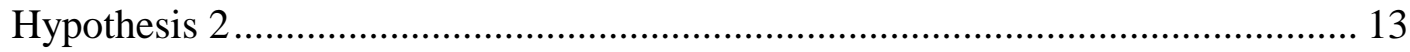

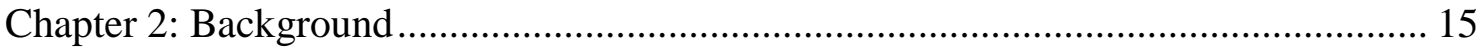

Northwest Coastal Alaska History ............................................................... 15

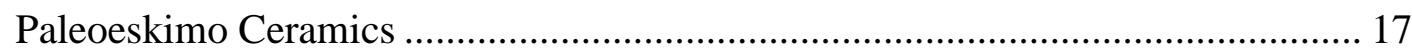

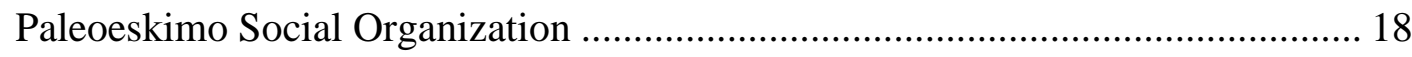

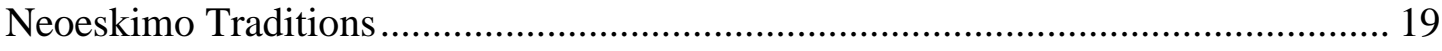

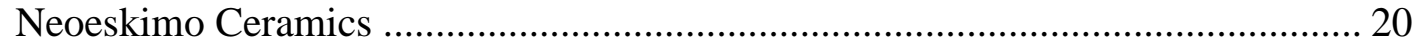

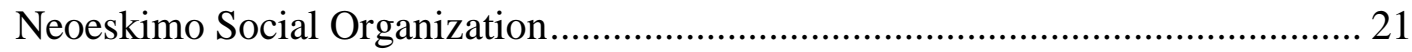

Ethnographic History in Northwest Alaska ...................................................... 22

Roles of Ethnographic Alaskan Women ........................................................ 25

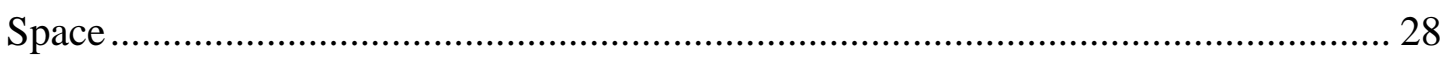

The Household as Socially Defined Space ......................................................... 28

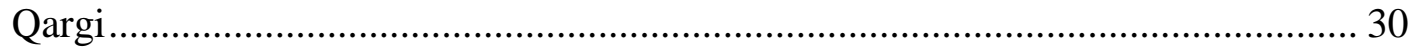




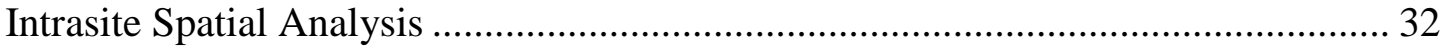

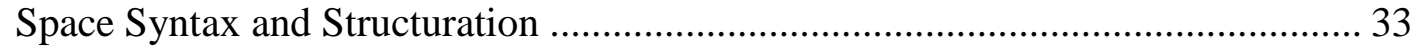

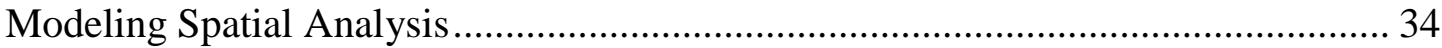

Site Formation Processes ................................................................................... 35

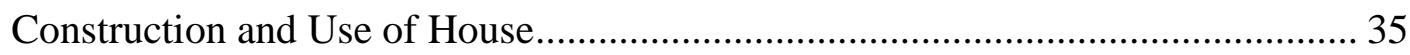

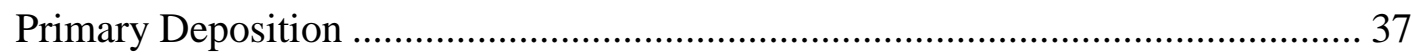

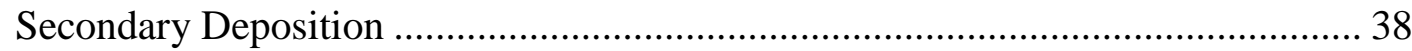

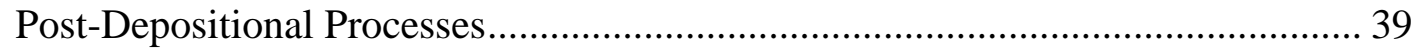

Chapter 3 Methods and Materials........................................................................ 42

The Cape Espenberg Site Complex ................................................................... 42

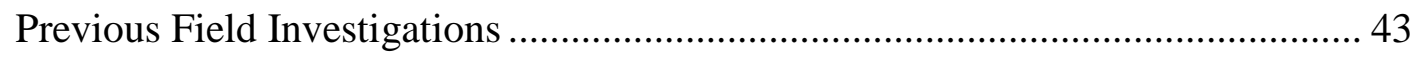

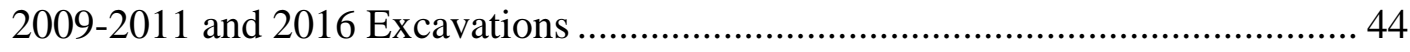

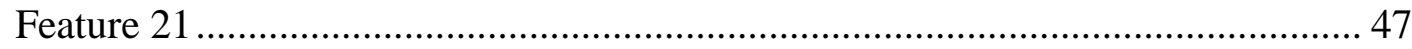

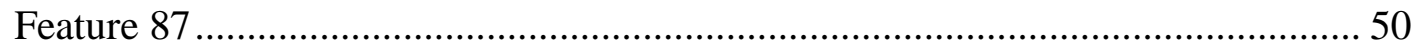

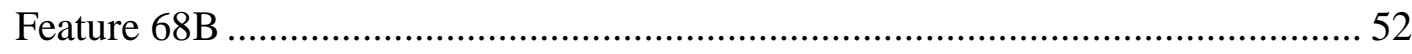

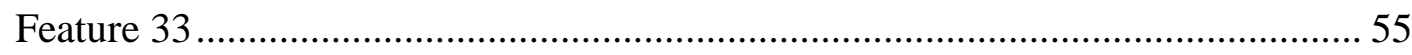

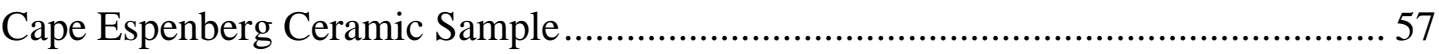

Excavated Volume and Ceramic Sample Size ..................................................... 59

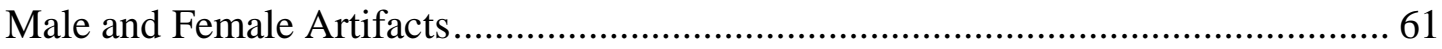

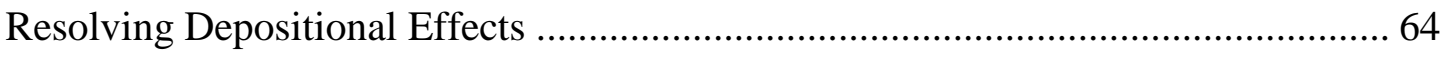

Depositional Effects Resolved Before Spatial Analysis ..................................... 64

Depositional Effects Resolved After Analysis through Study of Spatial Patterns and

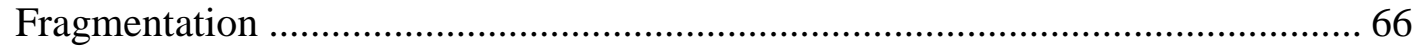

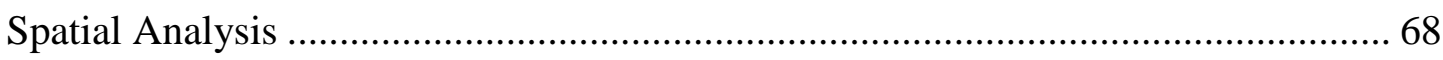

DBSCAN (Density Based Spatial Clustering of Applications with Noise)........... 69

HDBSCAN (Hierarchical Density Based Spatial Clustering of Applications with

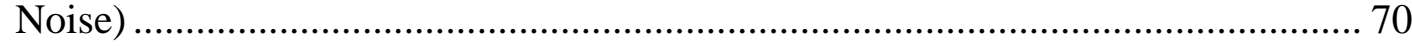

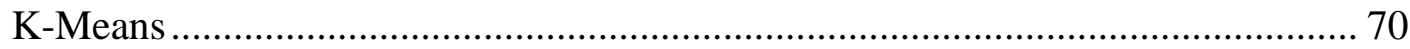

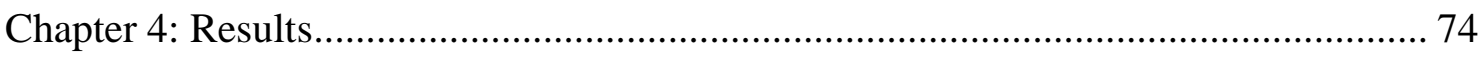

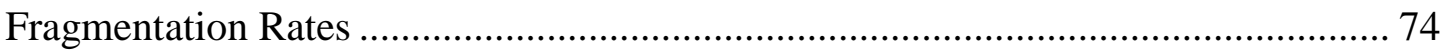




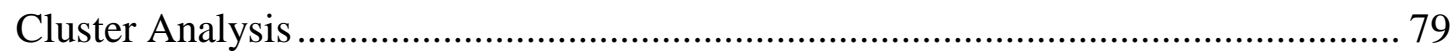

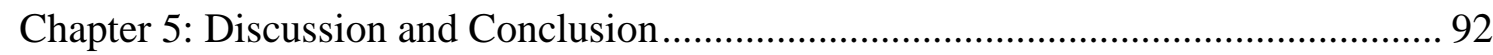

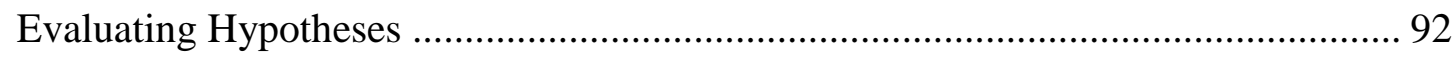

Hypothesis 1 Results-Evidence of Ceramic Clustering .................................... 92

Hypothesis 2 Results- Clustering of Ceramics with Other Women's Artifacts ...... 93

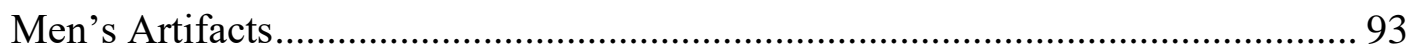

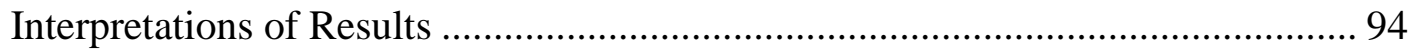

Data Limitations and Confounding Factors ...................................................... 96

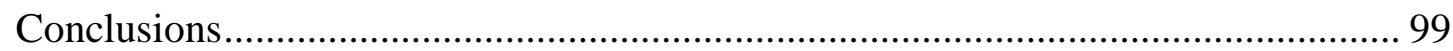

Spatial Analysis: Methodological Contributions ................................................ 102

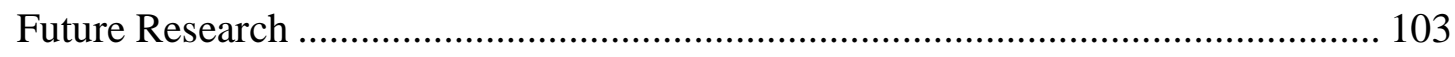

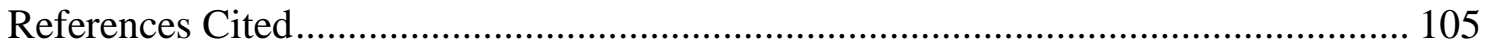

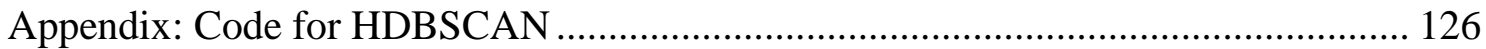




\section{List of Tables}

Table 1. Northern Alaskan Paleoeskimo traditions .................................................. 16

Table 2. Northern Alaskan Neoeskimo traditions present at Cape Espenberg.................19

Table 3. List of male, female and gender-neutral tasks..........................................26

Table 4. List of depositional and post-depositional processes and archaeological

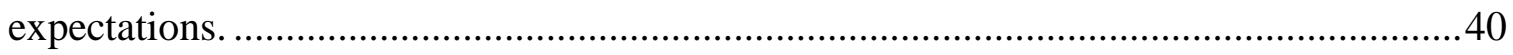

Table 5. Description of features selected for analysis at Cape Espenberg ......................46

Table 6. Number of total ceramics in Cape Espenberg assemblage as compared to

number of ceramics from floor levels that were used in spatial analysis. .......................57

Table 7. List of female, male, and gender-neutral artifacts and quantity found on floor

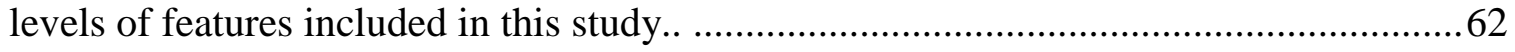

Table 8. Summary of artifact data from the floor of each analyzed feature. ..................74

Table 9. Comparative fragmentation of Cape Espenberg …......................................75

Table 10. Results of Kolmogorov-Smirnov test .................................................... 76

Table 11. Presence of, numbers of clusters, and cluster persistence for floor-level

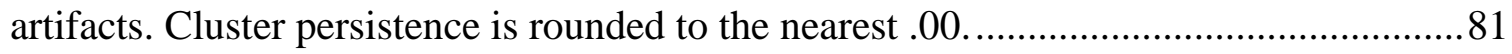

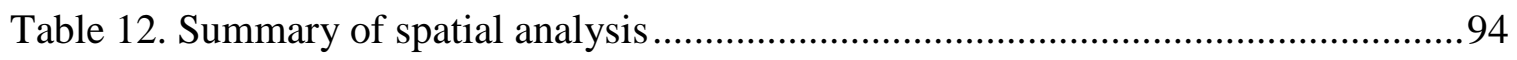




\section{List of Figures}

Figure 1. Cape Espenberg location..................................................................

Figure 2. Examples of Neoeskimo decorated pottery ............................................21

Figure 3. Location of some major villages on the Seward Peninsula ............................23

Figure 4. Excavated House Features within Cape Espenberg. .....................................45

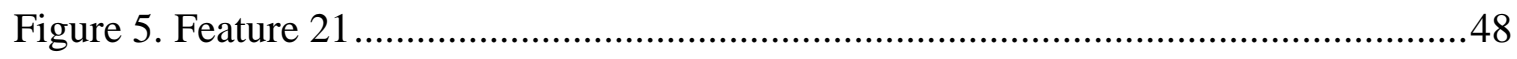

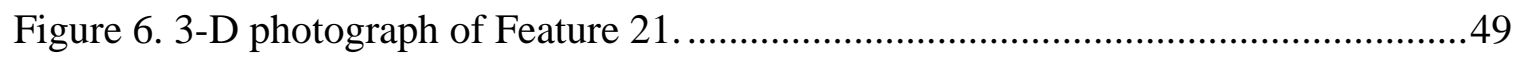

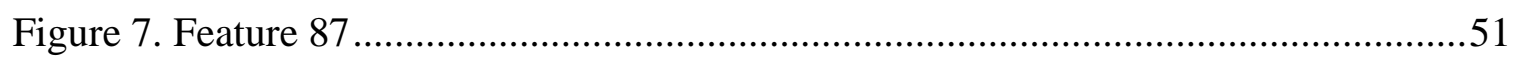

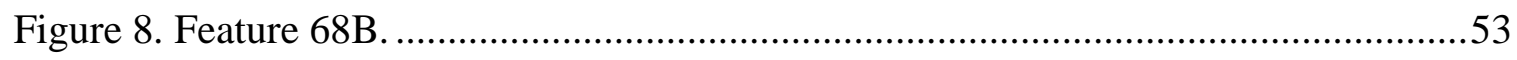

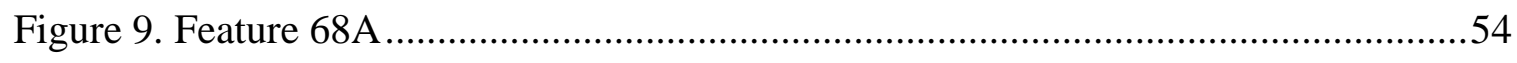

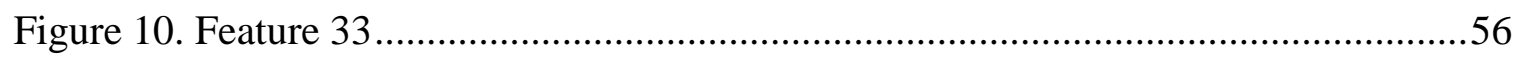

Figure 11. Relationship between sherd count and weight for floor deposits. ..................59

Figure 12. Scatterplot of excavated volume $\left(\mathrm{m}^{3}\right)$ against ceramics recovered.................60

Figure 13. HDBSCAN cluster result of 68Ars.................................................... 72

Figure 14. K-means analysis of Feature 68A ceramics............................................ 73

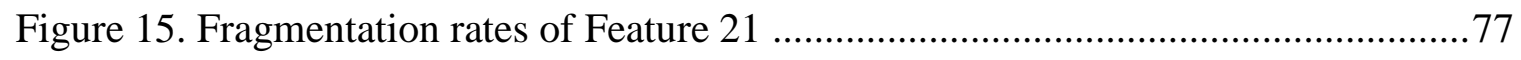

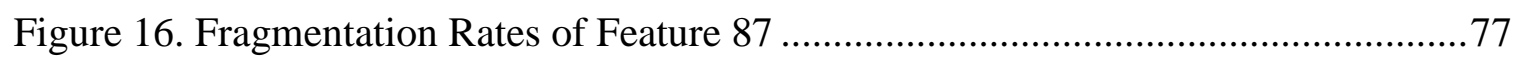

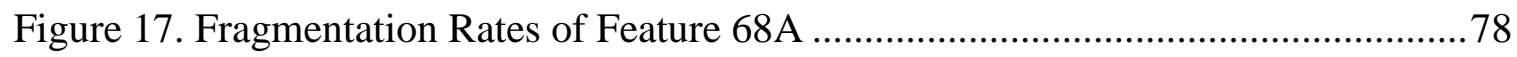

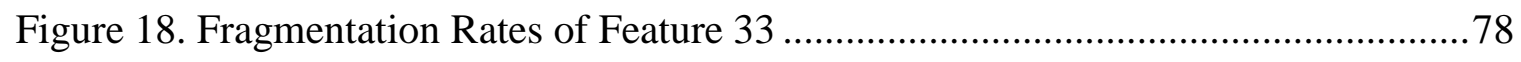

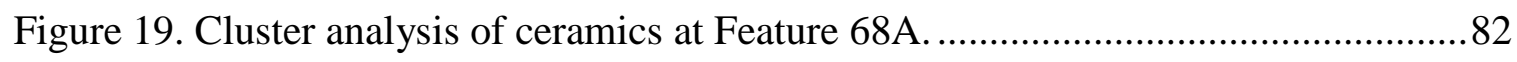

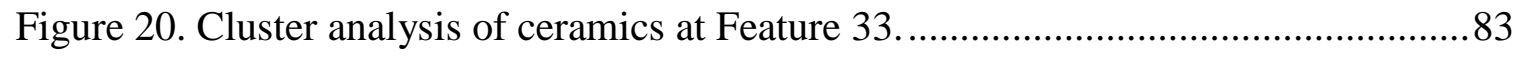

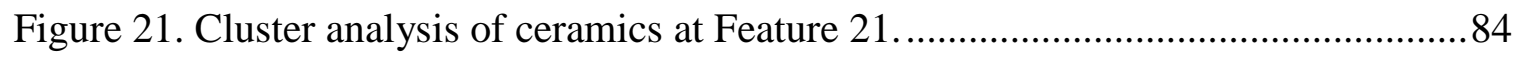




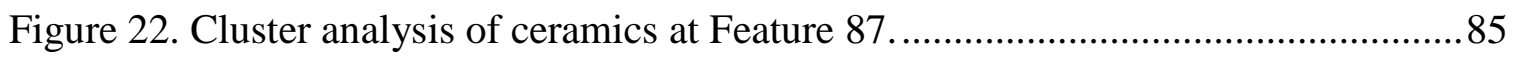

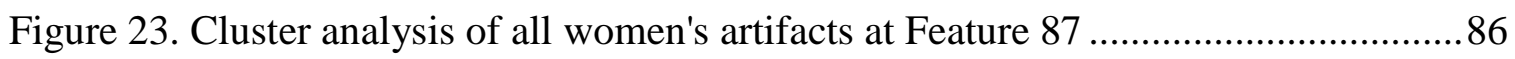

Figure 24. Cluster analysis of all women's artifacts at Feature 68A............................ 87

Figure 25. Cluster analysis of men's artifacts at Feature 21 ....................................89

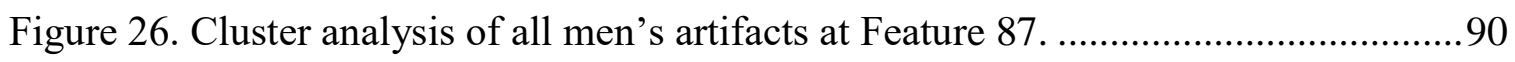

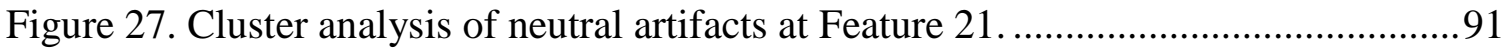




\section{Chapter 1: Gender, Ethnographic Analogy and Use of Space in Northern Alaska}

Like many hunter-gatherer societies (Estioko-Griffin and Griffin 1981, Kehoe 1995, Hawkes et al. 1997, Waguespeck 2005), activities and production among Arctic peoples during the 18th century contact era were primarily divided by gender (Ager 1980, Billson and Mancini 2007, Giffen 1930). Ethnographic evidence indicates that some of the cultures of Alaska extended this gendered division of labor to a spatially segregated pattern within the household (Giffen 1930, Spencer 1959). Other cultures in Alaska and the greater Arctic region had a less hierarchical, or more gender-integrated spatial pattern (Giffen 1930, Hennebury 1999). In this thesis, I study the use of household space in precontact Northwest Alaska, addressing the question of whether or not there was a gendered division of space in the past. This is one of only a few studies that address precontact gender in Northern Alaska (see also Reinhardt 2002, Whitridge 1999) and adds to the rather scanty archaeological literature surrounding gender in the Arctic.

In this thesis, I test intrasite ceramic spatial patterning within Northwest Alaskan archaeological sites and evaluate the existence of a gender specific use of space in precontact Northwest Alaska. Intrasite spatial analysis is a useful tool to study the patterns and behaviors of the micro-scale, such as intra and inter-household cooperation, (Hietla 1984, Hodder and Orton 1976, Hodson 1970), division of labor (Lyons 1992) and disposal patterns (Fowler 2011) as well as studying everyday activities, such as food preparation or tool production, and the traces these activities left behind. A spatial analysis of daily use objects, like ceramics, is an ideal way to uncover these everyday activities. Ethnographic evidence indicates that women were most likely the primary 
makers and users of ceramics (Burch 1998, Frink and Harry 2008). Therefore, I propose that ceramics can be used as an archaeological proxy for the organization of women's activity spaces in the Arctic household. Ceramics are abundant and well-preserved in many Northwestern Alaskan sites, unlike other evidence of gendered activities like clothing production.

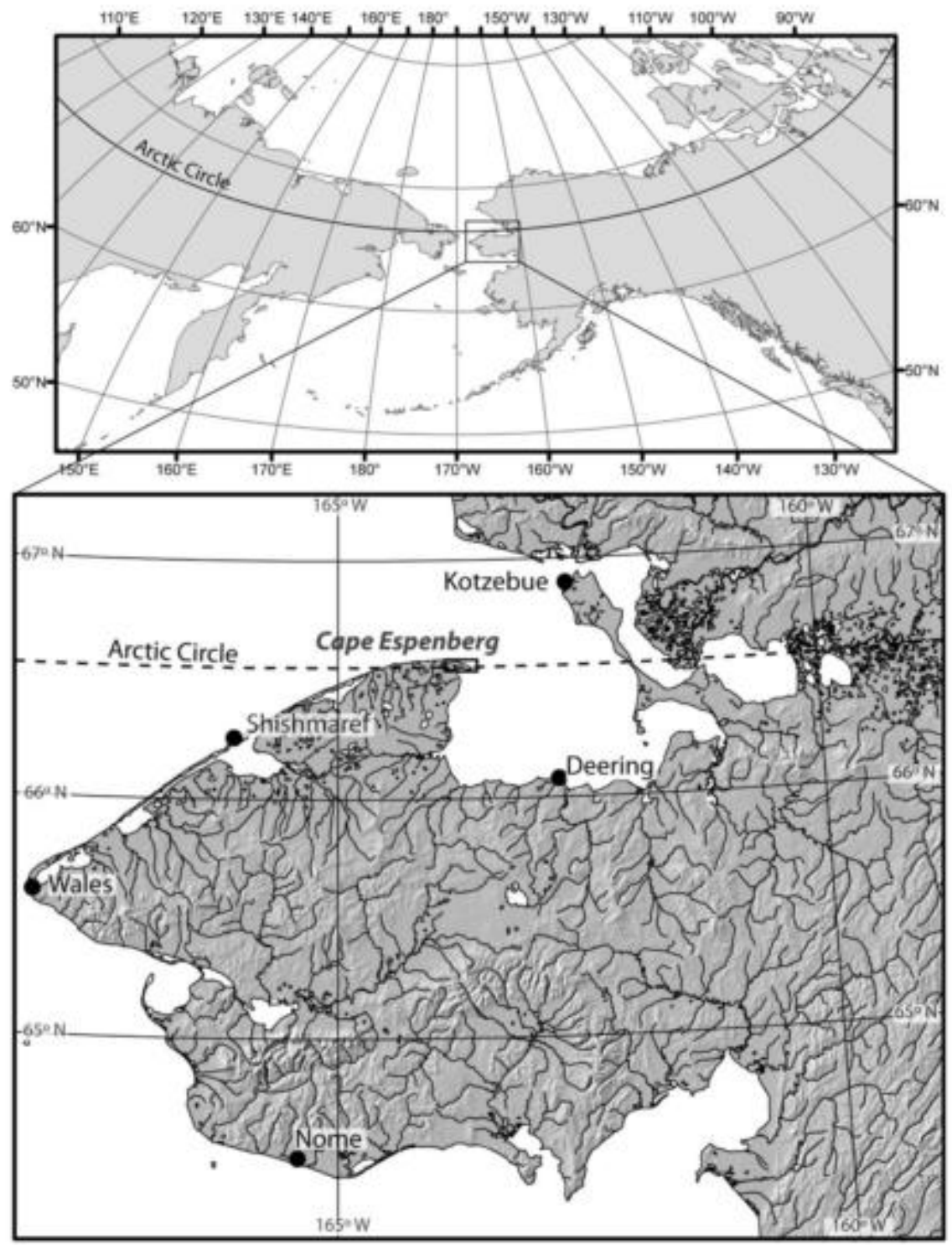

Figure 1. Cape Espenberg location (Cooper et. al 2014. Page 177: Figure 1). 
In this thesis, I use several spatial analysis tests to determine clusters of both ceramics and other gendered artifacts within five different Birnirk (approximately 1300-800 BP) and Thule Phase (1000-150 BP) house features at the Cape Espenberg site complex (Figure 1). The goal of this spatial analysis is two-fold: first, to identify potential clustering patterns that occur in pre-contact Western Alaskan houses and second, to evaluate these clusters as possible evidence for the existence of separate activity spaces for men and women within the house. To evaluate the cluster results, I draw from two main theoretical perspectives: ethnoarchaeology and gender/feminist archaeology.

\section{Theoretical Perspectives}

\section{Ethnoarchaeology}

Most of the core assumptions that shape my analyses and interpretation come from the use of ethnographic analogy and ethnoarchaeology. These terms refer to the use of comparative data from modern or ethnographic period societies to inform reconstructions of past human societies (Currie 2016). My assumption of women's roles in ceramic production and the gendered nature of some tools in pre-contact Northwestern Alaska is derived from ethnographic resources in the same area from the late 18th to early 20 th century (e.g. Burch 2006, Giffen 1930, Spencer 1959). One major complication of using ethnographic analogy is the influence of European contact on Native Alaskan cultures. Obviously, European contact had a major impact on Indigenous societies and on recorded ethnographic data. We cannot directly correlate all post-contact information to pre- 
contact sites (Wiley 1982), but ethnographic information can inform archaeological interpretations.

Though the use of ethnographic analogy has undoubtedly broadened our interpretation of the archaeological record, analogical inference has always held an uneasy place for archaeologists (Wylie 1985). Many ethnographies written in the early part of the twentieth century, especially those about native peoples, are androcentric, or Eurocentric, if not outwardly bigoted (Albers and Medicine 1993, Whelen 1995). Another critique, and one that is not so easily addressed, is the problem with the use of analogy itself. An analogy does not prove or test anything. Instead, it offers a lens of interpretation. If one accepts that all cultures are historically unique and cannot be compared to one another, then the use of ethnographic analogy is not appropriate (Johnson 2010). This critique is primarily directed towards early use of ethnographic analogy in archaeology, which often involved making unfortunate assumptions about hunter-gatherer peoples living in a pristine, untouched, unchanging state (Gould and Watson 1982, Wylie 1985).

While recognizing the potential problems of ethnoarchaeology, the information found in ethnographies help archaeologists see possibilities in interpreting archaeological sites, as in the classic example of smudge pits and hide smoking (Binford 1967). Binford used ethnographic analogy to explain the occurrence of small caches of carbonized corncobs in south-central Illinois archaeological sites. Archaeologists had interpreted these small pits as post molds, ceremonial features, or as a way of controlling mosquitos (Binford 1967: 6). But, these caches exhibited little internal variability, so Binford proposed that they represent a single type of feature and a single activity, hide smoking pits with corn cobs 
used as fuel. Binford drew on ethnographic examples of this activity in several Indigenous groups from the southeast United States. The use of ethnographic analogy in this case does not prove these pits were hide smoking pits, but it provides an explanation, or a set of archaeological expectations, that can be further tested against alternative hypotheses (Binford 1972).

Archaeologists need to both be aware of ethnographic data and beware of it because of the possibilities for bias within the ethnographic record. However, even flawed ethnographic data can be an appropriate analogy for a particular site if it is subject to methodologically self-critical archaeology (Wylie 1985). As Wylie (1982a, 1985) argues, the strength of the ethnographic analogy is increased the more criteria of number and nature of similarities in form. Both Wylie and Hodder (1982) argue for relational analogies, rather than formal analogies. A formal analogy is an analogy made with the assumption that if some elements of two objects or contexts are similar, other elements (most typically function) must also be similar (Lane 2005). Formal analogies are often made with lithics. If one tool in France is similar to one in America, a formal analogy supposes that their function is similar. Those who make formal analogies are often accused of cultural uniformitarianism (Watson and Gould 1982). A relational analogy, on the other hand, depends on some form of demonstrated cultural continuity between the ethnographic and archaeological groups (Wylie 1985). A similar concept is a direct, or specific, historical analogy. Analogical reasoning can incorporate different sorts of background knowledge and can be systemically tested for plausibility and strength (Wiley 1985). In this research, I am instead making an analogy between the technology 
and spatial patterns of Iñupiat groups of the ethnographic period (the 18th century) and their direct ancestors (Raghaven et al. 2014).

The use of ethnographic analogy in Alaska is more accepted than in many other places mostly due to the comparatively late colonial history, uninterrupted Indigenous occupation, and the retention of subsistence economies into the present day. Most Indigenous Alaskans were not removed from their land or distanced from subsistence practices, and other traditional or ancient practices, with the notable exception of the introduction of Christianity (Frink 2008, Jarvenpa and Brumbach 2006, Shepard and Reinhardt 2002). Indigenous Northern Alaskans are also the direct descendants of the Thule culture-bearing people (Darwent et al. 2013), and material culture of the $18^{\text {th }}$ century is very similar to pre-contact material culture. The ethnographic period does not represent all evidence, there were cultural and material culture changes between the Thule phase and post-contact Iñupiat people, but there is a historical relationship between the people living across this 1000 year time period. Ethnographic data are widely used in the Arctic to make archaeological assumptions (Brumbach and Jarvenpa 2006, FienupRiordan 1983, Frink and Harry 2008, Harritt 2013). I am therefore confident in assuming that pre-contact Arctic women performed similar economic and production activities to women during the ethnographic period.

\section{Gender and Feminist Archaeology}

At the beginning of this introduction, I referred to gender as a primary means of structuring labor within many hunter-gatherer societies. While this is true, it is important 
to note that "gender is constructed by society at the same time as it is a primary structure for society" (Sorenson 2000: 10). Gender archaeology and the use of a feminist epistemology when approaching archaeological material can bring a unique perspective on labor. Archaeology was characterized by an ungendered but male-biased narrative until the 1970's. Through the 1980's and early 1990's there was an increasing concern for greater visibility of women and attention to equality of recognition and representation of women in the past (Gilchrest 1999). Today, most academic feminism is third-wave feminism, which has roots in both poststructuralism and postcolonialism.

Poststructuralism rejects the narrative of "essential" characteristics or experiences that typifies men or women. Instead, the emphasis is on the difference of experiences between men and women or between women of different ethnicity or social class. There is very little orthodoxy in gender archaeology, and very little gatekeeping on what is or is not gender archaeology (Nelson 2006). This is not necessarily a bad thing. It means that gender archaeologists can draw from varying fields of theory, from human behavioral ecology (Whelan et al. 2013) to postmodernism (Adovasio, Soffer, and Page 2007).

Gender is now recognized as a necessary part of any explanation of social relations and social systems (Sørenson 2000). One of the tasks of gendered archaeology is to question and clarify whether gender is always relevant and at what level and what form. Modern versions of feminist and gender archaeology, influenced by third-wave feminism and intersectionality, often include both (and sometimes more than two) genders (Bolger 2013b). For example, throughout North America, many groups had third or fourth genders for non-conforming males and females (Lang 1998): the kipijuituq among the 
Netsilik of Nunavut (Stewart 2002), the Lhamana of the Zuni (Roscoe 1991) or the Miati of the Hidatsa (Murray 1994). These do not necessarily reflect homosexuality, nor simply cross-dressing. Rather, they are distinct categories of acceptable social interaction (Hill 1998). This is because different genders are often defined in relation to one another. That is, they are defined by what they are, but also by what they are not (Brumfiel 2006).

My research draws from gender and feminist theory because it is about how women intentionally construct space and conduct activities within a house. Like many other feminist approaches, this emphasizes female agency. I assume that the women of Cape Espenberg intentionally made choices that impacted their daily lives and, at a broader level, their culture. My own application of feminist-focused archaeology draws from a few key paradigms (from Bolger 2013a, Conkey and Gero 1991, Nelson 1997). First, my approach is focused on neither biological nor psychological essentialism. While gender is the primary social variable of the labor process in forager or hunter-gatherer societies, the idea of man the hunter/woman the gatherer (or man the hunter/woman the childbearer) is more of an imposition of American postwar values and sexual ideology than an actual reflection on prehistory or hunter-gatherer cultures (Kent 1995). More briefly, as Javenpra and Brumbach (2006) state, “Ozzy and Harriet do prehistory”. Second, the gendered division of labor that is one of the foundations of my assumptions is only applicable to the Iñupiaq and their ancestors in Northwest Alaska. Any conclusions I draw or explanations I develop cannot be applied to another unrelated culture. My research on gender-specific use of space is limited and discrete. Third, while the crux of this research is on the differences between female and male activities, it does not mean 
that other categories of differences, such as relative age, are not equally as meaningful and important.

There have been challenges to the idea of attributing gender to a particular type of artifact or to a feature, not only because this might be overly simplistic (Kent 1995), but

more importantly, gender attribution has been accused of merely considering gender as another checklist item, the "add women and stir" approach (Nelson 1997, Tomášková 2011). It is true gender attribution can sometimes lead to consideration of gender being no more than a methodology for making male and female activities visible (Gilchrest 1999). However, gender attribution is necessary to create the human quality of the past, to replace the 'faceless blobs' of prehistory (Tringham 1991).

\section{Gender, Space, and the Ethnographic Roles of Alaskan Women}

\section{Conceptualization of Gender Roles among the Historic Iñupiat}

Gender, as well as sex, is historically and cross-culturally unstable (Butler 1993, Fausto-Sterling 2000). By no means are the gender roles discussed here typical of cultures outside of the very limited spatio-temporal period of Neoeskimo and ethnographic Iñupiat of the Northwest Alaskan Coast. Many Arctic texts minimize the importance, or even discussion of gender relations and focus instead on technoenvironmental adaptations (Damas 1972, Dumond 1987). There also exists a largely essentialist narrative of Arctic woman as the food gatherer, child care giver, and sewer. Of course, they did do all these tasks, but this ignores the diversity of women's daily lives (Ortner 1974, Woodhouse-Beyer 2001). 
The fundamental economic unit in Iñupiat culture (and by inference, pre-contact Thule culture) is a married man and woman. Among the historic Iñupiat, men and women had very specific and clear economic roles to perform (Jarvenpa and Brumbach 2008, Giffen 1930, Burch 2006, Nelson 1899). Gender differentiation in space and facilities seems to be connected with economic specialization. The division of labor is often seen as an exclusionary, rather than a complementary, procedure (Conkey and Gero 1991). However, in the Arctic the roles are not mutually exclusive, but are often complementary and focused on the nuclear family, the husband and wife, as a team rather than individuals (Jarvenpa and Brumbach 2008).

There is often an implicit assumption that women's tasks are simple, expedient and irrelevant (Gifford- Gonzalez 1993, Hoffman 2002, Kehoe 2005, Spector 1993). Women in large-game hunter-forager societies are typically portrayed in a limited array of roles, as Waguespack says of Clovis women as "plant gatherers, hide scrapers, and breast feeders" (Waguespack 2005: 667). These have been seen as less valuable roles than hunting by researchers in the same way many women's activities have been seen as less valuable by Euro-American researchers (Moss 1993). This is true all over the world and Native Alaska is no exception. However, as widespread as this assumption is, it is far from the truth. These "simple, expedient and irrelevant" tasks often take years of training and practice and not all people become masters (Frink 2009). While early ethnographic and missionary accounts (generally written by men) extolled the role of man, the hunter, and diminished the role of the woman (Kent 1995), portraying her as little more than a 
subservient woman with little economic value (Ager 1980), neither partner was peripheral or marginal to survival (Billson and Mancini 2007, Briggs 1974).

Despite the fact that there is often overlap of the actual roles of men and women (women may be considered the primary sewers, but it would be dangerous for a man to be on a hunting trip, rip his parka and not know how to fix it), there is a very real and ideal pan-Arctic division of labor based on gender (Barker 1993, Friedl 1975, Jarvenpa and Brumbach 2006, Mason 1891). In addition, while men and women might have used each other's tools (Jenness 1922), many parts of Iñupiat material culture are intrinsically connected to gendered practice (Whitridge 2004). The processing and storage techniques developed by women in the Arctic would have been crucial for the survival of both men and women. Men might have hunted the big game, but women preserved animal products to ensure a regular supply of food. Once they touched that food, it became their property and theirs to divide. Similarly, the manufacture of clothing (a woman's role) was of paramount importance in the Arctic in the prolonged cold. Rasmussen noted "It is the task of the woman to make and mend the man's clothes no less than it is his to get the daily food" (1921: 18). This clear ideological split of labor manifests itself on a practical and daily level. My research aims to test whether or not this gendered division of labor extends into a division of activity spaces as well. Based on ethnographic evidence, there are specific male or female tools, as well as gender-neutral artifacts. If the ideological division of labor manifests itself in the organization of household activity spaces, then these gender-specific artifacts should be located in different areas of the house. 


\section{Hypotheses and Expectations}

To test for the existence of gendered activity spaces, I propose two working hypotheses that I will evaluate through spatial analysis.

These hypotheses are predicated on three assumptions. First, that women were the ceramic makers and users. Second, that the people of Cape Espenberg had clearly defined gender roles, which were either spatially segregated or integrated. Third, that these gender roles were expressed in a way that is identifiable within the archaeological record.

Question 1: Are there any patterns in the distribution of ceramic sherds at Cape Espenberg?

\section{Hypothesis 1}

The null hypothesis is that the ceramics will have random or pseudo-random distribution with little to no consistent clustering. The alternative to this hypothesis is that there will be consistent clustering in discrete areas. Consistent clustering is when the clusters are in similar areas of the house (i.e., near hearths, in tunnels, around benches, etc) across the different house features,

Based on testing of Hypothesis 1, I evaluated Hypothesis 2. 
Question 2: Do ceramic clusters overlap or cluster spatially with women's artifacts or areas within the house?

\section{Hypothesis 2}

The null hypothesis is that women's artifacts do not cluster or do not cluster in similar locations as ceramic clusters. The first alternative to this is that as a woman's artifact, ceramics will be clustered with women's artifacts and/or areas within the house. For this to be true, the ceramic clusters will be concurrent with other female-oriented artifacts such as needles, ulus or lamps and/or centered around areas associated with female activities like cooking and processing. These areas include hearths and areas designated as "kitchens." Other alternatives are that 1) ceramics may cluster with men's artifacts (e.g. harpoon points, adzes, bola weights) or 2) they may not cluster with men's or women's artifacts.

These hypotheses were tested using HDBSCAN (Hierarchical Density Based Spatial Clustering of Applications with Noise), a density based algorithm that maps the location of artifact clusters while eliminating noise (or individual objects not associated with any clusters). By interpreting this through a gendered lens (women's artifacts versus men's

artifacts), I am testing for a segregated use of space among the Birnirk and Thule culturebearing people. In addition, I am adding to the limited archaeological studies of gender, especially of the spatial distribution of women's activities and place within the household, in the Arctic. 
This thesis is organized into five chapters. In Chapter 2, I present archaeological and theoretical background to support the arguments made and evaluated over the course of this thesis. This includes a brief overview of the archaeological and ethnographic history of Northwest Alaska, an in-depth discussion of women's roles and ceramics, and a discussion of intrasite spatial analysis.

Chapter 3 discusses the background of prehistorical research in Cape Espenberg. It also includes the data used in the spatial analysis in this thesis and the methods I employ throughout, including a discussion on resolving post-depositional effects.

In Chapter 4, I present the results of my analysis and discuss how they relate to my original two hypotheses.

In Chapter 5, I draw conclusions based on the results and my knowledge of the contextual information. I discuss the possible existence of a gendered use of space in Northwest Alaska and present my own interpretation of the spatial analysis results. Possibilities for future research are also addressed. 


\section{Chapter 2: Background}

This background section is intended to give the reader necessary cultural context in order to interpret the results and discussion section. This includes a brief summary of northwest coastal Alaska prehistory, focusing on the development of household and social organization that culminates into what was observed during the ethnographic period. My focus is on Neoeskimo era contexts (1300-150 BP), but I have provided a larger context in order to understand the changes in technology and social organization. Also included in this section is a discussion of the daily roles of ethnographic Alaskans, including subsistence strategies that would make ceramic use more likely.

\section{Northwest Coastal Alaska History}

Northwest Alaska has been occupied for at least 12,400 years (Goebel et al. 2013), but I focus on the last 5500 years when the ancestors of modern Inupiat people first migrated to Alaska. The last 5500 years of coastal occupation can be very broadly split into two groups: Paleoeskimo (including Arctic Small Tool tradition (ASTt), Choris, Norton and possibly Ipiutak cultures) (Table 1) and Neoeskimo (including Old Bering Sea, Okvik, Punuk, Birnirk, and Thule cultures) (Table 2) traditions. There is no agreed upon development of pre-contact northern Alaskan culture (Dumond 2000); the development and interrelationships of culture complexes are still hotly debated. For example, some researchers (e.g. Darwent and Darwent 2016) subsume Choris Phase into the Norton Tradition. Other researchers (Lutz 1972) place Choris, Norton and Ipiutak with an expanded ASTt. This lack of agreement with the timeline and the relationships of these 
archaeological cultures demonstrates some of the uncertainty surrounding Alaskan prehistory. This culture history is intended to give a summary understanding of the development of household and gender organization that is observed in the ethnographic period.

Table 1. Northern Alaskan Paleoeskimo traditions

\begin{tabular}{|c|c|c|c|c|}
\hline Phase & $\begin{array}{c}\text { Approximate } \\
\text { Date Range }\end{array}$ & House Type & Ceramics & References \\
\hline $\begin{array}{c}\text { Arctic } \\
\text { Small } \\
\text { Tool } \\
\text { Tradition } \\
\text { (includes } \\
\text { Denbigh) }\end{array}$ & $4550-2800 \mathrm{BP}$ & $\begin{array}{c}\text { Shallow, semi- } \\
\text { subterranean sod } \\
\text { houses with short } \\
\text { entrance tunnels. } \\
\text { House floors were } \\
\text { either square or } \\
\text { round, with large, } \\
\text { stone-lined central } \\
\text { hearths } \\
\end{array}$ & No ceramics & $\begin{array}{c}\text { Giddings (1952, } \\
\text { 1964); Powers } \\
\text { and Jordan } \\
\text { (1990); Schaaf } \\
\text { (1988); Tremayne } \\
\text { (2015) }\end{array}$ \\
\hline Choris & $2750-2450 \mathrm{BP}$ & $\begin{array}{c}\text { Large, oval } \\
\text { structures with } \\
\text { stone-paved central } \\
\text { hearths }\end{array}$ & $\begin{array}{c}\text { Introduction } \\
\text { of pottery to } \\
\text { Alaska. Cord } \\
\text { marked and } \\
\text { linear } \\
\text { stamped } \\
\text { pottery. } \\
\text { Pottery thin, } \\
\text { hard/higher } \\
\text { fired, and } \\
\text { cylindrical in } \\
\text { shape. }\end{array}$ & $\begin{array}{c}\text { Darwent and } \\
\text { Darwent (2016); } \\
\text { Dumond (1982); } \\
\text { Harritt (1994); } \\
\text { Mason (2009); } \\
\text { Oswalt (1955); }\end{array}$ \\
\hline $\begin{array}{l}\text { Norton } \\
\text { Tradition } \\
\text { (Near } \\
\text { Ipiutak in } \\
\text { Northwest } \\
\text { Alaska) }\end{array}$ & $2500-2000 \mathrm{BP}$ & $\begin{array}{l}\text { Houses vary } \\
\text { depending on the } \\
\text { region, either small } \\
\text { houses with short } \\
\text { entrance tunnels or } \\
\text { large houses with } \\
\text { long entrance } \\
\text { tunnels. During } \\
\text { later periods of this }\end{array}$ & $\begin{array}{l}\text { Linear and } \\
\text { check } \\
\text { stamped } \\
\text { ceramics. } \\
\text { Pottery thin, } \\
\text { hard/higher } \\
\text { fired, and } \\
\text { cylindrical in } \\
\text { shape. }\end{array}$ & $\begin{array}{l}\text { Anderson (1979, } \\
\text { 1980); Dumond } \\
\text { (1982, 2000); } \\
\text { Harritt (1994); } \\
\text { Larson and } \\
\text { Rainey (1948); } \\
\text { Mason (2009) }\end{array}$ \\
\hline
\end{tabular}




\begin{tabular}{|c|c|c|c|c|}
\hline & & $\begin{array}{l}\text { phase, there is } \\
\text { evidence for some } \\
\text { larger structures }\end{array}$ & & \\
\hline Ipiutak & 1750-1150BP & $\begin{array}{l}\text { Driftwood log } \\
\text { structures with both } \\
\text { winter and summer } \\
\text { forms (the summer } \\
\text { houses lacking } \\
\text { entrance tunnels). } \\
\text { The houses are } \\
\text { variable sizes but } \\
\text { there are some large } \\
\text { structures that are } \\
\text { three or four times } \\
\text { larger than the } \\
\text { smaller houses }\end{array}$ & $\begin{array}{l}\text { No ceramics } \\
\text { associated } \\
\text { with Ipiutak } \\
\text { culture. }\end{array}$ & $\begin{array}{l}\text { Harritt (1994); } \\
\text { Mason (1998, } \\
\text { 2009); Schaaf } \\
\text { (1988) }\end{array}$ \\
\hline
\end{tabular}

\section{Paleoeskimo Ceramics}

While ceramic technology was adopted in the Russian Far East between 17,200 and 14,700 BP (Jordan and Zvelebil 2009), and reached the interior of Chukotka by 5000 BP (Ackerman 1982), pottery was adopted late among Alaskan people: only 2500-2800 years ago (Giddings and Anderson 1986, Ponkratova 2006, Stanford 1976). It is generally accepted that ceramics were adopted along with the other changes in material culture associated with the Choris archaeological culture (Dumond 1982, Giddings and Anderson 1986). Ceramic technology was adopted during a period of changing environmental conditions, increased sedentism and increased contact with Chukotkan people (Mason and Gerlach 1995, Mason 1998). Pottery may have been adopted for a number of reasons. Some hypotheses for pottery adoption are rendering and storing marine mammal and fish oil, parboiling foods, or for storing or processing oil as an exchange commodity (Anderson, Tushingham and Buonasera 2017). The aceramic Ipiutak are the exception to 
the other Paleoeskimo peoples. Possible explanations for the absence of pottery include a sudden decrease in the amount of fuel available for firing (Anderson 2011). Other hypotheses include a shift in cooking strategies due to changing subsistence patterns, or an increase in mobility (Anderson 2011; Mason 1998). The Paleoeskimo clay cooking pots were generally thin walled, round bottomed and decorated with linear, check or cord stamping (Anderson et al. 2011, Arnold and Stimmell 1983, Harry and Frink 2009). These early ceramics are quite rare, especially compared to the later Neoeskimo ceramics (Anderson 2016).

\section{Paleoeskimo Social Organization}

Data on Paleoeskimo cultural traditions are limited. Based on the available evidence, early Paleoeskimo cultural traditions were small-scale communities (Mason 2009). Sites usually include only one or two houses and it is likely the early Paleoeskimo were fairly mobile (Anderson 1984, Giddings and Anderson 1986). The early ASTt were highly mobile specialized caribou hunters (Tremayne 2015). Around as early as 1000 BP, sedentary, ranked communities started developing around the Bering Strait region (Mason 2009). This is demonstrated by larger communities with multiple sized houses, and burial goods within large cemeteries. The Ipiutak, in particular, were considerably complex and ritualistic, especially for a culture that was not based on whaling (Mason 1998). 


\section{Neoeskimo Traditions}

The Neoeskimo, or Northern Maritime Tradition, defined by Collins (1964) was likely the direct replacement of the Paleoeskimo Tradition. These two traditions likely represent two separate migrations of people from Siberia, based on genetic evidence, however, gene flow existed in both directions (Raghavan, et al. 2014). The Neoeskimo Tradition is comprised of the Punuk, Old Bering Sea, Okvik, Birnirk and Thule cultures. I will only describe the Birnirk and Thule culture assemblages, as they are the culture complexes found at Cape Espenberg. The Thule culture-bearing people were a distinct people from Paleoeskimo peoples and are the genetic and cultural ancestors of modern-day Inuit people (Raghavan et al. 2014). As with the Paleoeskimo groups, there is no smooth panregional change (Harritt 2004) and there was extensive overlap between culture complexes in Northwest Alaska. The Birnirk culture-bearing people are likely the cultural and genetic ancestors of the Thule; a larger goal of current Cape Espenberg research is exploring Birnirk origins.

Table 2. Northern Alaskan Neoeskimo traditions present at Cape Espenberg

\begin{tabular}{cccccc} 
Phase & $\begin{array}{c}\text { Approximate } \\
\text { Date Range }\end{array}$ & House Type & $\begin{array}{c}\text { Social } \\
\text { Organization }\end{array}$ & Ceramics & References \\
\hline Birnirk & $1300-700 \mathrm{BP}$ & $\begin{array}{c}\text { Small, } \\
\text { subterranean, } \\
\text { sod houses } \\
\text { with large } \\
\text { entrance } \\
\text { tunnels }\end{array}$ & $\begin{array}{c}\text { Later Birnirk } \\
\text { sees the } \\
\text { emergence of } \\
\text { whaling }\end{array}$ & $\begin{array}{c}\text { Line } \\
\text { decorated } \\
\text { and } \\
\text { concentric } \\
\text { circle }\end{array}$ & $\begin{array}{c}\text { Dumond } \\
(1988) ; \\
\end{array}$ \\
& & & Giddings \\
decorations \\
\end{tabular}




\begin{tabular}{|c|c|c|c|c|c|}
\hline Thule & 1000-150 BP & $\begin{array}{c}\text { Multiple } \\
\text { rooms in } \\
\text { houses, with } \\
\text { long entry } \\
\text { way passages } \\
\text { and } \\
\text { specialized, } \\
\text { discrete } \\
\text { kitchen areas }\end{array}$ & $\begin{array}{c}\text { Fully } \\
\text { developed } \\
\text { whaling } \\
\text { economy. } \\
\text { Major } \\
\text { evidence of } \\
\text { social status } \\
\text { and } \\
\text { differentiation }\end{array}$ & $\begin{array}{l}\text { Decorated } \\
\text { in a variety } \\
\text { of } \\
\text { regionally } \\
\text { specific } \\
\text { ways. }\end{array}$ & $\begin{array}{c}\text { Bockstoce } \\
\text { (1979); } \\
\text { Giddings } \\
\text { and } \\
\text { Anderson } \\
\text { (1986); } \\
\text { Mason } \\
\text { (2009); Park } \\
\text { (2010) }\end{array}$ \\
\hline
\end{tabular}

\section{Neoeskimo Ceramics}

By 1000 BP, the Neoeskimo pots were thicker than Paleoeskimo ceramics and had coarse-textured, soft pastes, tend to crumble and exfoliate easily and were either underfired or not fired at all (Harry and Frink 2009, Frink and Harry 2008). They were flat bottomed and flower pot or bucket shaped. While most pots were undecorated, some had distinctive decorations, including cord pressed or imprinted decorations (Figure 2). Mineral and non-mineral tempers are used frequently in both Paleoeskimo and Neoeskimo ceramics. Ceramics sherds from this time period are numerous in archaeological sites. Ceramic and clay source provenance studies (Anderson et al. 2011, Anderson 2016) indicate that ceramics circulated throughout Northwest Alaska, as a result of exchange or seasonal mobility. The main purpose for ceramic pots was cooking, seen by residue analysis, and storage of food. 


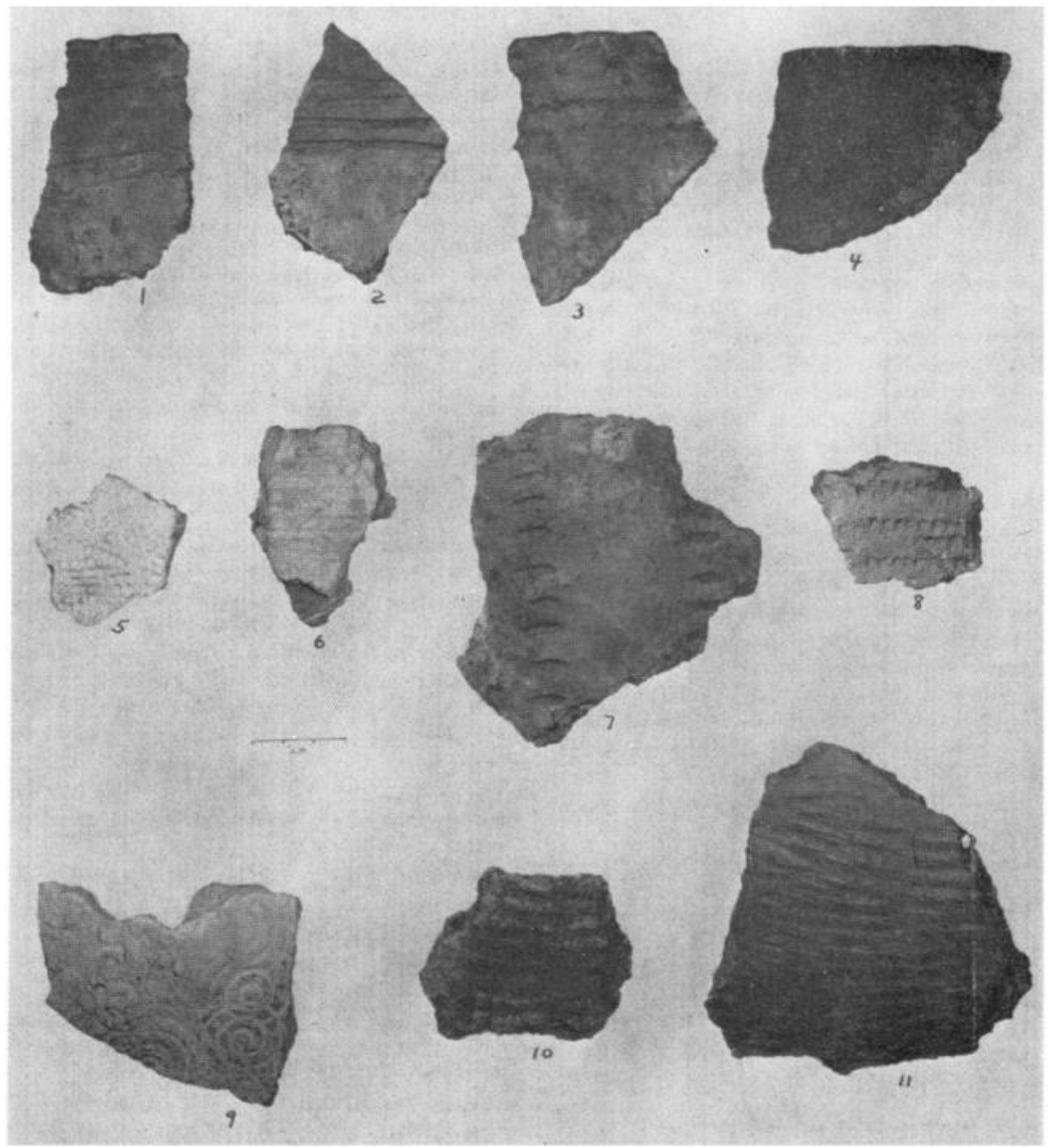

Figure 2. Examples of Neoeskimo decorated pottery (Oswalt 1955. Page 33: Figure 16)

\section{Neoeskimo Social Organization}

The influx of new people to Northwest Alaska brought both new technology and new social patterns (Mason 1998). There is evidence of increasing population and denser occupation. The larger houses present after 1500 BP suggest increased social differentiation (Mason 2009), and also indicate ] extended coastal occupation, reduced 
seasonal mobility and increasing reliance on marine mammals (Anderson and Freeburg 2013).

The later Birnirk period saw the emergence of whaling, which was fully developed during the Thule period. There is a relationship between whaling activity and social differentiation both within and between households (Whitridge 1999). Wealth, prestige and social power were accumulated by whaling leaders during the Thule period. This is inferred by the relative abundance of whaling gear, the size and complexity of household space, and access to exotic materials like jade and obsidian. While there was evidence of social differentiation in earlier Northwest Alaskan cultural traditions, the later Neoeskimo periods had more pronounced, or at least more readily apparent in the archaeological record, social differentiation, and also evidence of social and ideological differentiation in gender roles. As an example, men often had access to more exotic materials (Whitridge 1999). This increase in social differentiation eventually coalesced into the roles of men and women that we see in the ethnographic period.

\section{Ethnographic History in Northwest Alaska}

In order for the reader to have some context, and understand some of the assumptions I have made based on the ethnographic record, I provide a brief overview of the ethnographic history in Northwest Alaska. The ethnographic period in Northwest Alaska is between the late eighteenth and early twentieth centuries. While the exact start of the historic period in Northwest Alaska is debated, trade of Euroamerican goods to Alaska Native peoples started in the late 18th century (Ray 1975). Beginning in the mid- 
nineteenth century, more Euroamericans were in Northwest Alaska and by the end of the nineteenth century, missionaries, traders, and others were occupying Northwest Alaska year-round and had constant contact with native peoples. When Westerners first visited the Iñupiat nations of the Bering Strait (Figure 3), they found the land inhabited by a small and very scattered population of hunters and gatherers (during the 19th century there were about 200 individuals living from Shishmaref to Cape Espenberg). The early 19th century Iñupiat were composed of politically autonomous social groups over discrete territories (Burch 2006).

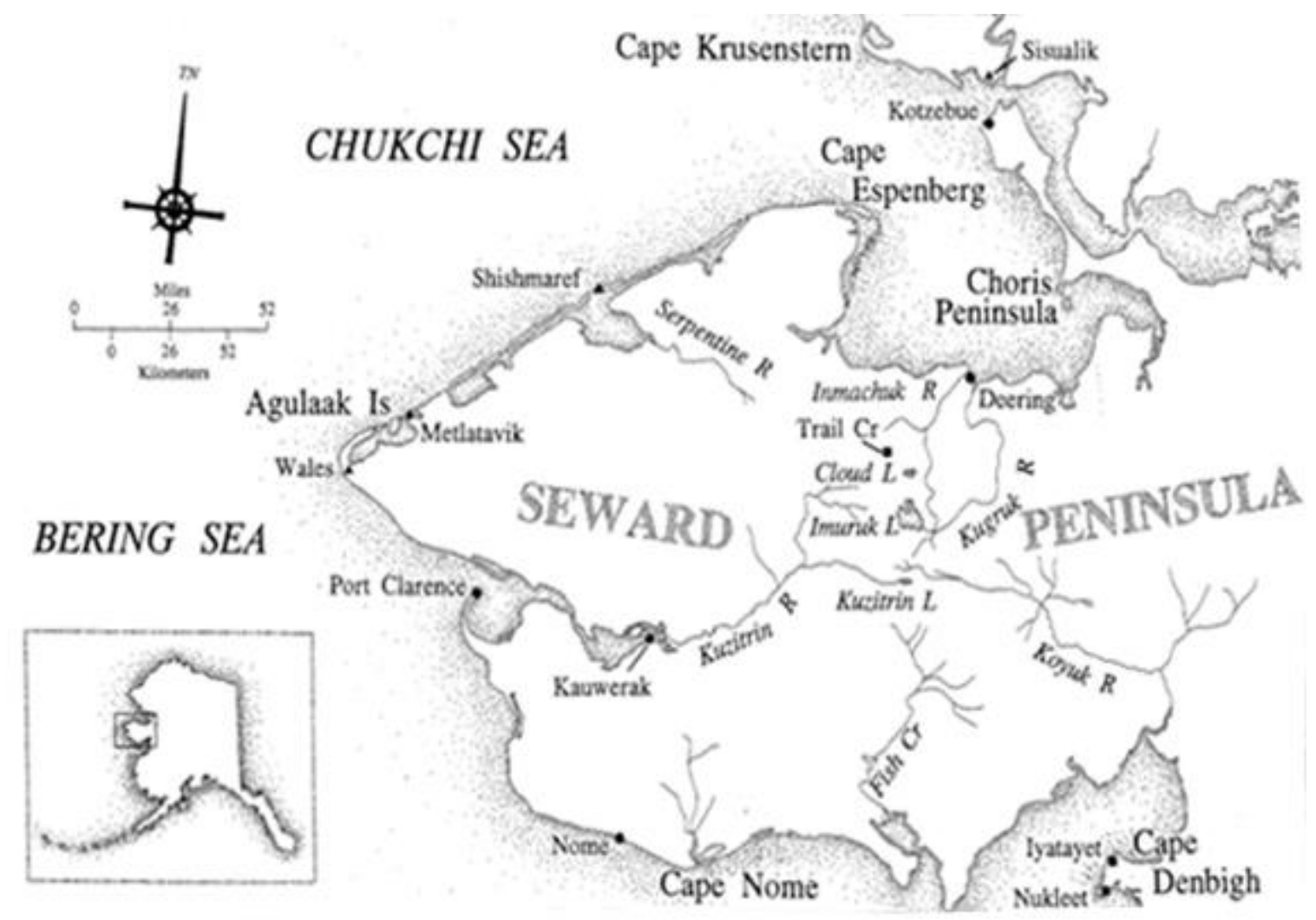

Figure 3. Location of some major villages on the Seward Peninsula (Harritt 1994. Page 2: Figure 1.1) 
Daily tasks were based on age, gender and political allocation. The most important of these were relative age and gender (Burch 2006, Nelson 1899, Curtis 1930). Throughout the world, one of the most common means of organizing economic activities in a hunter gatherer group is to assign tasks by gender (Conkey and Gero 1991: 8-10). The fundamental economic unit in Iñupiat culture (and by inference, pre-contact Thule culture) is a married man and woman. Among the historic Iñupiat, men and women had very specific and clear economic roles to perform (Jarvenpa and Brumbach 2008, Giffen 1930, Hennebury 1999). The differences in activities and duties were very pronounced for the Iñupiat. In general, men had greater authority than women and were the only ones who served as "chiefs" in the early contact time period (Nelson 1899). The specific roles of women will be described in much greater detail in the next section. For men, the great part of their day was spent hunting caribou or sea mammals, fishing, building or tending to fish weirs. After hunting, the men retired to the qargi (men's house) and manufactured or repaired tools, utensils or other equipment (Burch 2006, Giffen 1930).

In addition to the differentiation of tasks based on age and gender, other daily tasks depended on seasonality. Northwest Alaskans depended primarily on seals and fish, though different birds and eggs formed a large part of their diet. Berries, roots, and greens were utilized to a far greater extent here than in other areas of arctic Alaska (Ray 1964, Jones 2010). Ray (1964) defined three principle subsistence patterns present in Northwest Alaska during the ethnographic period: whale, walrus, seal and fishing (Whaling pattern), caribou, fishing, seal and beluga (Caribou pattern) and seal, beluga, fishing and caribou (Sea Mammal pattern). While these patterns were initially seen as distinct and discrete 
subsistence behaviors, we now understand them as different patterns that groups moved between depending on seasonality, geography and environmental change (Ray 1983, Harritt 1994). Like other hunter-gatherer groups, economic and social activity depended on the seasons. Seasonal variation in human activity is based less on changes in temperature and light, but more to the abundance and distribution of animal and plant life (Burch 2006). During the fall and winter, people hunted seals along and near the coast, hunted ptarmigan and other small game, fished, and hunted caribou in the interior. Winter was also a period of regrouping in villages; people held various celebrations including feasting, dancing, trading, and socializing. During mid to late March, the nations around Kotzebue Sound and the Seward Peninsula moved out to the sea ice in order to continue hunting of sea mammals, including bearded seals, walrus and occasionally whales. After the sea ice departed in late June or early July, people dispersed into their summer camps. Here, they picked berries and greens, hunted caribou and small game, and fished (Burch 1998). During the brief, busy summer season, women would also make ceramic pots, as storage and cooking vessels (Burch 2006, Frink and Harry 2008).

\section{Roles of Ethnographic Alaskan Women}

Generally speaking, women's roles in Northwest Alaskan society were most prominent in the butchery, processing and cooking of animals and making clothing (Table 3). Ethnographically, women processed, cooked and distributed foods after men had killed the animal. Women were in charge of meat and skins from the moment the animal was killed until it was consumed (Burch 2006, Jarvenpra and Brumbach 2006). 
When a man killed an animal, a woman would go fetch it from the kill site and bring it home to process. Women also gathered plants like seaweed, berries, roots and grasses during the short Arctic growing season (Giffen 1930). While men were primarily responsible for big game hunting (though some women hunted caribou and seals as well), women hunted small game like birds, foxes, marmots, ground squirrels or caribou calves, collected eggs, and fished (Giffen 1930).

The general care of the house, including cleaning, was left to women as well (Rasmussen 1921). The most important article of furniture within the house was the lamp, usually made of pottery in coastal Northwest Alaska, and soapstone in places with less access to driftwood (Frink and Harry 2008). The lamps are found without exception to be in complete charge of women- not only preparation and trimming of the wick, but extraction from blubber of the oil used as fuel (Lemoine 2003). The lamps, as well as pots, young children and puppies, were always the responsibility of the women when they moved (Stefansson 1919).

Table 3. List of male, female and gender-neutral tasks. From Giffen 1930, Jarvenpra and Brumbach 2008, Rasmussen 1921, Nelson 1899, Whitridge 2002, Birket-Smith 1929

\begin{tabular}{|c|c|c|c|c|c|}
\hline Task & $\begin{array}{l}\text { Exclusively } \\
\text { Male }\end{array}$ & $\begin{array}{c}\text { Exclusively } \\
\text { Female }\end{array}$ & $\begin{array}{l}\text { Primarily } \\
\text { Male }\end{array}$ & $\begin{array}{l}\text { Primarily } \\
\text { Female }\end{array}$ & Both \\
\hline $\begin{array}{l}\text { Hunting Large } \\
\text { Land Mammals }\end{array}$ & & & $\mathrm{X}$ & & \\
\hline $\begin{array}{l}\text { Hunting Large } \\
\text { Sea Mammals }\end{array}$ & & & $\mathrm{X}$ & & \\
\hline - In Kayak & $\mathrm{X}$ & & & & \\
\hline - In Umiak & & & $X$ & & \\
\hline Fishing & & & & & $X$ \\
\hline Collecting & & $\begin{array}{ll}X_{26} & \\
& \end{array}$ & & & \\
\hline
\end{tabular}


Birds and Eggs

Collecting $\quad \mathrm{X}$

Roots, Berries, and Greens

\begin{tabular}{lll}
$\begin{array}{c}\text { Butchery of } \\
\text { Animal }\end{array}$ & $\mathrm{X}$ & \\
Curing Meat & & $\mathrm{X}$ \\
\hline Curing Fish & $\mathrm{X}$ & \\
\hline Cooking Food & $\mathrm{X}$ & \\
\hline $\begin{array}{c}\text { Distribution of } \\
\text { Food }\end{array}$ & & $\mathrm{X}$
\end{tabular}

Procurement of $\quad \mathrm{X}$

Fuel

Procurement of $\quad \mathrm{X}$

Drinking Water

Pulling with

Dogs on Sled

Driving

Harnessing

Dogs

\begin{tabular}{ccc}
\hline Feeding Dogs & & $\mathrm{X}$ \\
\hline $\begin{array}{c}\text { Care of Young } \\
\text { Dogs }\end{array}$ & $\mathrm{X}$ & \\
\hline Care of & $\mathrm{X}$ & \\
Dwelling & & $\mathrm{X}$
\end{tabular}

(ownership of,

trimming of

wick,

furnishing with

oil)

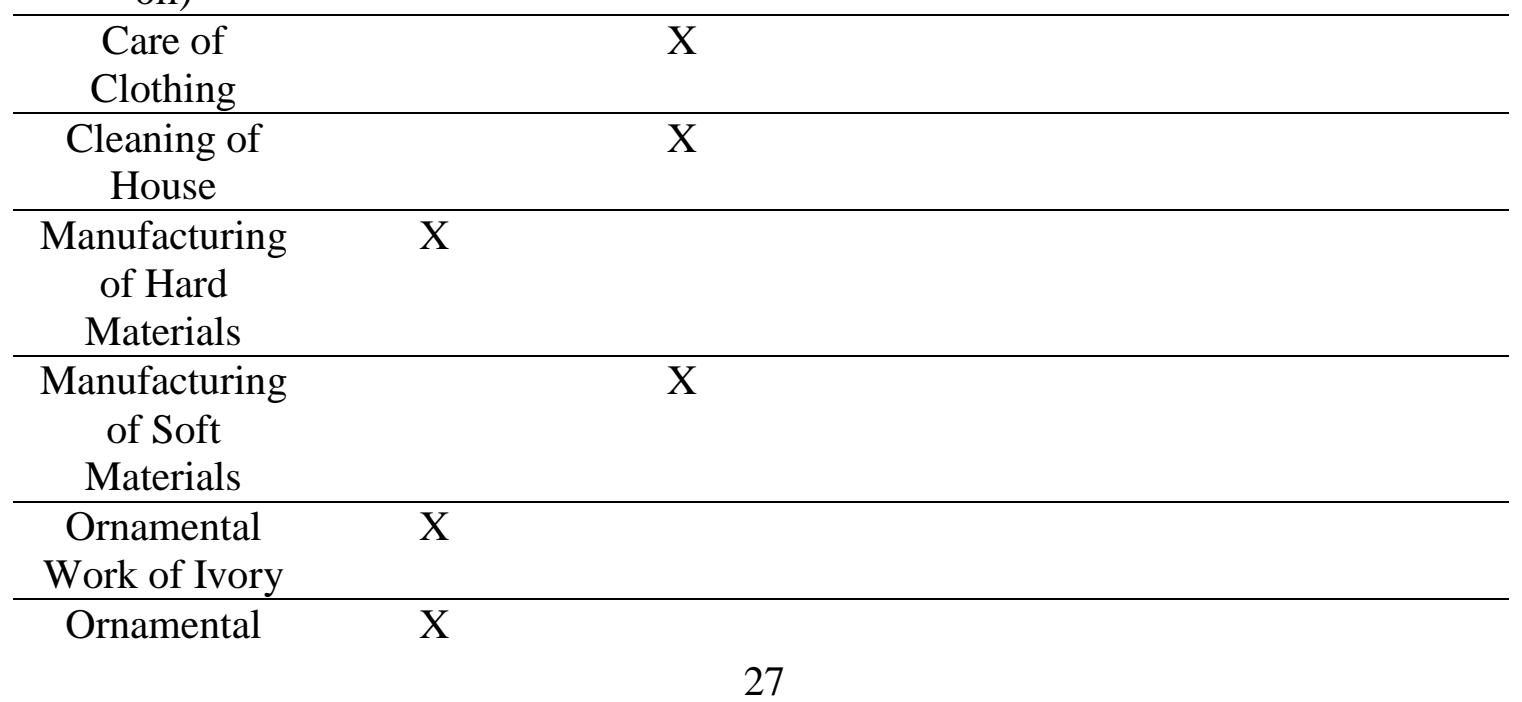




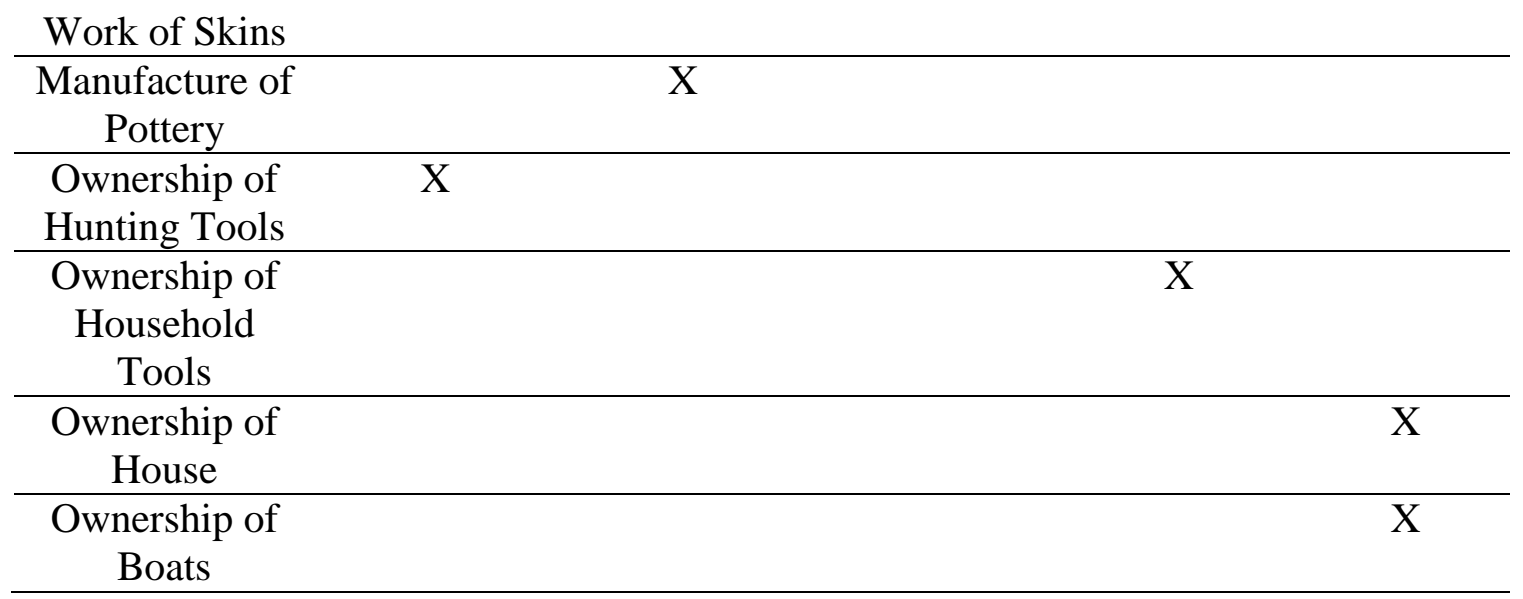

\section{Space}

\section{The Household as Socially Defined Space}

The household and immediate surrounding area is a useful unit of gender spatial analysis, and of testing the segregated/integrated gender model, because both genders were certain to interact in these areas (Tringham 1991). The household can also be a micro-example of the large spatial concerns of a group. Archaeologically speaking, instead of finding the "ideal" household, Allison (1999: 15) suggests that we focus on the "agencies which formulate a household." In order to find the micro-examples of the larger concerns of the group, we should try to understand the reasons why the households were constructed the way they were. Space and behavior are mutually dependent (Ardener 1981). Once space is socially defined, it is no longer a neutral background and exerts its own influence (Ardener 1981: 12). Houses are built in order to fulfill needs of the household, but they can recursively influence occupant behavior as well (Lemoine 2003, Hillier and Hanson 1984). Houses are shaped by and shape the social and ideological practices of their builders. 
Using this recursive theory of space and gender in in her study of gender and household design in Northern Cameroon, Lyons (1992), referred to the egalitarian/spatially indistinct model as cooperative and hierarchical/spatially expressive model as competitive. However, to avoid those potentially confusing and value-loaded terms, I will refer to the cooperative model as non-gender divided or integrated and the competitive model as gender-divided or segregated. A gender-divisive or segregated relationship refers to a gender situation, which could be hierarchical or egalitarian, where spatial expression of gender is very important. A non-gender divided or integrated relationship, either hierarchical or egalitarian, occurs where spatial expression of gender is less important (Lyons 1992).

If there was an integrated model, the result would be that there is no segregation of activity and the areas of the house would be used equally by men and women. as seen in Hennebury's analysis of Eastern Thule use of space (Hennebury 1999). Hennebury developed two possible models of gendered spatial relationships (very similar to my own gender integrated and gender segregated models) based on two Eastern Thule houses, on in Labrador and the other on Baffin Island, and tested it using K-means analysis. The results of the K-means analysis, as well as the subsequent significance tests, indicated that there were no gender exclusive spaces. She interpreted this as a mark that gender differences were not necessarily important when it came to completing tasks.

It should come as no surprise that the house is symbolically marked as a microcosm of the Inuit world (Fortescue 1988). Without reifying the idea of the woman's place being in the house (see the argument in Reinhardt 2002), there seems to be a close symbolic 
association between women's bodies and houses (Nuttall 1992, Lemoine 2003). Inuit and Thule houses were generally uncomplicated, relatively small structures with few architectural divisions; spatial clustering of activities could be due to gendered separation. Social organization is likely organized around features like hearths, rather than a distinct "male" room versus a distinct "female" room or even a distinct male and female side. There is conflicting ethnographic evidence of where these gender specific spaces exist. In some traditional Inuit houses, physical access to particular spaces (mostly kitchens) was restricted and controlled by women (Dawson 1995). Other evidence suggests that a woman's area is located directly in front of the hearth, and that men had exclusive access to the sleeping platform (Graburn and Strong 1973, Whitridge 1999, Giffen 1930). Some areas were considered the property of a particular gender (namely the kitchen area). In other ethnographic cases, women's materials were stored in the back half of the house, away from the door and under the sleeping platform (Graburn and Strong 1973).

Qargi

No discussion about gendered use of space among native Alaskans would be complete without a discussion of the qargi (this word has at least seventy-two orthographies (Larson 2004) but some of the more popular spellings are kazigi, qagli, karigi, or kashim). Qargis have often been referred to as men's houses in Alaskan ethnographic literature, especially for the Yupik, but can be more accurately described as community houses for the Iñupiat (Burch 2006, Larson 1991). While in general, it is true that for the 
Iñupiat, qargis were where men and older boys would spend most of their time, and manufacture much of their tools, it was also the main focus of social interaction outside of dwellings, and not strictly limited to men. Women served food, and participated in dances, festivals, feasts, and storytelling sessions (Nelson 1899, Larson 1995). No qargis were exclusively used by men and indeed, in the ethnographic record, it does not refer to one particular type of structure (Larson 1995, Spencer 1959). This makes identification of possible qargis in the archaeological record difficult.

Generally, qargis are larger than other structures (Larson 1995). However, this is not always the case. While the Ipiutak qargi Larsen excavated in Deering is larger than an Ipiutak house (Larsen 2001), Van Stone's qargi at Tikchik Village is no larger than the other houses (Lutz 1973). Another key difference between houses and qargis is the presence of benches along all four walls, but no sleeping platforms (Larson 1989). No distinct artifact type is associated with qargis (Lutz 1973). It appears that qargis are distinguished instead by a lack of certain artifacts in comparison to habitation structures. Van Stone's excavation of a qargi in the 19th century village of Akulivikchuk showed no pottery in the qargi or in the associated midden, in contrast to the other structures (Van Stone 1970). Other qargis (Irving 1962), also show no evidence of cooking debris. This fits with ethnographic records of women bringing meals in for consumption, rather than preparing them within the qargi (Burch 2006).

Qargis can be divided into two categories: temporary and permanent. Many of the qargi found in the interior are temporary and the presence of a qargi in any particular village is equally ephemeral (Giddings 1961). The permanent qargis found on the coast 
are built similarly to other structures: semisubterranean sod structures with whale bone or driftwood supports and often had subterranean entrance tunnels.

\section{Intrasite Spatial Analysis}

Intrasite spatial analysis is focused on analyzing patterns and relationships between and within small units, such as the household, over time and space (Hietala 1984). In this research, spatial analysis is focused on the household itself. Intrasite spatial analysis encompasses a broad range of theoretical and methodological perspectives (Hietala 1984, Carr 1984). Spatial analyses of archaeological remains are as old as the discipline itself (Kroll and Price 1991), though explicitly spatial approaches to archaeology developed along with functionalism in the mid-20th century (i.e. Clark 1954, Taylor 1948, Willey 1948). Intrasite spatial analysis also developed in the middle twentieth century out of increased emphasis on horizontal excavation and behavioral reconstruction (Sisk and Shea 2008). More recently, archaeological works continues to use spatial analysis to explore behavior (Hietala 1984; Kent 1990). Replicated behaviors, such as knapping (Carr 1991), or cleaning of activity areas (Hutson et al 2007, Fontana 1998) are much more likely to leave behind evidence in the archaeological record. These replicated behaviors contribute far more to our knowledge than single events. They also show us the broader context of site use (Kent 1990).

Spatial analyses are not constrained to any theoretical paradigms or meta-narratives of the social sciences. Spatial analyses, including intrasite spatial analysis, falls under the category of "middle-range theory", or theories that link human behavior to archaeological 
data (Trigger 2006). The results of the spatial analysis are interpreted using higher level theory, or seeking to explain the why of the results of the spatial analysis.

\section{Space Syntax and Structuration}

Two of the high-level theories that inform the background and construction of this spatial analysis, as well as the interpretation of the results are space syntax analysis and structuration. Space syntax analysis, developed by Hillier and Hanson (Hillier and Hanson 1984, Hillier 1996, Hanson 1998), views spatial analysis as an inherently social mechanism. This type of analysis seeks to analyze ways in which houses construct and constrain space. As mentioned earlier, space and behavior are mutually dependent and seek to reinforce each other (Ardener 1981, Lemoine 2003). The primary axiom of space

syntax is that spatial organization is a function of the form of social solidarity (Hillier and Hanson 1984). This assumes space is shaped and defined by social relations and that social relations both define and constrain the creation and maintenance of spatial relations. This is an inherently Durkheimian and functionalist approach of conceiving the organization of space in terms of organic and mechanical solidarity (Markus 1993).

Many scholars who use space syntax analysis in their work reject this functionalist approach and modify the theoretical perspective while maintaining the methodology (Siebert 2006). For example, Ferguson (1996) rejected the functionalist approach in favor of structuration theory, developed in the mid-1980's by sociologist Anthony Giddens. Structuration theory refers to the creation, maintenance, and reproduction of social systems that depends on both social structure and agency without giving priority to either 
(Giddens 1984). In the analysis and conceptualization of space, this means that space defined by architecture does more than simply represent society. Architectural space is one of the primary means through which society is constituted and the spaces created by architecture incorporate society by physically enabling and constraining social interaction (Ferguson 1996). From space syntax and structuration, I have assumed that the gender roles exhibited by Birnirk and Thule culture-bearing peoples are modeled in their architectural space.

\section{Modeling Spatial Analysis}

The theoretical discussion in the above section is necessary for both the creation of a spatial model that allows for the nuance of human behavior as well as the explanations for the data from the spatial model. There are no exclusively archaeological methods of spatial analysis. Archaeologists have liberally borrowed spatial analysis methods such as nearest neighbor or k-means cluster analysis from geography, biology and other disciplines, sometimes with mixed success (Pinder, Shamada and Gregory 1979, Voorrips and O'Shea 1987, Kintigh and Ammerman 1982). Spatial analysis in archaeology has become much more sophisticated over time, especially with advances in computer technology like R and GIS, as well as improvements in methodology of nonhierarchical spatial tests (e.g. Stutz and Estabrook 2004, Papageorgiou, Baxter, and Cau 2001).

Of course, contextual information is equally, if not more, important than data modeling (Carr 1991). The attitude and techniques of exploratory data analysis, which 
allow the integration of contextual data, are critical to identifying and interpreting intrasite spatial patterns. One of the most important types of contextual information to integrate into modeling is site formation processes, including depositional and postdepositional effects. Before archaeologists can form meaningful interpretations of spatial patterning, they must first evaluate the processes responsible for forming and transforming archaeological deposits (Hilton 2003).

\section{Site Formation Processes}

\section{Construction and Use of House}

Both pre-contact and post-contact houses were normally constructed small, as heating was a concern. Therefore, the houses were quite crowded (Burch 2006). The earliest recorded description of a house in the northern Seward Peninsula is by Otto von Kotzebue in 1816, on Shishmaref Island (von Kotzebue 1821). This house had two rooms and an entrance passage. The first room, a storage room, was 3 meters by 2 meters. The main room was 3 meters square.

Because of the small space, only one or two activities could occur in a dwelling at the same time. This necessitated storage, as well as frequent removal of used or discarded items (Burch 2006). There are few ethnographic accounts of cleaning. From the few ethnographic accounts that do mention waste removal, we know that debris was regularly brushed away from the floors and swept either into the tunnel, or a midden (Burch 2006).

During the summer, most activity would be done outside in the light (Frink and Harry 2008). However, in the winter, manufacture would be completed in the house or qargi 
around lamps (Dawson et al. 2007). In the spring, people would move out of their semisubterranean homes. In the Seward Peninsula, houses were often re-occupied over the course of a decade. People would take items that they would need during the summer, but leave tools and other objects in caches to return to the following winter (Burch 2006, Ray 1983). If the house was completely abandoned, the house structure and possessions were likely totally removed and transported to the new house (Lee and Reinhardt 2003). When a death occurred in a house, people would not be allowed to re-enter the house and all the items needed to be abandoned along with the house (Ray 1964). While this taboo could have been present for the Thule and Birnirk, archaeological excavation in Utqiagvik showed that people did re-enter the house after a death to take useful objects (Hall and Fullerton 1990).

Pre-contact houses are quite similar to ethnographic-era houses (Giddings and Anderson 1986, Lee and Reinhardt 2003). Birnirk and early Thule houses are similarly sized, with main rooms ranging from 3-7 meters square and tunnels ranging from 4-6 meters. Later Thule houses could be larger to accommodate larger families, with a main room of 6 meters by 4 meters, with foyers or smaller rooms for storage space. As with the ethnographic Iñupiat, there is evidence of reuse of materials during the pre-contact period. Abandonment and scavenging are more easily detected than other cultural postdepositional processes in the Arctic (Reynolds 1995) because these activities occurs at the architectural level as well as the artifact level. For example, driftwood is a precious commodity for building. Many houses, such as the mound found in Utqiagvik (also known as Barrow, Alaska) (Reynolds 1993), show the removal of floor boards and sill 
logs, with only wood chips still remaining. Excavation at the inland Thule site of Ekseavik showed similar reuse of timber logs (Giddings 1952).

\section{Primary Deposition}

The primary goal of this thesis is to understand how people behave within a house through spatial analysis. In order to do this, I must identify whether or not ceramics were recovered from primary or secondary depositional contexts (Table 4). Primary context is i.e. the process where objects enter the archaeological record at their location of use (Schiffer 1987, LaMotta and Schiffer 1999). Primary context is undisturbed context, where archaeological data have not been disturbed since the original process of deposition. Primary deposition comes largely from two processes: discard as primary refuse, or accidental deposition through loss.

My expectations of gendered spatial patterns come from ethnographic data of primary deposition. As discussed above, there is hardly any information about patterns of discard and the treatment of refuse among the ethnographic Iñupiat. We do have more information on storage patterns (Burch 2006). The entrance tunnel usually contained alcoves for storage. Larger houses would have separate rooms for storage (Burch 2006, Nelson 1899, Ray 1964). As mentioned earlier in this chapter, there is conflicting evidence for gendered storage. This is especially true with the sleeping platform. Some ethnographic evidence points to it being a storage area for men (Whitridge 1999), while others assert it was a woman's storage area (Graburn and Strong 1973). While accidental deposition through loss is rarer than discard, it does happen, especially with smaller 
objects (LaMotta and Schiffer 1999). These objects not only were unlikely to hinder activity, but they were also more likely to be missed by cleaning technology. Archaeologically, we see artifacts wedged between the cracks of the floor boards (Hoffecker and Mason 2011). Some of these artifacts could be examples of accidental deposition through loss.

\section{Secondary Deposition}

While this thesis is primarily interested in primary contexts and deposition, I have to consider secondary contexts and deposition (Table 4) for this spatial analysis to be robust. Secondary contexts are archaeological contexts that are disturbed, either by subsequent human activity or natural phenomena. Secondary deposition is the removal of refuse from a primary activity area to another location, such as a midden or abandoned structure (LaMotta and Schiffer 1999). Schiffer (1987) discusses five major cultural processes: abandonment, reuse, discard, maintenance, and reclamation. Like with primary deposition, ethnographic descriptions of secondary deposition in Inupiat houses are scanty. For instance, it is not known if there were any gendered differences in disposal. We do know that waste was regularly removed from the house floor and swept out (Burch 2006). From there, refuse was thrown out to around the sides and backs of houses, or deposited in middens (Burch 2006). Abandoned houses were occasionally used for refuse deposits, and middens could be the accumulation of refuse from several houses (Nelson 1899). My analysis is focused on floor deposits to avoid including ceramics that 
accumulated in house fill and collapsed roof deposits following the occupation and abandonment of the house.

\section{Post-Depositional Processes}

In addition to cultural processes of deposition, there are several natural processes that ultimately form a site and shape ceramic assemblages. The primary natural factors that affect the post-depositional treatment of artifacts in Arctic contexts are the effects of cryoturbation, erosion, and faunalturbation (Table 4). The freeze-thaw cycle causes expansion and contraction of the soils, and subsequent displacement of artifacts (Schweger 1985). Artifacts found at the surface and in the upper $30 \mathrm{~cm}$ of the soil will be less well preserved (Hilton 2003), and shallow permafrost ( $<1 \mathrm{~m}$ below surface) also exacerbates this (Esdale et al. 2001). Artifacts below $30 \mathrm{~cm}$ of soil and/or under a sod layer will be less affected by the freeze-thaw cycle (Reynolds 1995). Faunalturbation in the Arctic is mostly the result of burrowing ground squirrels, grizzlies that rip through the ground in search of small mammals, and domestic dogs that dig for bones (Reynolds 1995). Erosion is an extremely destructive force in coastal Alaska (Hall 1988). Storm surges can expose portions of houses destroy houses and human remains (Reynolds 1995). Natural formation processes listed above, can be detrimental to interpretation of household activities because natural processes alter or destroy cultural depositional processes. 
Table 4. List of depositional and post-depositional processes and archaeological expectations.

\begin{tabular}{|c|c|}
\hline Depositional/Post Depositional Process & Archaeological Expectation \\
\hline Storage & $\begin{array}{c}\text { Concentration of artifacts in tunnels or } \\
\text { secondary rooms (Burch 2006, Nelson } \\
1899 \text {, Ray 1964) }\end{array}$ \\
\hline Loss & $\begin{array}{l}\text { Artifacts wedged between cracks of the } \\
\text { floor (Hoffecker and Mason 2011) }\end{array}$ \\
\hline Frost disturbance/Cryoturbation & $\begin{array}{l}\text { Sedimentary characteristics of multiple } \\
\text { levels mixed together (Esdale 2001), frost } \\
\text { cracks, vertically oriented artifacts } \\
\text { (Benedict 1970) }\end{array}$ \\
\hline Faunalturbation & Rodent burrow features (Schiffer 1987) \\
\hline Sweeping/Cleaning & $\begin{array}{c}\text { Broken artifacts, fragmentation, and large } \\
\text { debris in tunnel entrances (Burch 2006), } \\
\text { some debris swept to sides of room } \\
\text { (Fontana 1998) or outside of house } \\
\text { (Schiffer 1987) }\end{array}$ \\
\hline Trampling & $\begin{array}{l}\text { Fragmentation (Large amounts of very } \\
\text { small ceramic sherds (less than } 20 \text { mm in } \\
\text { any direction), high percentage of } \\
\text { exfoliated ceramics (Pierce 1999, } \\
\text { Anderson 2011)) and vertical/horizontal } \\
\text { displacement of ceramics and other } \\
\text { artifacts, especially near high-traffic areas } \\
\text { like entrance tunnels (Schiffer 1987) }\end{array}$ \\
\hline Multi-episodic occupation & $\begin{array}{c}\text { Multiple "floor" levels, evidence of } \\
\text { separate recognizable populations } \\
\text { (Schiffer 1987) }\end{array}$ \\
\hline Scavenging & $\begin{array}{l}\text { Wood and other structural materials } \\
\text { missing. Ceramics and other artifacts near } \\
\text { structural material fragmented and/or } \\
\text { displaced (Schiffer 1987) }\end{array}$ \\
\hline
\end{tabular}

One major effect of depositional and post-depositional processes on ceramics is fragmentation. Initial discard and disposal (primary deposition) can fragment ceramics; subsequent cultural activities (secondary deposition) such as discard and disposal (Pierce 1999) can further fragment ceramics. Post-depositional processes, like scavenging and 
faunalturbation can also fragment ceramics (Table 4). Archaeologists study fragmentation rates to understand primary and secondary cultural depositional processes, and to identify post-depositional natural processes that form sites and ceramic assemblages (Beck 2006, Fowler 2011, Rosenwig 2009). Robert Rosenwig studied disposal patterns of ceramic and daub at an Olmec-period in Chiapas, Mexico (2009) to understand how an early sedentary community was occupied, and how middens accumulate and preserve. He found that ceramics were more fragmented in elite contexts than non-elite contexts. He interpreted this as a result of more intensive uses of elite space and a greater rate of trampling.

Variation in ceramic technology itself can factor into ceramic fragmentation rates; ceramic vessels can have differential breakage due to vessel size, durability, temper choices, clay processing, etc. (Anderson 2011, Skibo et al. 1989). Differences in technology can create variation within and across sites, complicating issues of sample size and spatial analysis. For example, assemblages with larger percentages of organic tempered sherds tend to have higher fragmentation rates than assemblages with inorganic temper (Skibo et al. 1989). Therefore, the results of my analysis should be treated with caution when comparing density patterns to other sites, even in the region.

I am studying fragmentation rates in order to identify patterns of primary and secondary deposition, as well as post-depositional processes. Since ceramics are susceptible to fragmentation, they become a strong proxy to identifying these patterns, and understanding the placement of artifacts within the site. 


\section{Chapter 3 Methods and Materials}

The previous chapter served to frame the Cape Espenberg data in the appropriate historical, archaeological and theoretical contexts. Those discussions are necessary background in order to inform the methods and materials, discussed in this chapter, that are appropriate in constructing a gender specific spatial analysis. In this chapter I discuss my study site, Cape Espenberg, and the specifics of the houses and ceramic assemblages that I analyzed from the site complex.

\section{The Cape Espenberg Site Complex}

Cape Espenberg is an accretional landform of about 7000 acres (Schaaf 1988) composed of dune capped beach ridges that extend back about 5600 years (Mason 1990, 1997). While Cape Espenberg was inhabited for approximately 4,500 years, use of the area intensified around 1,000 years ago, at the beginning of the Thule period. Within this last millennium, the Thule and their Iñupiat descendants (which occupied Cape Espenberg from about 950 cal BP to the early part of the 19th century AD) have unbroken cultural continuity to the site (Hoffecker and Mason 2010). There are possibly almost 400 sites in Cape Espenberg (Schaaf 1988). The houses tend to cluster in groups of four to six, with clusters probably representing periods of discrete occupation (Darwent et al. 2013). The larger villages and multi-roomed houses that occur in this area, along with the rest of Kotzebue Sound are thought to reflect a whaling culture (Darwent et al. 2013: 438), which might have led to more social stratification and hierarchy. 


\section{Previous Field Investigations}

Giddings was the first archaeologist to survey Cape Espenberg in 1959 (Giddings and Anderson 1986). However, his surveys were mostly on the oldest ridges, dating to the Choris time period. Giddings and Anderson did not obtain any radiometric ages from these ridges (Harritt 1994). Following the transfer of land to the National Park Service, Cape Espenberg was initially mapped and tested by Jeanne Schaaf in 1985 and 1986 as part of a larger project of testing the Bering National Land Bridge Preserve (Schaaf 1989). She surveyed approximately 1400 acres (roughly twenty percent of the cape) and recorded 76 sites. These sites were assignable to Denbigh Flint Complex, Choris, Norton, Western Thule, Kotzebue and Historic Iñupiat period occupations. The site types included 13 villages and 52 artifact scatters. At the time of Schaaf's survey, only three sites had been damaged by looting.

Roger Harritt also tested Cape Espenberg in the 1988 and 1989 field seasons. In 1988, the team sampled four eroding sites that were located on progressively older beach ridges at the southeastern tip of the cape (Harritt 1994). In 1989, the team went back for two weeks to try to fill in gaps of data collected from the previous field season. They tested several features within each site. Most of the features that underwent dating were from the last thousand years, though there was one site that dated to $4100 \mathrm{cal}$. BP, and there is some evidence of Ipiutak settlement. 
2009-2011 and 2016 Excavations

Cape Espenberg was systematically excavated from 2009-2011 by researchers from the Institute of Arctic and Alpine Research at University of Colorado-Boulder, University of California Davis, University of Alaska Fairbanks and the National Park Service, as well as visiting researchers. The goal of the 2009-2011 project was to collect and analyze data on patterns of human occupation and environmental conditions during a very important period of time during the history of native peoples with a focus on uncovering human reactions to climate change from AD 800-1400 (Hoffecker and Mason 2011).

In 2016, the Cape Espenberg Birnirk Project, led by Claire Alix and Owen Mason, reopened two features from the previous excavations. The 2016 project, "Birnirk Prehistory and the Emergence of Inupiaq Culture in Northwestern Alaska, Archaeological and Anthropological Perspectives" is an NSF funded collaboration between University of Alaska Fairbanks. the Institute of Arctic and Alpine Research at University of Colorado Boulder, Portland State University, University of Kansas and the Archaeology Commission of the French Ministry of Foreign Affairs. The main objective for the 2016 project was to investigate the origins of the Birnirk in Northwestern Alaska at around $1000 \mathrm{AD}$.

A total of six house features were partially or completely excavated during the 20092011 seasons. All of these features were located on younger ridges, dating from 1000-300 BP (Table 5). In 2010 Features 21, 33, and 68 were opened and investigated (Figure 4). Feature 68A was excavated and a possibly connected depression was excavated in 2011 as $68 \mathrm{~B}$. In addition to Feature 68B, Features 87 and 12 were opened. All except Features 
21 and 12 were nearly completely excavated during this study. In the 2016 and 2017 field seasons, Features 21 and 12 from KTZ-304 were reopened. Feature 21 was fully excavated in 2016. Feature 12 was partially excavated in the 2016 season and finished in 2017.

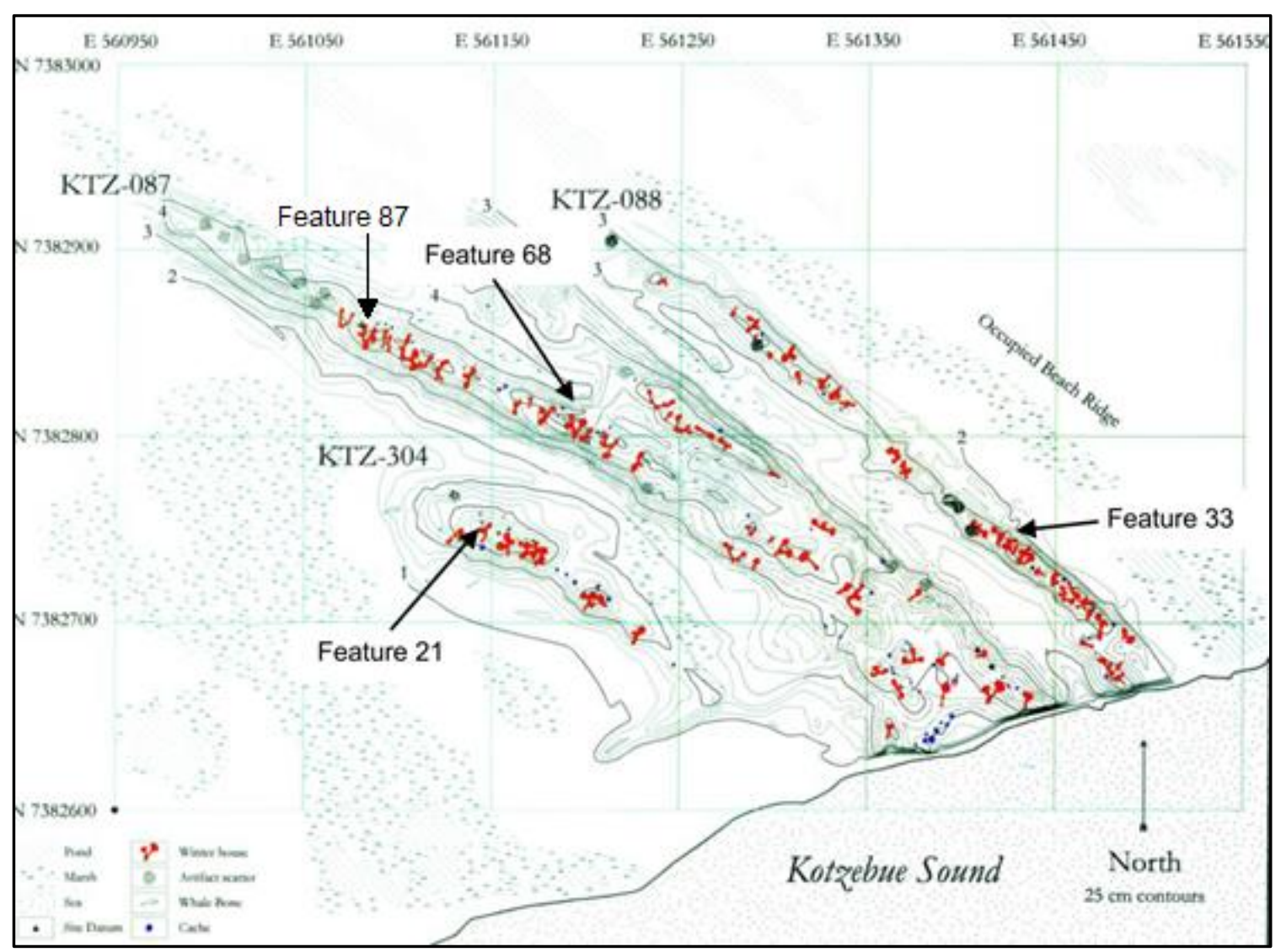

Figure 4. Excavated House Features within Cape Espenberg (Hoffecker and Mason 2010). Map by John Darwent. 


\begin{tabular}{|c|c|c|c|c|c|}
\hline & $\begin{array}{c}\text { KTZ-304 } \\
\text { Feature } \\
21\end{array}$ & $\begin{array}{c}\text { KTZ-087 } \\
\text { Feature } \\
87\end{array}$ & $\begin{array}{c}\text { KTZ-087 } \\
\text { Feature } \\
\text { 68B }\end{array}$ & $\begin{array}{c}\text { KTZ-087 } \\
\text { Feature } \\
\text { 68A }\end{array}$ & $\begin{array}{c}\text { KTZ-088 } \\
\text { Feature } 33\end{array}$ \\
\hline $\begin{array}{c}\text { Approximate } \\
\text { Age Range in } \\
\text { cal. BP }\end{array}$ & $700-1000$ & $500-650$ & $600-650$ & $550-300$ & $250-400$ \\
\hline Multiroom? & Yes & No & No & No & No \\
\hline $\begin{array}{c}\text { Size of Main } \\
\text { Room } \\
\text { (meters) }\end{array}$ & $3 \times 3$ & $\begin{array}{c}3.0-3.3 \mathrm{x} \\
2.5-3.0\end{array}$ & $2.5 \times 2.5$ & $3 \times 3$ & $3 \times 2.5$ \\
\hline $\begin{array}{c}\text { Size of } \\
\text { Tunnel } \\
\text { (meters) }\end{array}$ & 5 & 7.5 & 2.4 & 5.5 & 4 \\
\hline $\begin{array}{l}\text { Excavated } \\
\text { Area in } \mathrm{m}^{2} \\
\end{array}$ & 45 & 42 & 12.5 & 26 & 31 \\
\hline $\begin{array}{c}\text { Excavated } \\
\text { Volume in } \\
\mathrm{m}^{3}\end{array}$ & 46 & 29.6 & 35.1 & 23.1 & 20.6 \\
\hline $\begin{array}{l}\text { Excavated } \\
\text { Volume of } \\
\text { floor levels } \\
\text { in } \mathrm{m}^{3}\end{array}$ & 9.7 & 8.0 & 8.19 & & 5.7 \\
\hline
\end{tabular}

Table 5. Description of features selected for analysis at Cape Espenberg

The systematic excavations from the 2009-2011 and the 2016-2017 projects yielded high resolution spatial data that made it possible to do this spatial analysis. In 2016, the Cape Espenberg Birnirk Project reopened Features 21 and 12. Most of Feature 21 was excavated, and those artifacts are included in this analysis, but the floor of Feature 12 remained mostly unexcavated at the end of the 2016 field season and so that feature is excluded from my study. All sediment excavated from the house features was screened through 0.25 -inch mesh screens and, when possible, house floor sediment was screened through 0.125-inch mesh. Ceramic rim and base sherds, as well as other diagnostic artifacts, were given three-point provenience. Body sherds were collected by quadrant 
within the $1 \times 1$ meter unit. The following is a brief description of the features excavated over the three field seasons so as to frame my interpretation of spatial data in Chapters 4 and 5.

\section{Feature 21}

Excavated in 2010, Feature 21 (Figure 5) is the earliest known Inupiat settlement at Cape Espenberg, with radiocarbon dates of 1000 BP (Hoffecker and Mason 2010). It is a multi-room house. A 2 meter by 2 meter room (Table 5), connected to the main room by a 1 meter long passageway. This room is possibly a kitchen area, due to the seal-oil laden and burnt soil. This room is located to the west of the entrance tunnel, which is just over 5 meters long. The main room is a slightly trapezoidal area that measured approximately 3 meters by three meters. In 2010, excavators uncovered human remains and excavation stopped. The feature was reopened in 2016 (Figure 6) and the floor was uncovered in all but two 1x1 meter units. 


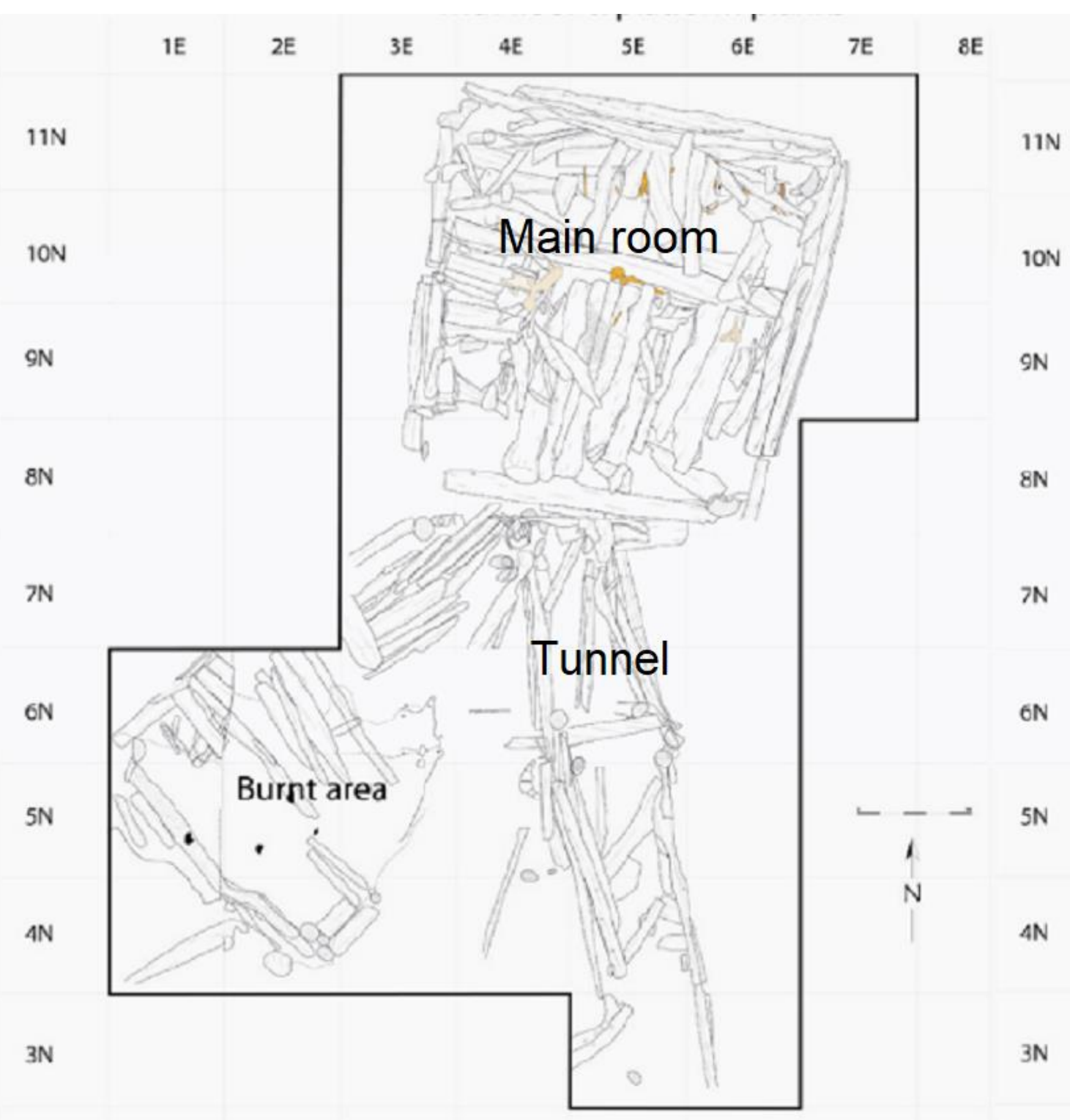

Figure 5. Feature 21 (Alix et al. 2017). Figure by Claire Alix, Lauren Norman and Sylvie Elies. 


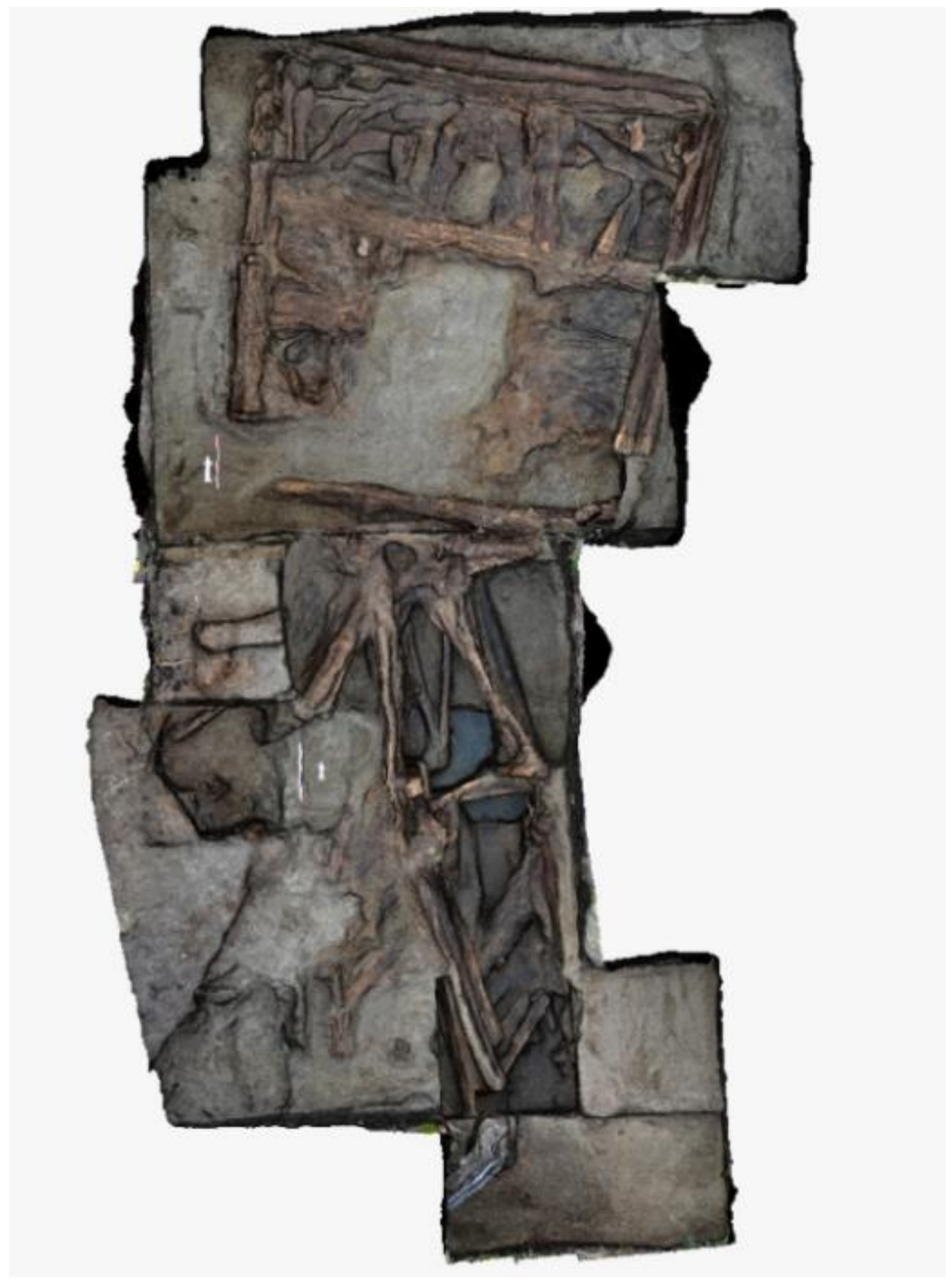

Figure 6. 3-D photograph of Feature 21 (Alix et. al 2017). Photo by Laura Poupon. The full extent of the burnt area is unmapped in this photograph. 


\section{Feature 87}

Feature 87 (Figure 7) is a very well-preserved early Thule semi-subterranean house, with radiocarbon dates indicating occupation from 500-650 BP (Norman et al. 2017). Most of the objects dated from the intermediate Kotzebue (500 BP) period (Norman 2015). The excavations were finished in 2011. In addition to the artifacts recovered from the feature, a large amount of faunal material was recovered, mostly from a midden to the south of the entry. Part of this was due to special sampling protocols that were set in place for a $\mathrm{PhD}$ research project focused on analysis of faunal remains (Norman 2015). The main room is a rough rectangle (Table 5), $3.0-3.3 \mathrm{~m}$ in length and $2.5-3.0 \mathrm{~m}$ in width. The entrance tunnel is $7.5 \mathrm{~m}$ long. At the end of the room, there is a raised platform composed of six wooden boards. An area to the southeast is presumed to be the kitchen alcove. 


\section{Feature 87 Map Overview}
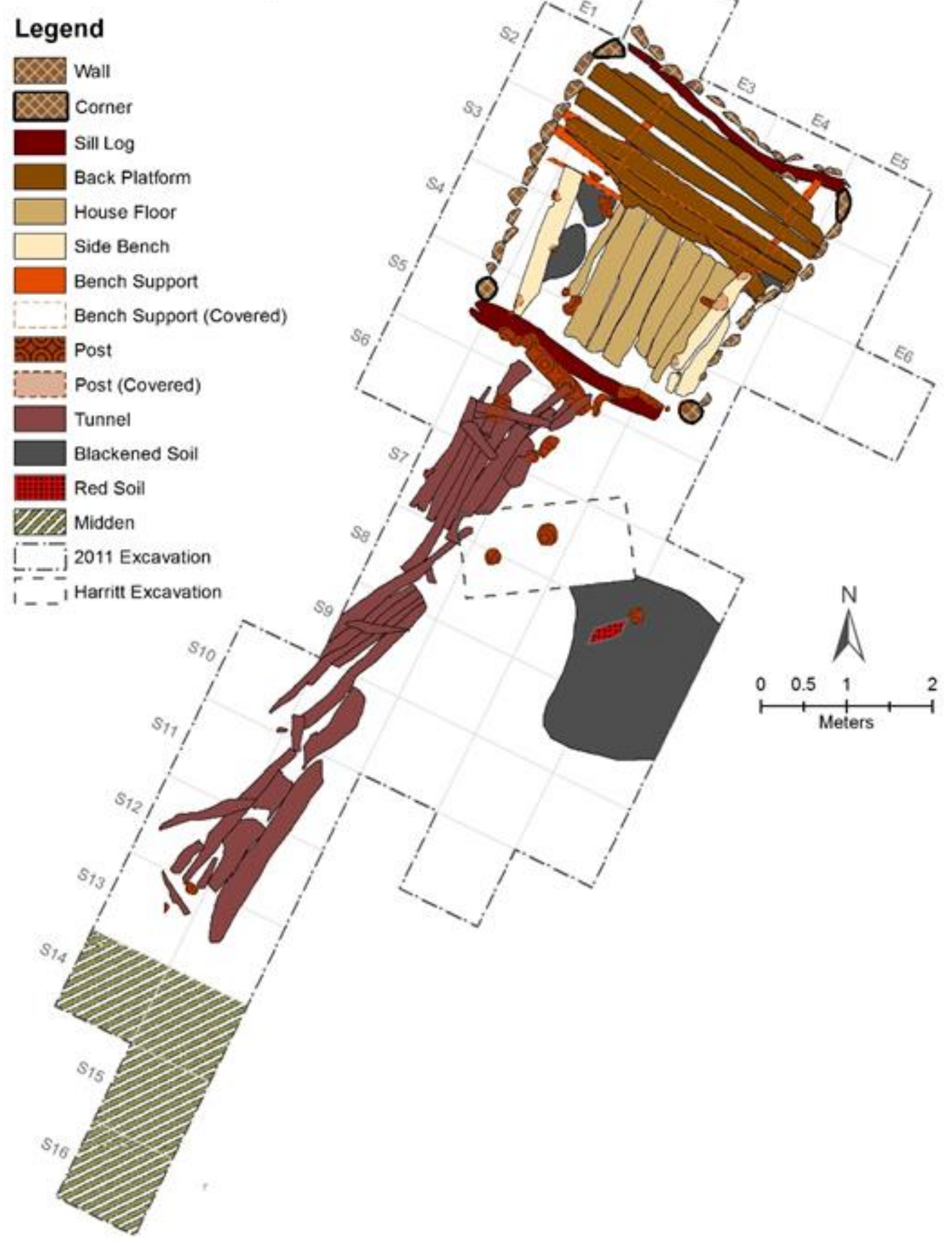

Figure 7. Feature 87 (Norman et al. 2017). 


\section{Feature 68B}

Feature 68B (Figure 8) is not a standard Thule or Iñupiat house. There are several hypotheses as to the nature of this feature (Hoffecker and Mason 2011). One is that it was a qargi, or an outdoor area for celebration or feasting. Another hypothesis is that the structure was either disassembled or unfinished. The feature has a short, $2.4 \mathrm{~m}$, long tunnel (Table 5) with horizontal stacked logs forming the tunnel walls. The main room is smaller than the other features (Hoffecker and Mason 2011): a square of 2.5 meters. In contrast to house features excavated at Espenberg, Feature 68B has significantly fewer artifacts than recovered from other features, including neighboring Feature 68A. This is particularly true for ceramics, which only represent $4 \%$ of the total assemblage at Feature 68B (Table 6).

\section{Feature $68 \mathrm{~A}$}

Feature 68A (Figure 9) was excavated in 2010; this effort revealed a single room house, measuring approximately 3 meters by 3 meters, with a 5.5 -meter-long entrance tunnel (Table 5). In addition, there is a concentration of burnt bone and ceramic in an open-air activity area to the west of the entrance tunnel. This concentration could be an outdoor area used for cooking and/or pottery production (Hoffecker and Mason 2010). 


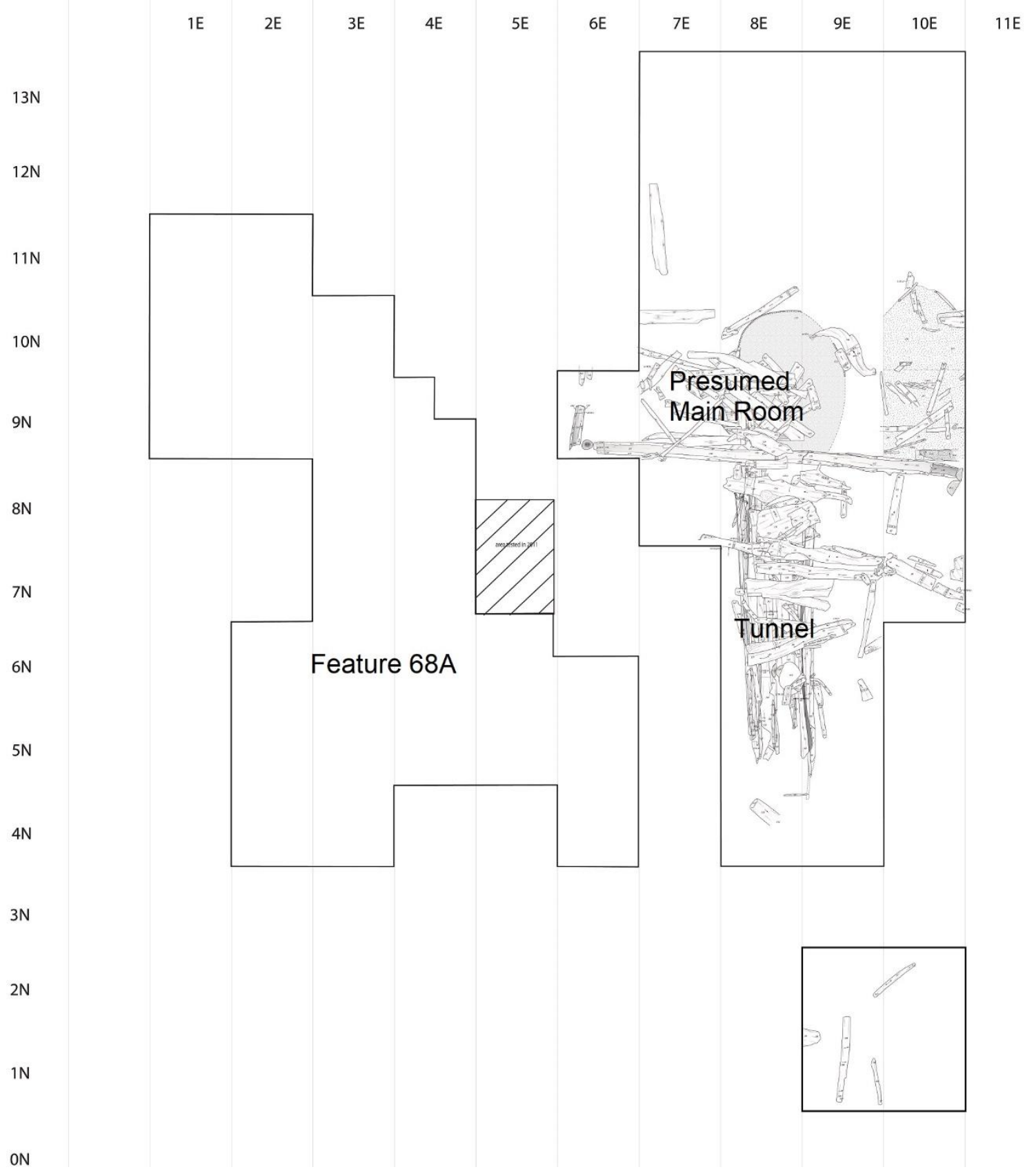

Figure 8. Feature 68B (Figure by Claire Alix). 


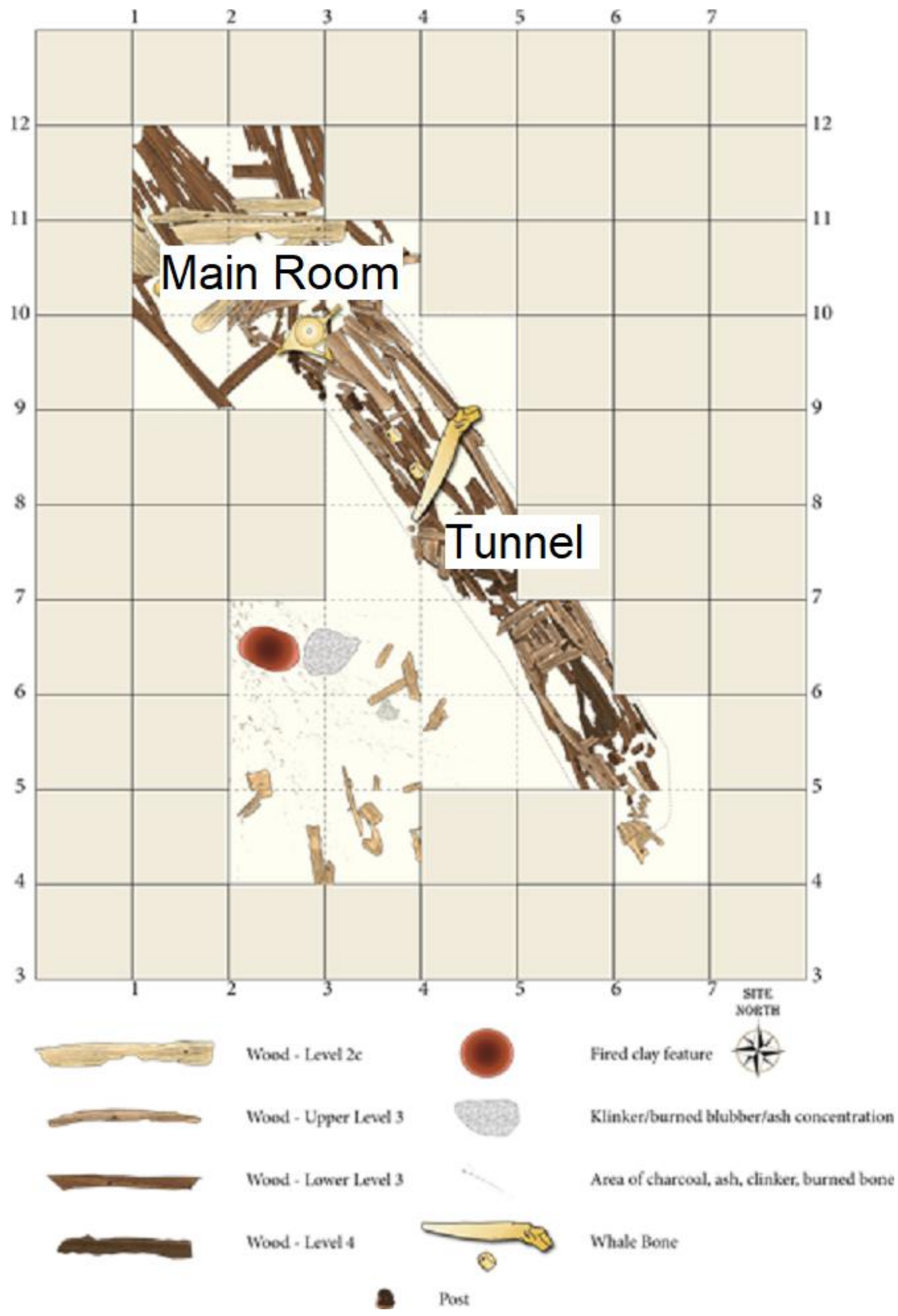

Figure 9. Feature 68A (Darwent et al. 2013) Map by John Darwent. 


\section{Feature 33}

Feature 33 (Figure 10) is the youngest feature in this study set, dating from 250-400 $\mathrm{BP}$ (Table 5). The tunnel is 4 meters long, and the main room is 3 meters long and approximately 2.5 meters wide (Table 5). Like the older houses, Feature 33 contained both whale bone elements and whale bone artifacts, including a mattock and sealing harpoon. Lithic waste and pottery fragments (Table 6) were the most commonly recovered artifacts (Hoffecker and Mason 2011). 


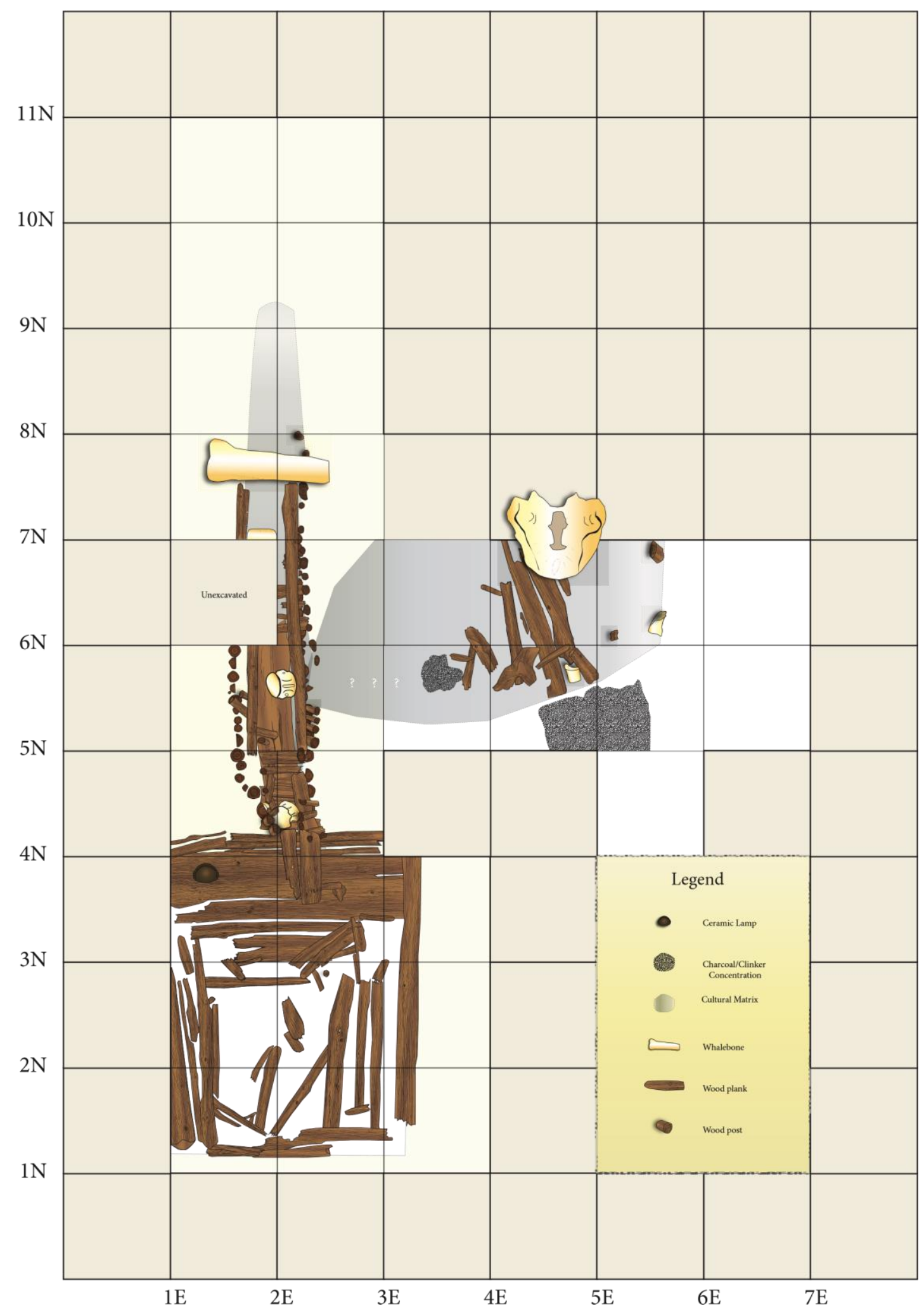

Figure 10. Feature 33 (Darwent et al. 2013). Map by John Darwent. 


\section{Cape Espenberg Ceramic Sample}

During the four field seasons, 4,484 sherds were collected from the five features I focus on in this research (Table 6). However, the spatial analysis for the Cape Espenberg features is limited to the floor and tunnel levels of the house features. This is where primary and secondary deposition would have taken place (LaMotta and Schiffer 1999). Other ceramics and artifacts found outside of the floor levels were usually part of the fill (material accumulated or deposited into a feature after the house was occupied and abandoned) and will be excluded in the analysis because they are removed from their primary deposition. Artifacts in the non-floor deposits are also much more likely to have been affected by post-depositional factors. About one-quarter of the ceramics from the initial list of ceramic samples found in Table 6 could be used in the spatial analysis (Table 6). Note that because Feature 68B was such a small sample size for all artifacts including ceramics, I decided to exclude it from the spatial analysis.

Table 6. Number of total ceramics in Cape Espenberg assemblage as compared to number of ceramics from floor levels that were used in spatial analysis.

\begin{tabular}{|c|c|c|c|c|c|c|}
\hline & $\begin{array}{c}\text { KTZ-304 } \\
\text { Feature } \\
21 \text { (Floor } \\
=\text { Levels } \\
2-3)\end{array}$ & $\begin{array}{c}\text { KTZ-087 } \\
\text { Feature } \\
87 \text { (Floor } \\
=\text { Level } \\
\text { 3) }\end{array}$ & $\begin{array}{c}\text { KTZ-087 } \\
\text { Feature } \\
68 B \\
\text { (Floor = } \\
\text { Levels } \\
2 A-4 A)\end{array}$ & $\begin{array}{c}\text { KTZ-087 } \\
\text { Feature } \\
68 A \\
\text { (Floor = } \\
\text { Levels } \\
\text { 2A-4A) }\end{array}$ & $\begin{array}{c}\text { KTZ-088 } \\
\text { Feature } \\
33 \\
\text { (Floor = } \\
\text { Levels } \\
\text { 2A-3A) }\end{array}$ & Total \\
\hline $\begin{array}{l}\text { Total number } \\
\text { of ceramics }\end{array}$ & 1780 & 1474 & 122 & 464 & 644 & 4484 \\
\hline $\begin{array}{c}\text { Number of } \\
\text { ceramics from } \\
\text { floor levels }\end{array}$ & 347 & 388 & 15 & 252 & 73 & 1075 \\
\hline
\end{tabular}


Density is the measure of HDBSCAN so further consideration of ceramic density in relationship to fragmentation, counts, weights, and excavated volume are necessary before moving forward with the spatial analysis. I did not give counts for all ceramic fragments less than $20 \mathrm{~mm}$ in any direction. This was for two reasons. First, the sheer number of very small ceramic fragments could artificially inflate my density. Secondly, the friable nature of these fragments mean that they often break in transit, and in analysis. So I weighed all fragments less than $20 \mathrm{~mm}$ in any direction and used this in my fragmentation analysis, which I discuss in more detail below). I did not attempt to calculate the minimum number of vessels for this spatial analysis, which is not only imprecise but often yields a minimum number of vessels that are well below any reasonable number (Orton and Hughes 2013). Instead, I analyzed density (the measure of HDBSCAN) based on both number of sherds and weight. The number of sherds, which were compared to the overall weight, was the input variable of my HDBSCAN analysis. I compared both ceramic counts and weights, as measures of overall density or abundance of ceramics, across excavated floor levels. In order to provide context for clusters identified by HDBSCAN analysis, I first calculated the number of sherds per cubic meter, and the weight of sherds per cubic meter of the floor deposit. I found that counts and weights were quite similar for each feature (Figure 11). This demonstrates that both count and weight are appropriate proxies for this ceramic spatial analysis (Figure 19). Note also that Features 21 and 68A had similar density. Feature 87 had a very high number of sherds per cubic meter. Feature 33 had a lower number of sherds, as well as the weight of sherds per cubic meter. 


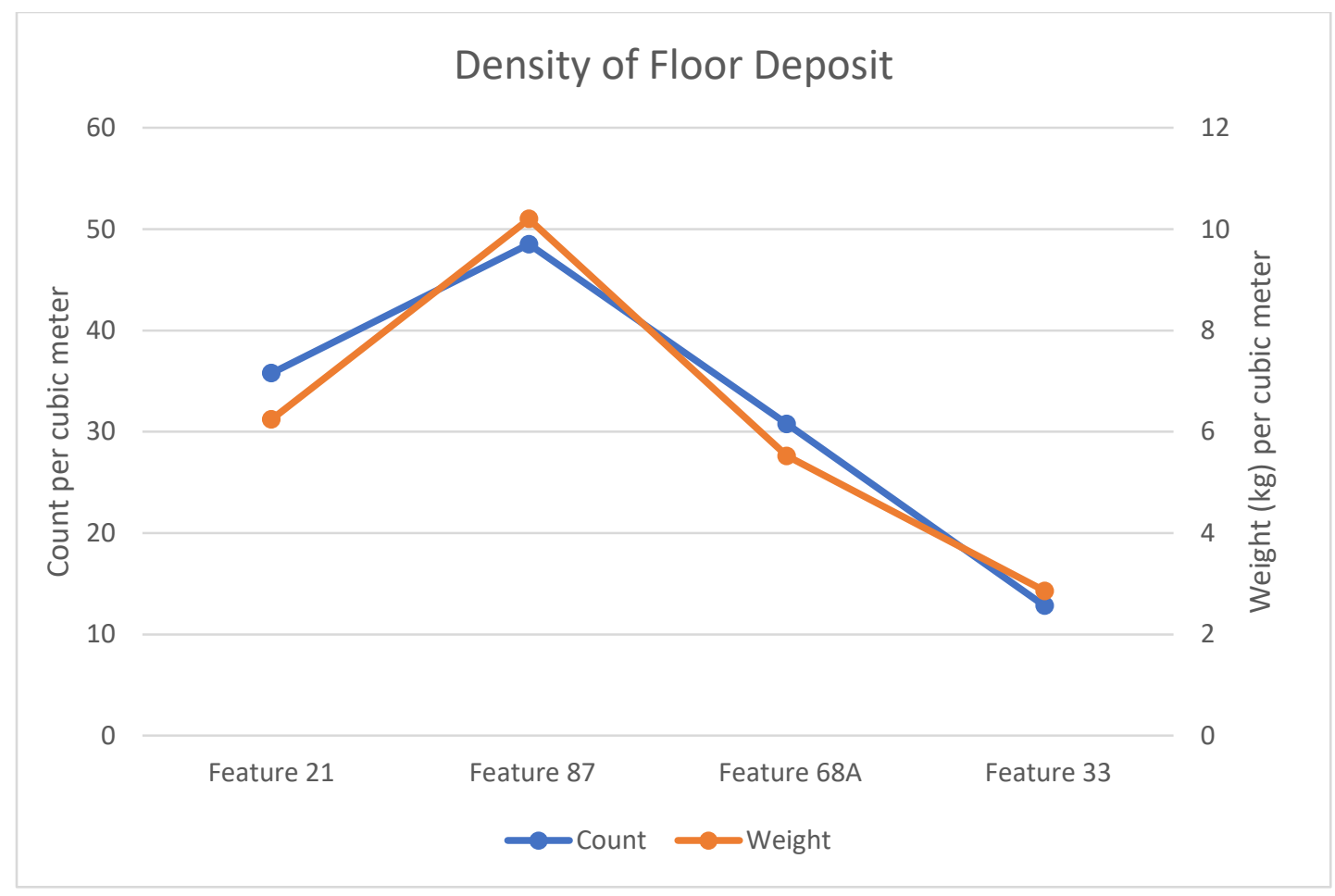

Figure 11. Relationship between sherd count and weight for floor deposits.

\section{Excavated Volume and Ceramic Sample Size}

It is important to consider the relationship between excavated volume and sample size. What may be perceived as difference in site function, or length of occupation, may simply be the result of excavation size (Betz 2009). It is clear from Table 6 that there is a marked difference between the ceramic sample sizes of the features. An unusually rich, or unusually empty feature could bias my analysis. Using Pearson's r test (Betz 2009), a measure of the strength of a linear association between two variables, I tested if the number of sherds is correlated with the excavated volume of the floors. Pearson's $r$ ranges from -1 to 1 . A value of 0 shows that there is no association. A positive value shows a positive association: when one variable increases, the other does as well. A 
negative value is the exact opposite: when one variable increases, the other decreases. The results of this Pearson's $r$ test is 0.68 (Figure 12). There is a correlation between the amount of excavated volume, and the number of ceramics recovered. This means that the overall density of ceramics in each feature could be, in part, a function of excavated volume rather than a product of human activity within the houses. Since my cluster analysis is density dependent, the correlation between ceramic sample size and excavated volume could be influencing the results of my analysis. I cannot mitigate this effect, but must consider its potential impact on the results of my analysis. I return to this issue in the discussion of results.

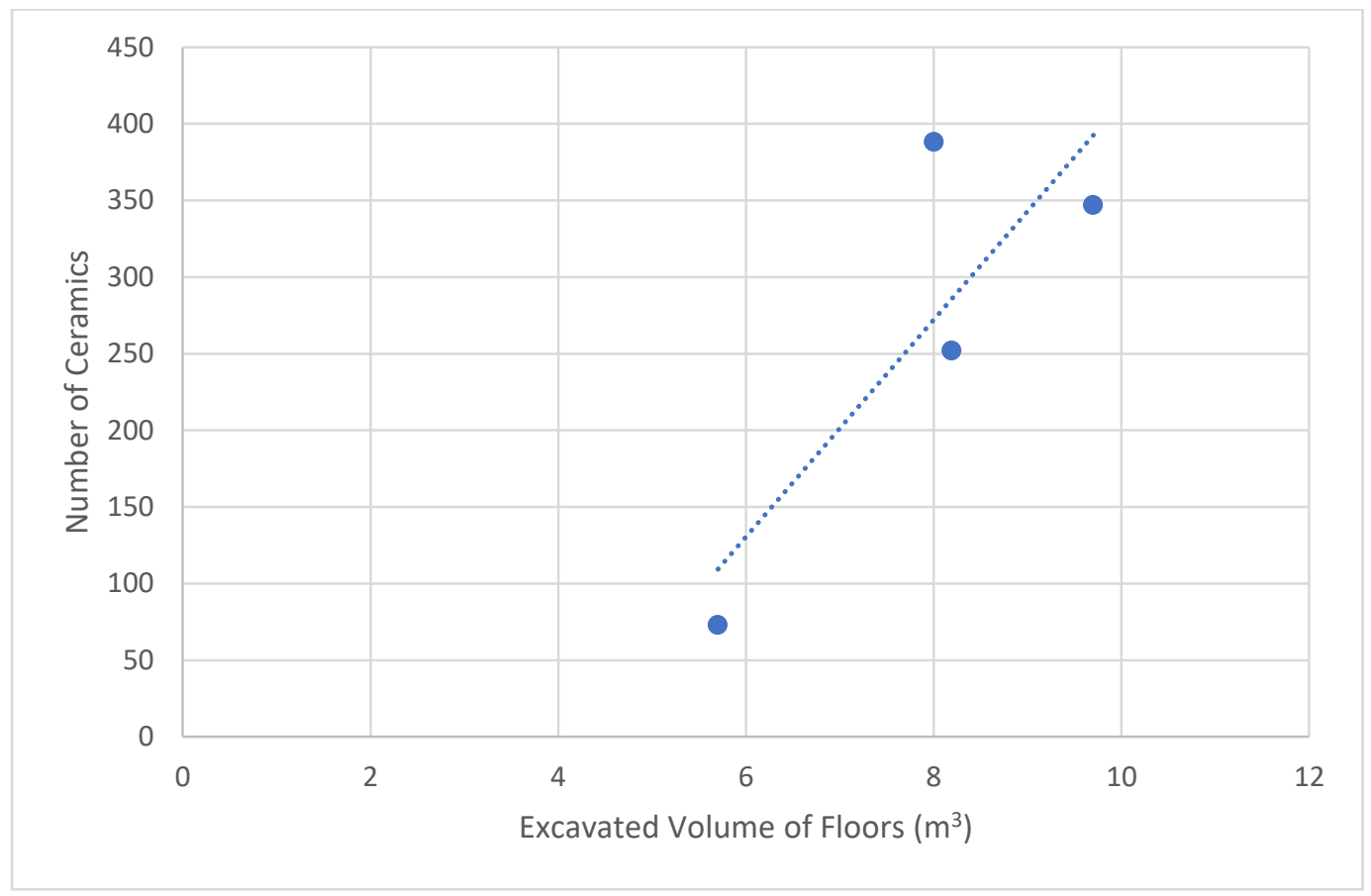

Figure 12. Scatterplot of excavated volume $\left(\mathrm{m}^{3}\right)$ against number of ceramics recovered from the features. Best fit line $\left(r^{2}=0.6953\right)$ is represented by the dotted line. 


\section{Male and Female Artifacts}

It is likely that men were the primary maker of organic tools, as seen in Table 7, (Boismier 1991, Griffen 1930, Rasmussen 1922), even those used by women. However, the focus of this spatial analysis is the tools used by the different genders, not the manufacturing of the tools. So, in this context, male artifacts are artifacts that are used by men while female artifacts are those artifacts used by women. I assumed that the artifacts that were found on the floors and tunnels of the features were items that were the result of primary refuse deposition (LaMotta and Schiffer 1999). I also assumed that the artifacts were discarded or lost by occupants and subsequently missed during cleaning, or that cleaning did not occur.

Because of the small number of floor-level artifacts present in each feature, I did not have to sample artifacts, and could gender (or exclude) each artifact present. I did not have access to the physical artifacts. I had to ascribe gender using catalog records of the artifacts, primarily the name and physical description of the tools given by prior analysts. In part due to this, I adopted a conservative method in attributing the different artifacts present in the Cape Espenberg 2009-2011 and 2016 collections (Table 7). If the typology or description of the artifact was unclear, I eliminated the artifact from analysis. All unidentified objects (like "worked bone object") were excluded from the analysis. Other objects excluded from the spatial analysis were faunal material, manufacturing debris, and flakes. Not only are such items not explicitly gendered, the sheer number of these artifacts would artificially inflate the density analysis and cause patterns to emerge (or hide other patterns). 
In addition to excluding ambiguously identified artifacts, I excluded probably gendered artifacts that were vaguely labeled. For example, unless knives were explicitly labeled as "end blade" (male) or "ulu" (female), I excluded them from the analysis, because they could be used exclusively by either gender. While labrets were primarily worn by men (Burch 2006, Nelson 1898), women did occasionally wear labrets in the Arctic. There is specific mention of women wearing labrets at Besboro Island and Prince William Sound (Giffen 1930), so I designated them as "gender neutral." Because both men and women fished, all of the fishing gear (except the salmon spear) is designated as "gender neutral" Although men were likely the makers of all the antler, bone, ivory, and stone tools (Giffen 1930), I focused on who used the artifacts as the markers of "male" or "female". Following this methodology, I identified 297 separate artifacts (excluding ceramics) spread unevenly throughout the five features.

Table 7. List of female, male, and gender-neutral artifacts and quantity found on floor levels of features included in this study. List adapted from Burch 2006, Griffen 1930, Hennebury 1999, Reinhardt 2002, and Whitridge 1999.

\begin{tabular}{lccc} 
Artifact & Female & Male & $\begin{array}{c}\text { Gender- } \\
\text { Neutral }\end{array}$ \\
\hline Adze & & 19 & \\
\hline $\begin{array}{l}\text { Arrow Points and other } \\
\text { Projectile Points }\end{array}$ & 40 & \\
\hline Atlatl Hook & & 1 & \\
\hline Awl & 10 & & \\
\hline Bead & & & 24 \\
\hline Biface & & 3 & \\
\hline Bird Blunt & & 2 & \\
\hline Bola Weight & & & \\
\hline Boot Creaser & 1 & & \\
\hline Bowl & 2 & & \\
\hline Bow Stabilizer & & 4
\end{tabular}




\begin{tabular}{|c|c|c|c|}
\hline Box & 1 & & \\
\hline Burin & & 1 & \\
\hline Chisel & & 2 & \\
\hline Clay Ball & & & 1 \\
\hline Club & & 1 & \\
\hline Comb & & & 2 \\
\hline Cord Attacher & & 2 & \\
\hline Dart & & 8 & \\
\hline Drill Bows & & 6 & \\
\hline End Slotted Knife & & 7 & \\
\hline $\begin{array}{l}\text { Fishing Equipment (Barbs Lures, } \\
\text { Prongs) }\end{array}$ & & & 15 \\
\hline Floats & & & 4 \\
\hline Foreshaft & & 5 & \\
\hline $\begin{array}{l}\text { Food Serving Objects (Spoons, } \\
\text { Ladles) }\end{array}$ & 3 & & \\
\hline Graver & & 3 & \\
\hline Harpoon & & 15 & \\
\hline Handle & 2 & & \\
\hline Ice Pick & & 5 & \\
\hline Labrets & & & 2 \\
\hline Lamp & 3 & & \\
\hline Leister Barb & & 3 & \\
\hline Marlinspike & & 2 & \\
\hline Needle & 4 & & \\
\hline Needle Case & 1 & & \\
\hline Netsinker & & & 1 \\
\hline Pendant & & & 3 \\
\hline Scaler & 2 & & \\
\hline Scraper & 25 & & \\
\hline Slat Armor & & 4 & \\
\hline Slate Blade & & & 9 \\
\hline Sled Equipment & & & 3 \\
\hline Ulu & 14 & & \\
\hline Wedge & & & 3 \\
\hline Whetstone & & & 25 \\
\hline Wick Trimmer & 1 & & \\
\hline Total & 69 & 136 & 92 \\
\hline
\end{tabular}




\section{Resolving Depositional Effects}

Cape Espenberg, like nearly all archaeological sites, has undergone primary, secondary, and post-depositional processes (Table 4). These processes have shaped and subsequently altered the primary deposition of artifacts (Carr 1984). The primary, secondary and post-depositional processes are an enormous influence on the archaeological contexts. Due to these processes, any discrete activity areas within the house are probably not intact, and interpretation must proceed with caution.

In many ways, Cape Espenberg is an ideal site to study, not in the least because of its relative lack of natural post-depositional effects. There is little evidence of the natural post-depositional effects (the one feature most impacted by ground squirrel activity was eliminated from this study because the excavation is incomplete) and there is little indication of extensive cultural secondary and post-depositional effects.

\section{Depositional Effects Resolved Before Spatial Analysis}

The main effects that needed to be resolved before spatial analysis was the possibility of various natural post-depositional processes and multi-episodic occupations or abandonment at Cape Espenberg. As I discussed in chapter 2, and referenced in Table 4, the natural post-depositional processes most likely to affect the Cape Espenberg features are faunalturbation, frost disturbance, and erosion. I relied on detailed field notes, level forms, and profile drawings to identify evidence of these processes. Like my method of ascertaining gender of objects (Table 7), I used a conservative approach in dealing with post-depositional effects. If I found evidence of krotovinas, frost disturbance, or severe 
erosion, I would eliminate the quadrant, or even the whole unit if the disturbance was large enough, from my spatial analysis.

Fortunately, I found no evidence of krotovinas, frost heave, or erosion at the floor levels. It is unlikely that ground squirrels caused enough damage at the site to render the analysis unusable. While this does not mean that some minor faunalturbation (like dogs or bears digging up artifacts, which would show gnawed bones and/or soil fluctuation) did not happen, I did not find any evidence of severe faunalturbation in the stratigraphy. I also consulted with Owen Mason, the project geoarchaeologist, who did not detect any evidence of severe natural post-depositional disturbance of the stratigraphy in any of the features (Owen Mason, personal communication 2016).

In addition to finding no evidence of natural post-depositional processes, I found little evidence of secondary deposition. There is no evidence of multi-episodic occupations at any of the features. For each house, there is only one occupation level, with no sterile layers in between floor levels, and no evidence of large gaps between occupations. For example, there is no Choris pottery in a Birnirk style house. Neither did I find evidence of scavenging or looting following initial site occupation/formation. As mentioned previously, I eliminated ceramics from secondary deposits (i.e. house fill and roof) from my analysis. I did find evidence of sweeping and cleaning, both as primary and secondary deposition. These effects, in part, were interpreted from the results of spatial analysis and the fragmentation data, which could only be analyzed/resolved after analysis. 
Depositional Effects Resolved After Analysis through Study of Spatial Patterns and

\section{Fragmentation}

Some of the possible secondary depositional effects could only be accounted for during interpretation of my spatial analysis. This includes mostly cultural effects like cleaning and sweeping.

Evidence of cleaning and sweeping was a relatively easy interpretation. If the formed artifacts and ceramics concentrated primarily at the edges of the house, or in the tunnel, it is more likely that that pattern is due to sweeping debris away from the main living and working areas than by a preference of working at the edges of the house (generally away from light sources) or in the sometimes-cold tunnel. Storage is another reason why artifacts may concentrate in the tunnel. There is archaeological evidence (Whitridge 1999) that artifacts, especially those related to food production, were stored in alcoves within the tunnel in northern Alaskan houses.

Scavenging required interpretation both before and after the analysis. As referenced in Table 4, scavenging is taking structural materials, including wood, from existing houses. If those materials were missing, then the artifacts near those materials may be fragmented. I did not find evidence of missing structural materials, nor was there evidence of looting holes (Hoffecker and Mason 2011).

One of the ways to identify primary, secondary, and natural post depositional processes is to study fragmentation of ceramic artifacts (Orton and Hughes 2013, Schiffer 1987). Fragmentation rates were estimated by comparing fragment size classes, based on maximum dimension of each sherd (Cannon 2012, Lyman and O'Brien 1987). This 
method has most often been used in zooarchaeology (Cannon 2012, Colaninno, Hadden and Emmons et al. 2015, Lyman and O'Brien 1987, Marom 2016) but is applicable in this case to ceramic fragmentation. The ceramic sherds were previously measured for all features except for Feature 21. For that feature, I measured the floor-level sherds with digital calipers that are accurate to $0.01 \mathrm{~mm}$. I also weighed all fragments smaller than 20 $\mathrm{mm}$ with a digital scale accurate to the nearest $0.01 \mathrm{~g}$. I divided the sherds larger than 20 $\mathrm{mm}$ in their maximum direction from each feature into size classes with $10 \mathrm{~mm}$ increments.

Very small sherds, or fragments, cannot be included because of the limited information that they provide. They also can artificially inflate the density of areas that have higher fragmentation rates. To try to partially account for this, sherds that were smaller than $20 \mathrm{~mm}$ in all directions were not included in the density analysis. While they were not included in the density analysis, these very small sherds were included in the fragmentation results in chapter 4 to give greater evidence of primary, secondary, and post-depositional effects.

Within my analysis, I compared the rates of fragmentation between houses using the Kolmogorov-Smirnov test, which I completed in Python. The Kolmogorov-Smirnov test is a statistical test that compares continuous data of two or more samples. Because I compared multiple features simultaneously, the chance of incorrectly rejecting a null hypothesis, or a Type 1 error, increases (Weisstein 2017). In order to account for this, I applied the Bonferroni correction to the Kolmogorov-Smirnov test. The Bonferroni correction sets the alpha value for the entire set of comparisons equal to the alpha value 
divided by the number of comparisons (Weisstein 2017). This lowers the alpha value in order to not have Type 1 errors.

If the difference between rates of fragmentation between houses were statistically insignificant, then I can compare the results of the spatial analysis between houses. In addition to fragmentation rates between houses, I also studied the fragmentation within houses, which gave me more insight on the primary, secondary, and post-depositional processes. Based on the ethnographic and archaeological information (Table 4), I expected to see greater amounts of fragmentation in the tunnel as compared to the main room, due to secondary depositional effects like trampling. It should be noted that there are other reasons besides depositional effects for higher fragmentation rates. Lower fire temperature and higher fiber content would make ceramics fragment more easily (Anderson 2011, Harry et. al 2009). The results of the fragmentation analysis, including the Kolmogorov-Smirnov test, are discussed in chapter 4.

\section{Spatial Analysis}

I undertook a series of analyses called clustering algorithms. Clusters refer to a region of densely connected points that are separated by regions of non-dense points (Kumar and Reddy 2016). All of the analysis was conducted in Python, a free, widely-used, open source, and dynamic programming language. This is an alternative to more widely used archaeological spatial analysis tools like ArcGIS or SPSS. Python has mostly been used for machine learning, or teaching computers to act without being explicitly programmed. This gives priority to accuracy over interpretability. However, Python can be adapted for 
readable data analysis (the representation of data that can be naturally read by humans, instead of computers) (Kinder and Nelson 2015).

There are a number of different clustering algorithms available in different software packages. All cluster algorithms are not created equally. They differ in parameters, stability, and the number of observations needed. During exploratory data analysis, I needed an algorithm that was stable (returning the same clusters back when the algorithm was run twice with different random initializations), had intuitive parameters, and was conservative in assigning clusters. During exploratory data analysis, no results are preferable to incorrect results. I needed a clustering algorithm that would not force points into clusters. It is unlikely that all of the artifacts included in the analysis belong to a cluster, and some clustering algorithms can falsely assign membership to clusters, or create clusters that do not actually exist (Baxter 2009). I therefore chose to use a densitybased algorithm, HDBSCAN (Hierarchical Density Based Spatial Clustering of Applications with Noise). I used HDBSCAN to identify clusters. From HDBSCAN, I measured the level of cluster persistence. Cluster persistence is defined as the stability of a cluster across all distance scales. HDBSCAN's default distance measure is Euclidean distance (the straight-line distance between two points).

\section{DBSCAN (Density Based Spatial Clustering of Applications with Noise)}

This is a density based algorithm which assumes clusters for dense regions. This algorithm eliminates noise: not every point needs to be assigned to a cluster, which is important. In addition, this algorithm can be scaled to dataset sizes that cannot be used by 
other clustering algorithms (Ester et al. 1996, Valentine et al. 2015). Some of these algorithms require very large data sets (more than ten thousand samples), much larger than the vast majority of archaeological data sets. Perhaps the biggest problem with DBSCAN is that this algorithm requires an input of minimum samples; the analysis then only identifies clusters at or above that density. If data have variable density clusters (which the Cape Espenberg data set almost certainly does) then DBSCAN could either split or lump the clusters, or miss them altogether.

HDBSCAN (Hierarchical Density Based Spatial Clustering of Applications with Noise)

This algorithm is nearly identical to DBSCAN, but improves upon the original algorithm with a few changes (Li and Xi 2011, Tran, Drab and Daszykowski 2013). Most importantly, it allows for varying density cluster size (Sun 2012). The only issue that remains from DBSCAN is the minimum sample parameter. In order to run the analysis, I still had to choose the minimum number of samples that would be considered a cluster. I used the default setting for HDBSCAN which is five samples for a cluster.

\section{K-Means}

This is the most popular clustering algorithm in archaeology because it is fast, easy to understand, and available in nearly every statistical or machine learning tool (Anderson and Burke 2008, Enloe et al 1994, Gregg et al. 1991, Kintigh and Ammerman 1982, Koetje 1992, Simek 1984, Voorrips and O'Shea 1987). However, K-means can be problematic. First, it is not really a clustering algorithm. Rather, it is a partitioning 
algorithm. K-means does not "find clusters" but instead partitions the dataset into as many chunks as are input, while minimizing the distance between points within the cluster. If a point is above a certain minimum threshold, the point will be partitioned into another cluster to which it is closer. In order to use K-means cluster, one must specify exactly how many clusters are expected. While this is a good tool when the number of clusters is already known, it is a poor choice for an exploratory data analysis. K-means analysis also returns globular clusters, which means that "natural" clusters will be split into more globular shapes during analysis, even if that is not the actual shape of the cluster. "Noise" or points that do not fit into any cluster also tend to be lumped into these globular clusters. In combination with other methods of spatial analysis, however, Kmeans cluster analysis provides a very good method of identifying discrete clusters in three dimensions (Galanidou 2000, Mellars 1996, Pettit 1997).

I originally intended to use K-means analysis to further validate my results and to further identify the presence of three dimensional clusters, as well as the ability to run significance tests on the K-means. However, I ultimately chose not to run the K-means analysis on the Cape Espenberg data set for two reasons. First, the artifact clusters for Cape Espenberg were oddly shaped: thin clusters, long clusters, etc. K-means works best with clusters in roughly globular shapes, which my data were not. Secondly, data at Cape Espenberg were very noisy. Many of the sherds and formed artifacts did not fall into any clusters. This seems obvious and necessary; after all, not all artifacts would fall into a cluster or even an activity space. However, K-means does not account for noise. Instead, the analysis adds the noise points to clusters, artificially creating clusters where there are 
none, and adding unrelated points to existing clusters. Ultimately, it made more sense to eliminate the K-means analysis and focus solely on HDBSCAN (Figure 13), than to run the K-means analysis (Figure 14) and try to account for all the apparent conflicts.

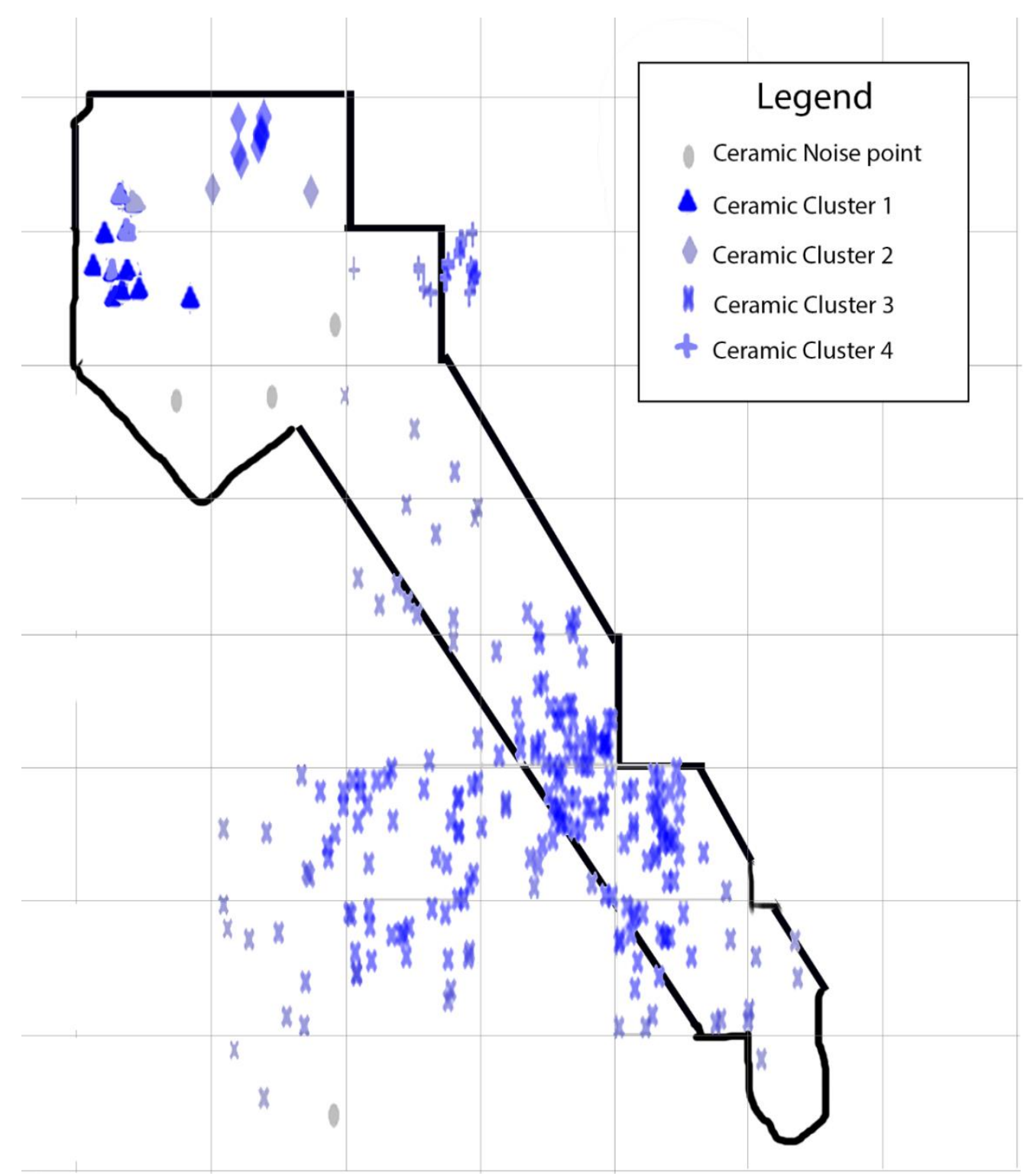

Figure 13. HDBSCAN cluster result of 68A. Notice noise points (represented by grey dots) and shape of clusters. 


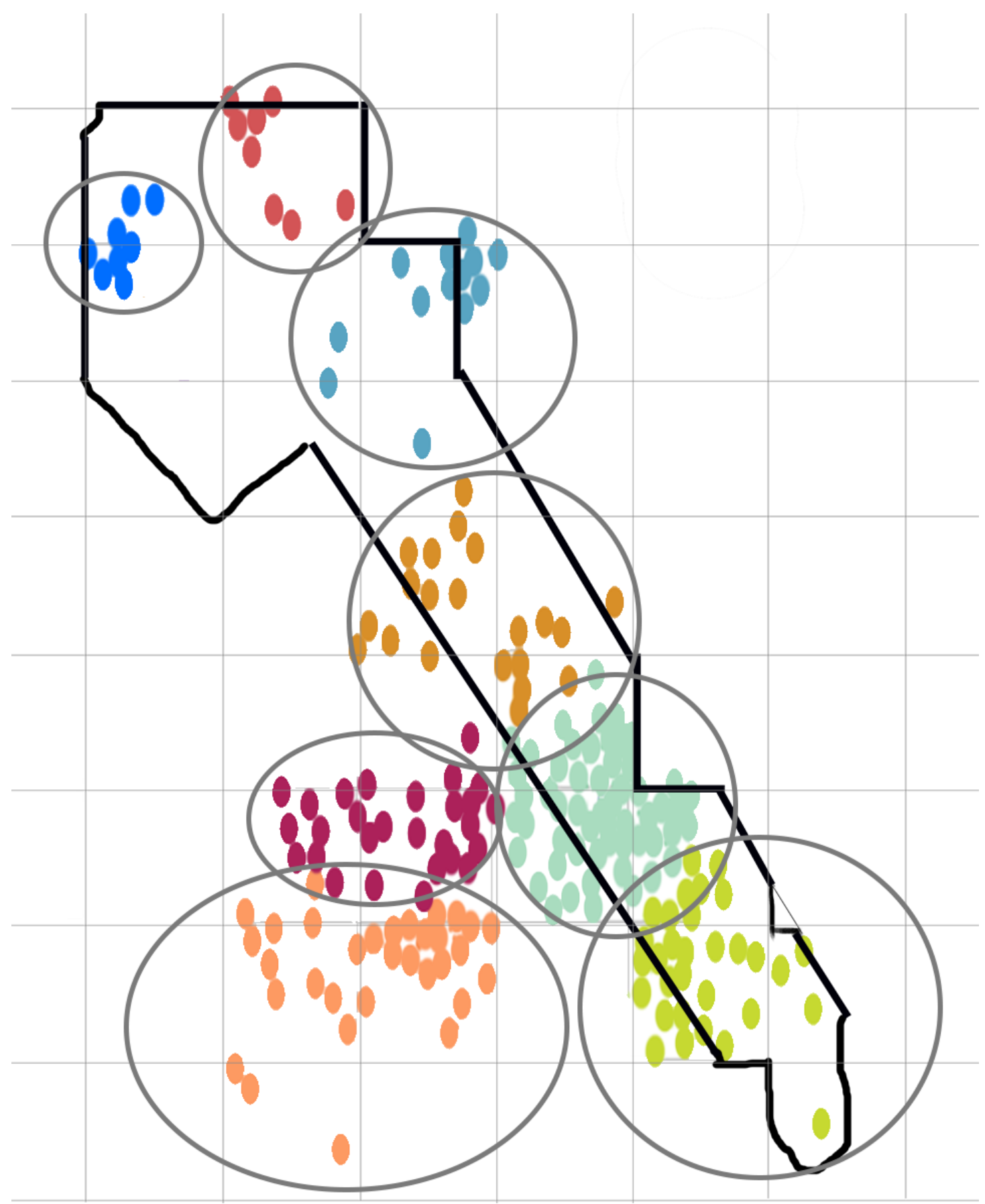

Figure 14. K-means analysis of Feature 68A ceramics. The different colors are distinct clusters identified by the analysis. Note the globular shapes and lack of noise points. 


\section{Chapter 4: Results}

Chapter 3 was an overview of the Cape Espenberg study site, and the associated artifacts. I also discussed the clustering algorithms I used, and the possible limitations of the modeling, including issues with ceramic fragmentation and post-depositional effects. This overview served to give the reader an understanding of how I conducted spatial analysis of the artifacts (summarized in Table 8) at Cape Espenberg. In this chapter, I present the results of my analysis.

Table 8. Summary of artifact data from the floor of each analyzed feature.

\begin{tabular}{lllllll} 
Feature & $\begin{array}{l}\text { Area of } \\
\text { Feature } \\
\text { in } \mathbf{~ m}^{2}\end{array}$ & $\begin{array}{l}\text { Volume of } \\
\text { Feature in } \\
\mathbf{m}^{\mathbf{3}}\end{array}$ & $\begin{array}{l}\text { Number } \\
\text { of } \\
\text { Ceramics }\end{array}$ & $\begin{array}{l}\text { Number } \\
\text { of Other } \\
\text { Female } \\
\text { Artifacts }\end{array}$ & $\begin{array}{l}\text { Number } \\
\text { of Male } \\
\text { Artifacts }\end{array}$ & $\begin{array}{l}\text { Number } \\
\text { of } \\
\text { Neutral } \\
\text { Artifacts }\end{array}$ \\
\hline 21 & 45 & 46 & 347 & 15 & 31 & 25 \\
\hline 87 & 42 & 29.6 & 388 & 19 & 42 & 22 \\
\hline $68 \mathrm{~A}$ & 26 & 35.1 & 252 & 22 & 27 & 23 \\
\hline 33 & 31 & 20.6 & 73 & 9 & 19 & 11
\end{tabular}

\section{Fragmentation Rates}

Before I could complete my analysis using HDBSCAN, I needed to analyze the fragmentation rates of the ceramics. First, fragmentation rates help me to identify, and possibly eliminate, the effects of secondary deposition. Secondly, as mentioned in chapter 3, similar fragmentation rates means that I could compare the results of the analysis across features (Table 9, Figure 14); differences in cluster density would not be the product of differential fragmentation rates. If the features had wildly different fragmentation rates, it becomes much more difficult to look at the density clusters and compare them across features. In addition, the resulting patterns would likely reveal more 
about primary/secondary deposition or post-depositional effects than gendered use of space. For sherds smaller than $20 \mathrm{~mm}$, I have included the weight of all the fragments. The percentage of sherds in each category is listed in Table 9.

Table 9. Comparative fragmentation of Cape Espenberg. Numbers listed are a percentage of the whole rounded to the nearest .01\%, except for fragments smaller than $<20 \mathrm{~mm}$.

\begin{tabular}{ccccc} 
& $\begin{array}{c}\text { Feature } \\
\mathbf{2 1}\end{array}$ & $\begin{array}{c}\text { Feature } \\
\mathbf{8 7}\end{array}$ & $\begin{array}{c}\text { Feature } \\
\mathbf{6 8 A}\end{array}$ & $\begin{array}{c}\text { Feature } \\
\mathbf{3 3}\end{array}$ \\
\hline Size Class & & & & \\
\hline $\begin{array}{c}<20 \mathrm{~mm} \text { (in } \\
\text { g) }\end{array}$ & 249.01 & 8776.8 & 48.6 & 10.6 \\
\hline $20-30 \mathrm{~mm}$ & 34.87 & 39.19 & 30.08 & 21.92 \\
\hline $30-40 \mathrm{~mm}$ & 25.99 & 18.11 & 29.24 & 24.66 \\
\hline $40-50 \mathrm{~mm}$ & 15.79 & 13.24 & 15.68 & 19.18 \\
\hline $50-60 \mathrm{~mm}$ & 11.84 & 8.92 & 9.75 & 9.57 \\
\hline $60-70 \mathrm{~mm}$ & 2.96 & 6.49 & 5.93 & 12.32 \\
\hline $70-80 \mathrm{~mm}$ & 3.29 & 3.51 & 4.66 & 5.48 \\
\hline $80-90 \mathrm{~mm}$ & 3.29 & 3.51 & 1.69 & 4.11 \\
\hline $90-100 \mathrm{~mm}$ & 0.98 & 1.89 & 0.85 & 1.37 \\
\hline $100+\mathrm{mm}$ & 0.66 & 5.14 & 2.12 & 4.11
\end{tabular}

There are some noticeable trends in the fragmentation across the five features. Most of the ceramic sherds fall within the first three size classes. Because of the small sizes throughout the features, it is likely that some trampling and other post-depositional breakage occurred. There is a noticeable difference in the amount of very small sherds $(<20 \mathrm{~mm})$ in size. Features 21 and 87 have a similar amount of ceramics, yet Feature 87 has 35 times the weight of the fragmented pieces. It is therefore likely that Feature 87 had a much higher rate of trampling, or other primary, secondary or post-depositional behaviors. While there is some difference in the fragmentation rates for sherds over 20 $\mathrm{mm}$ in size across the features, none are extreme outliers, and they are all comparable to 
each other based on the Kolmogorov-Smirnov test (Table 10). The relative similarity in fragmentation rates means that I can compare density data across features.

Table 10. Results of Kolmogorov-Smirnov test

\begin{tabular}{lllll} 
Feature A & Feature B & Result & P value & $\begin{array}{l}\text { Statistically significantly } \\
\text { different? }\end{array}$ \\
\hline 33 & 21 & 0.17 & 0.03 & False \\
\hline 33 & $68 \mathrm{a}$ & 0.17 & 0.04 & False \\
\hline 33 & $68 \mathrm{~b}$ & 0.27 & 0.25 & False \\
\hline 33 & 87 & 0.18 & 0.02 & False \\
\hline $68 \mathrm{a}$ & 21 & 0.05 & 0.82 & False \\
\hline $68 \mathrm{a}$ & $68 \mathrm{~b}$ & 0.15 & 0.87 & False \\
\hline $68 \mathrm{a}$ & 87 & 0.08 & 0.20 & False \\
\hline $68 \mathrm{~b}$ & 21 & 0.14 & 0.91 & False \\
\hline 87 & 87 & 0.14 & 0.91 & False
\end{tabular}

However, when I calculated fragmentation rates for different house areas (Figures 15-18), I found that rates of fragmentation vary drastically between features. 


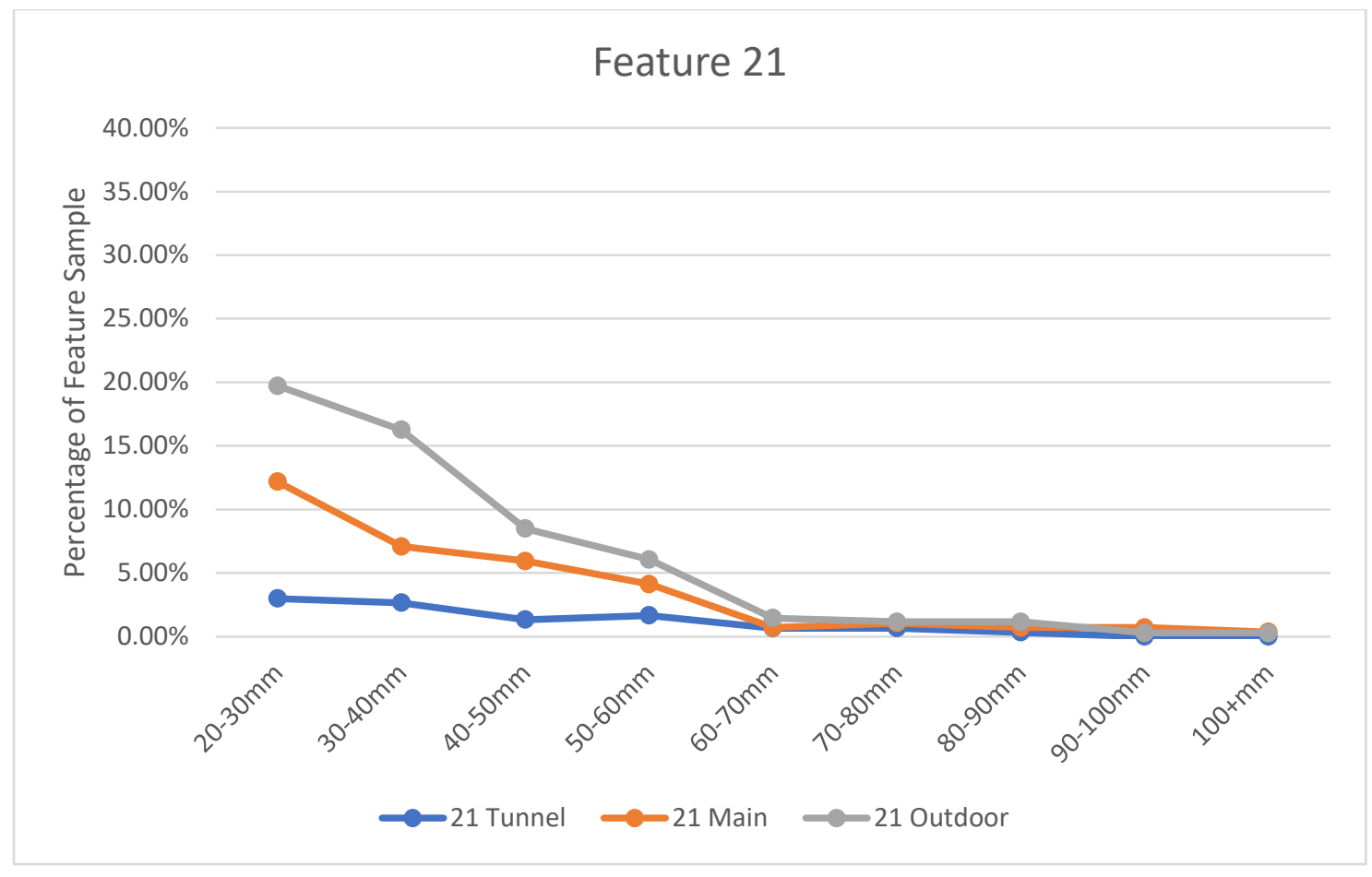

Figure 15. Fragmentation rates of Feature 21

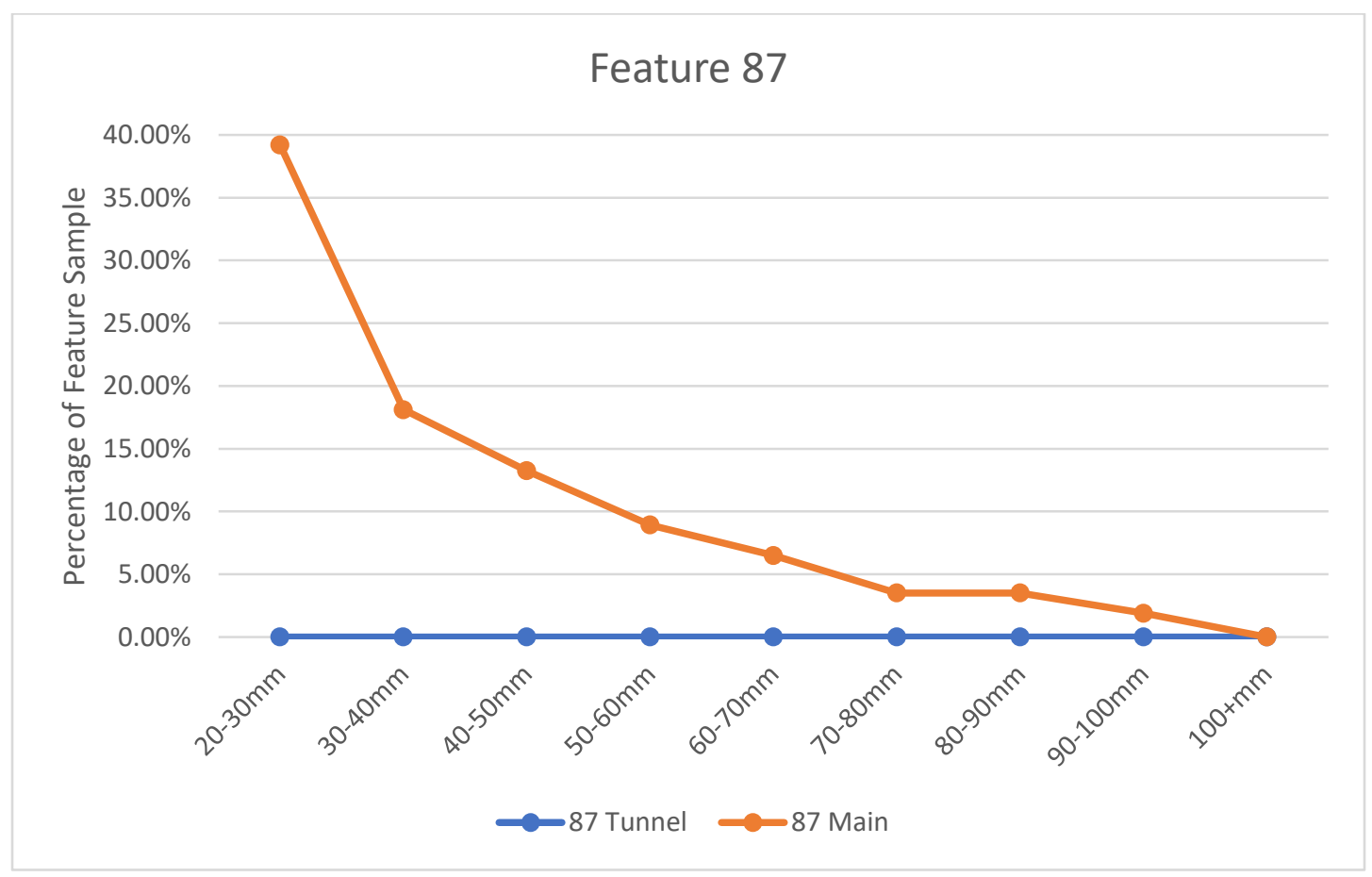

Figure 16. Fragmentation Rates of Feature 87 


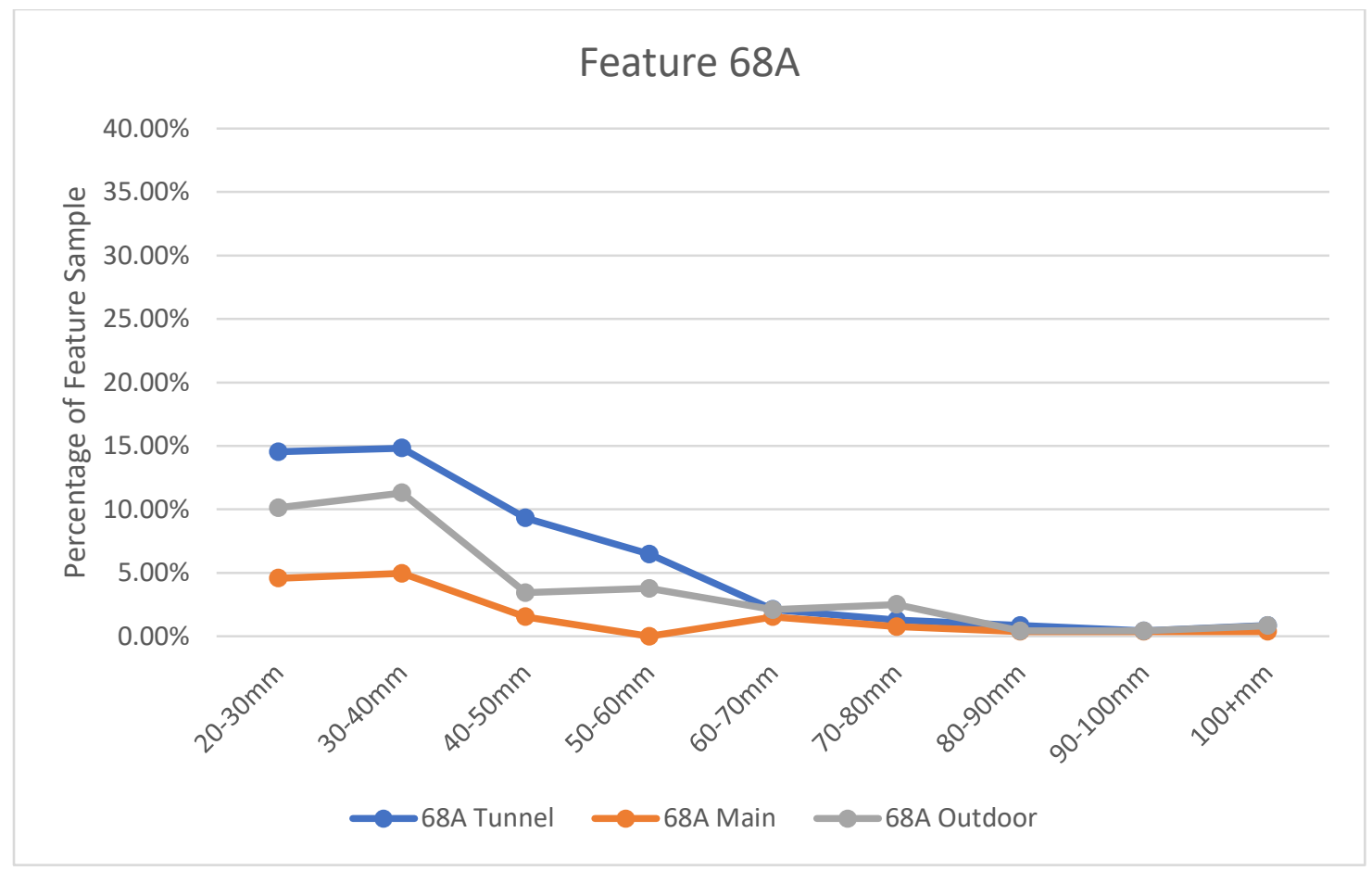

Figure 17. Fragmentation Rates of Feature 68A

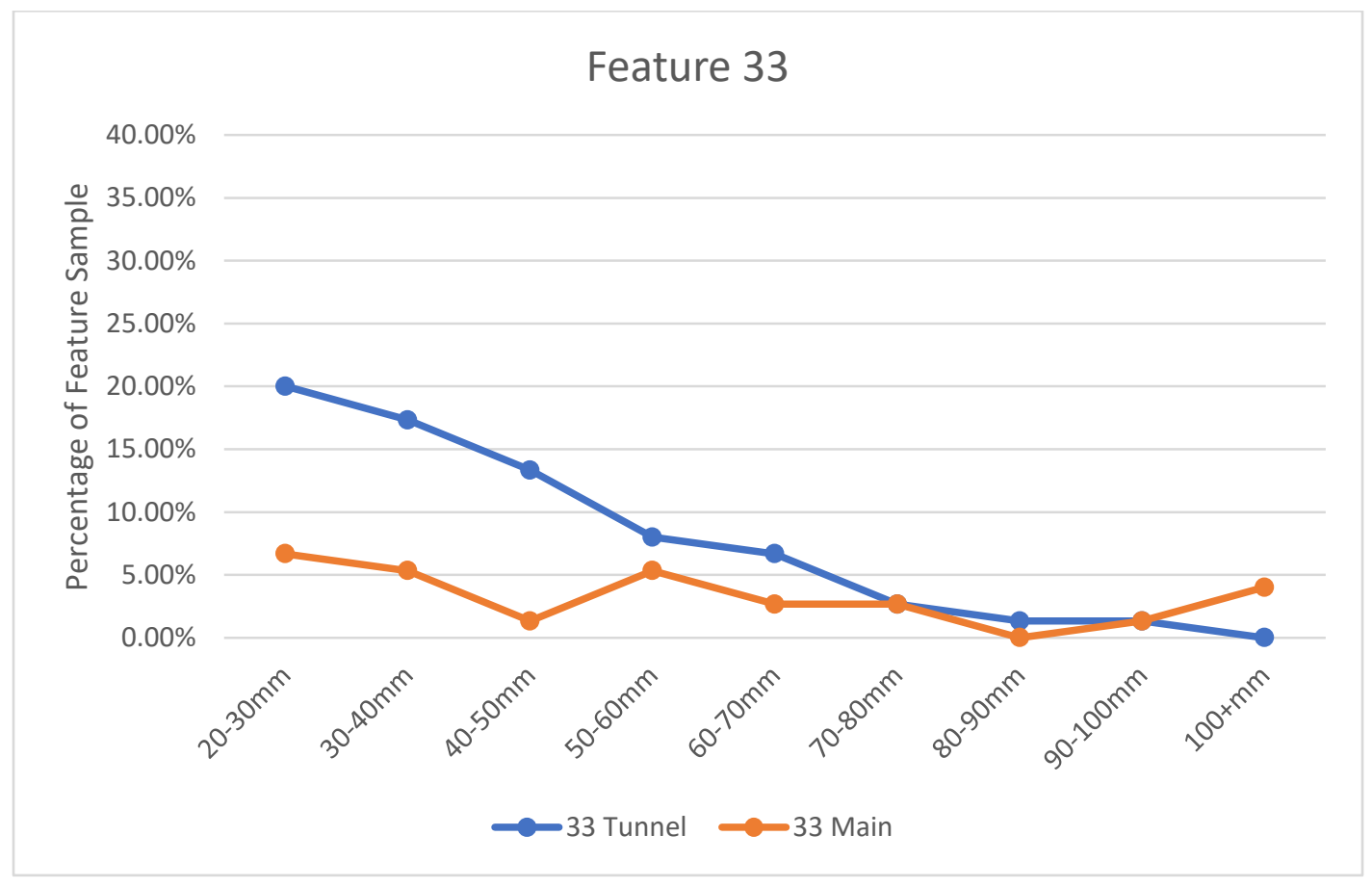

Figure 18. Fragmentation Rates of Feature 33 
Overall, there is a large difference between fragmentation rates in the tunnel and the house. While the majority of the ceramics are smaller than $50 \mathrm{~mm}$ in any direction, the main room has a larger share of the small $(20-40 \mathrm{~mm})$ sherds than does the tunnel in Features 21 and 87 . The tunnel of Feature 33 has nearly $75 \%$ of the total floor level ceramics, and has a larger share of the smaller ceramic sherds (Figure 18). In feature $68 \mathrm{~A}$, the tunnel has just over half of the overall total ceramics. The main room has only $14.5 \%$, while the remaining $32.5 \%$ of the ceramics are outside of the tunnel in the openair activity area (Figure 17). This is similar to Feature 21 as well, which has a larger share of ceramics in the outdoor area than either the tunnel or the main room (Figure 15). For both Features 21 and 68A, these outdoor areas could be examples of secondary contexts. As mentioned earlier, waste was often thrown outside of the house, into middens or sometimes just outside the house walls (Burch 2006). Rather surprisingly, there are no floor-level ceramics in the Feature 87 tunnel (Figure 16). Overall, there a variable amount of relative fragmentation in tunnels and the main rooms. The significance of the fragmentation rates is discussed further in Chapter 5 .

\section{Cluster Analysis}

As mentioned in the previous chapter, HDBSCAN is a density based clustering algorithm. All the figures were created in the Jupyter Notebook App, which contains both computer code (Python in this case) and rich text elements (paragraph, equations, figures, etc.). The cluster results were overlaid on a map of the feature. Each point on a figure represents a single artifact. 
The minimum size of the cluster was left at the default of five members. The symbols representing the cluster are randomly generated and the different symbols represent membership in different clusters (see Figure 13). The more saturated the symbol color, the stronger the artifact's association with the cluster. The circular grey points are artifacts that are not members of any cluster, but are "noise points". Cluster persistence is a measure of the stability of each cluster (Table 11). A score of 1.0 means that the cluster is perfectly stable, i.e. persists over all distance scales. A score of 0.0 , on the other hand, represents an ephemeral cluster which is likely to change with a change of the distance scale.

Overall, all of the features have ceramic clustering (Table 11). Features 68A and 33 present slight ceramic clustering (Figures 19 and 20), while Features 21 and 87 (Figures 21 and 22) have very stable ceramic cluster persistence, with more than 10 ceramic clusters. 


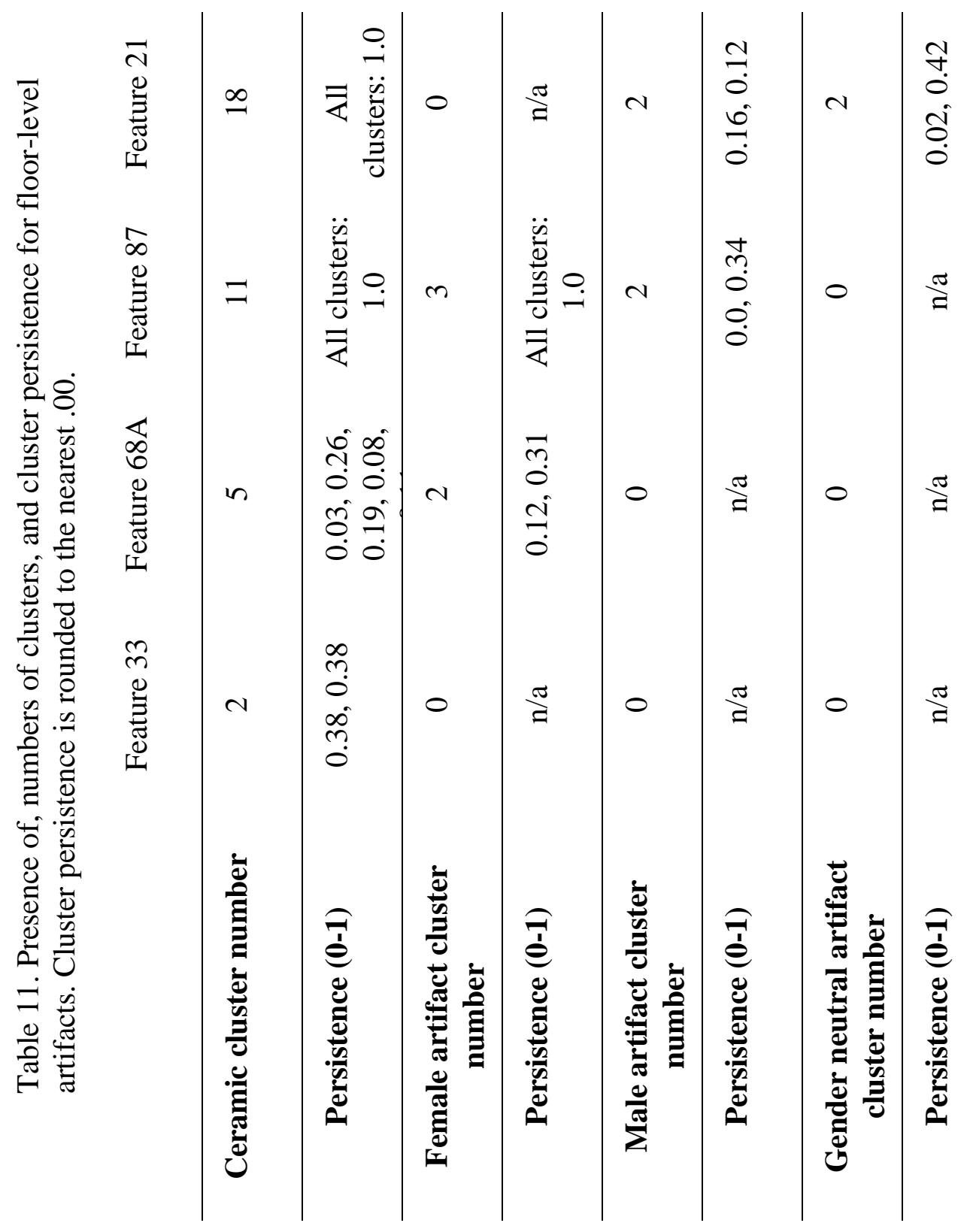




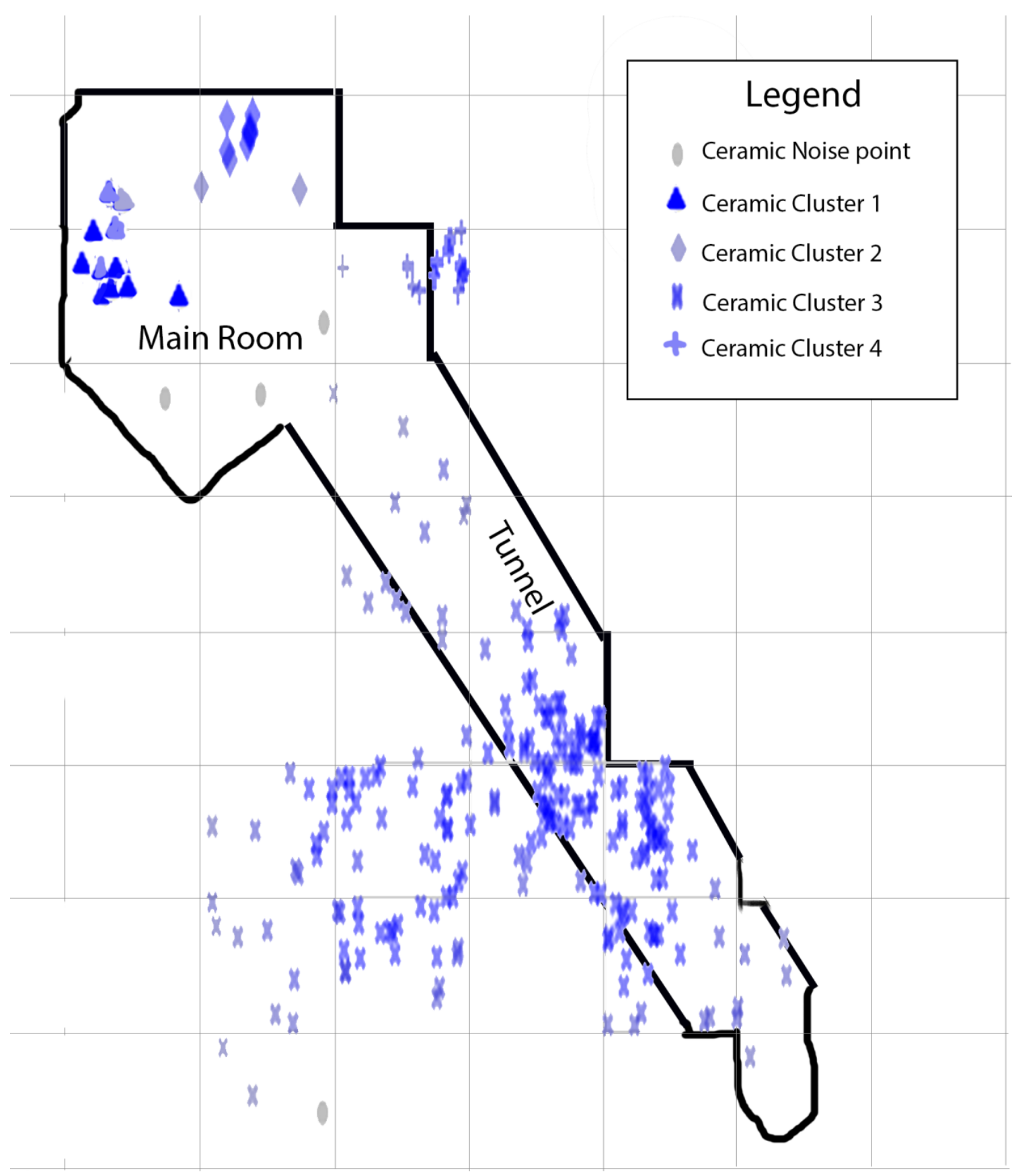

Figure 19. Cluster analysis of ceramics at Feature 68A. 


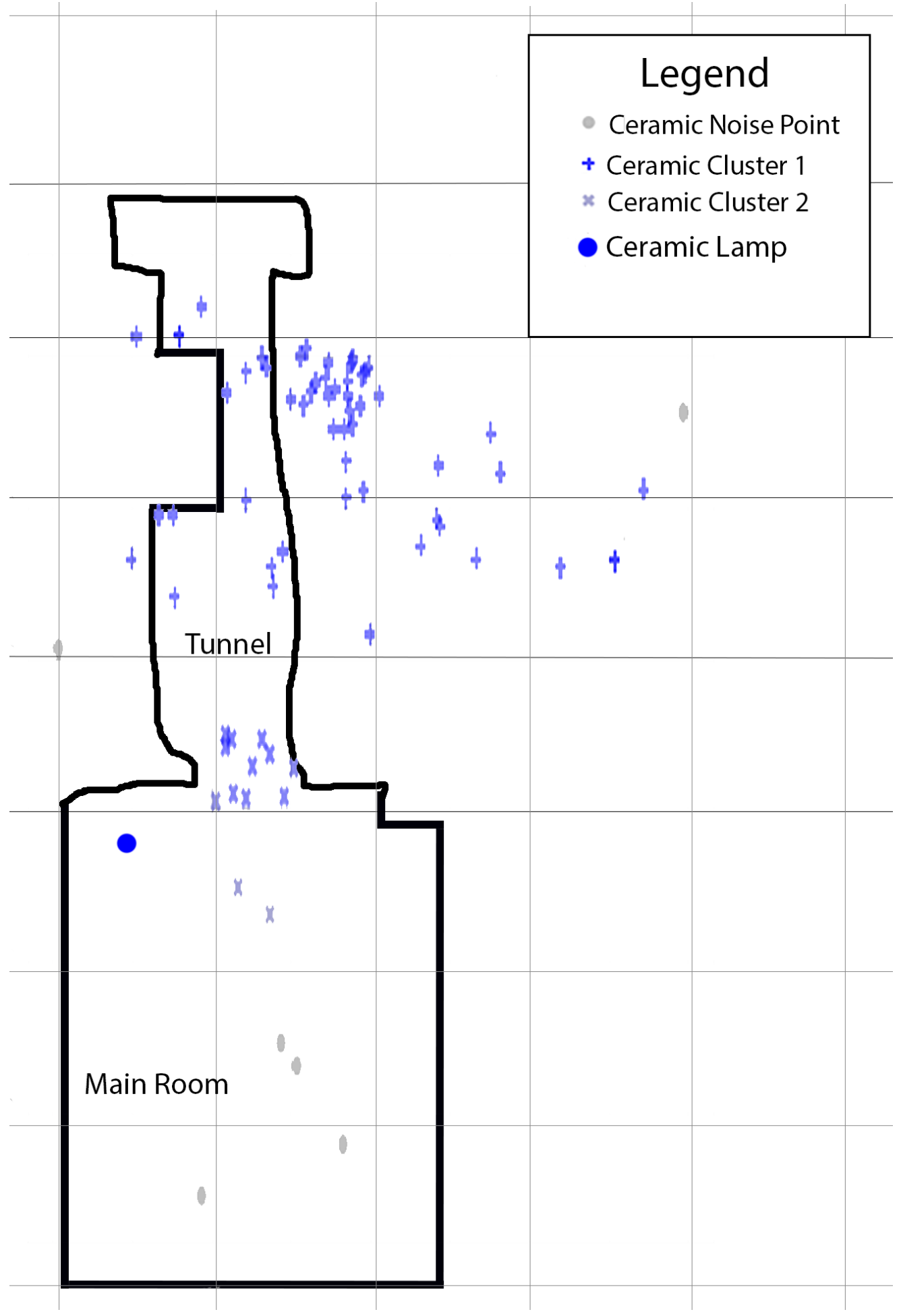

Figure 20. Cluster analysis of ceramics at Feature 33. 


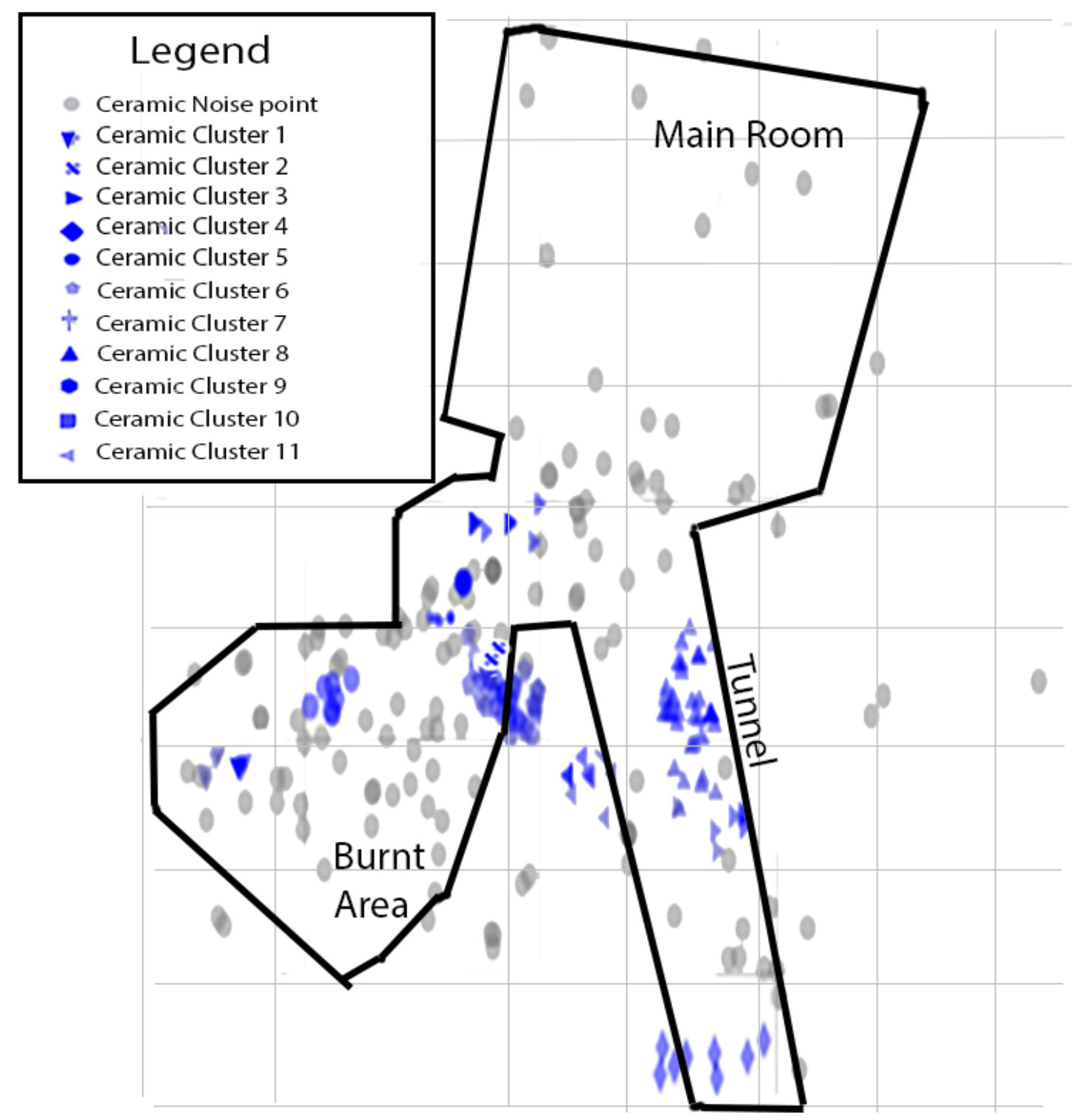

Figure 21. Cluster analysis of ceramics at Feature 21. 


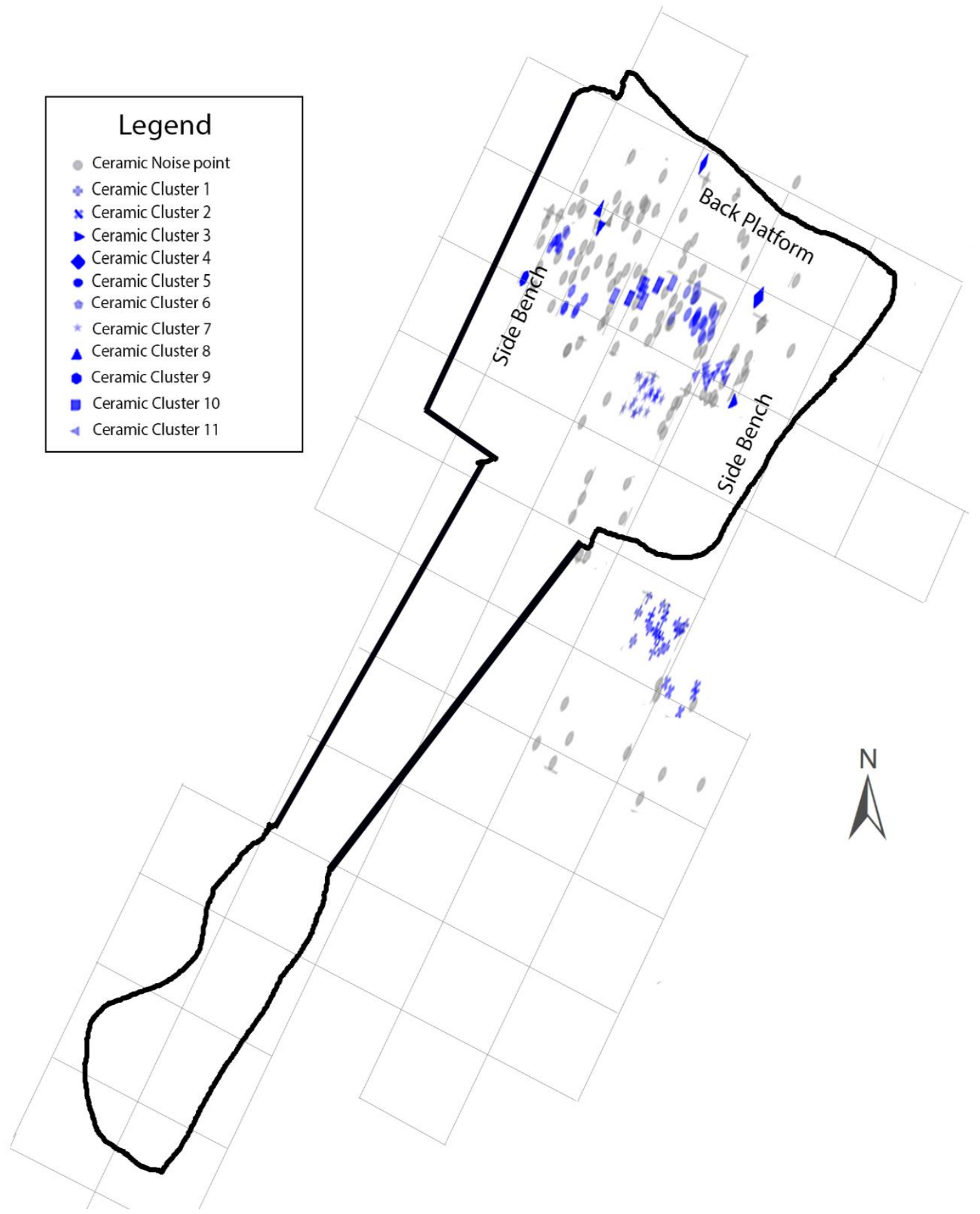

Figure 22. Cluster analysis of ceramics at Feature 87. 
Compared to the ceramics, the other female artifacts for Features 87 and 68A (Table

11, Figures 23 and 24) clustered; only Feature 87 had strong cluster persistence. Features $21,68 \mathrm{~B}$ and 33 showed no clustering.

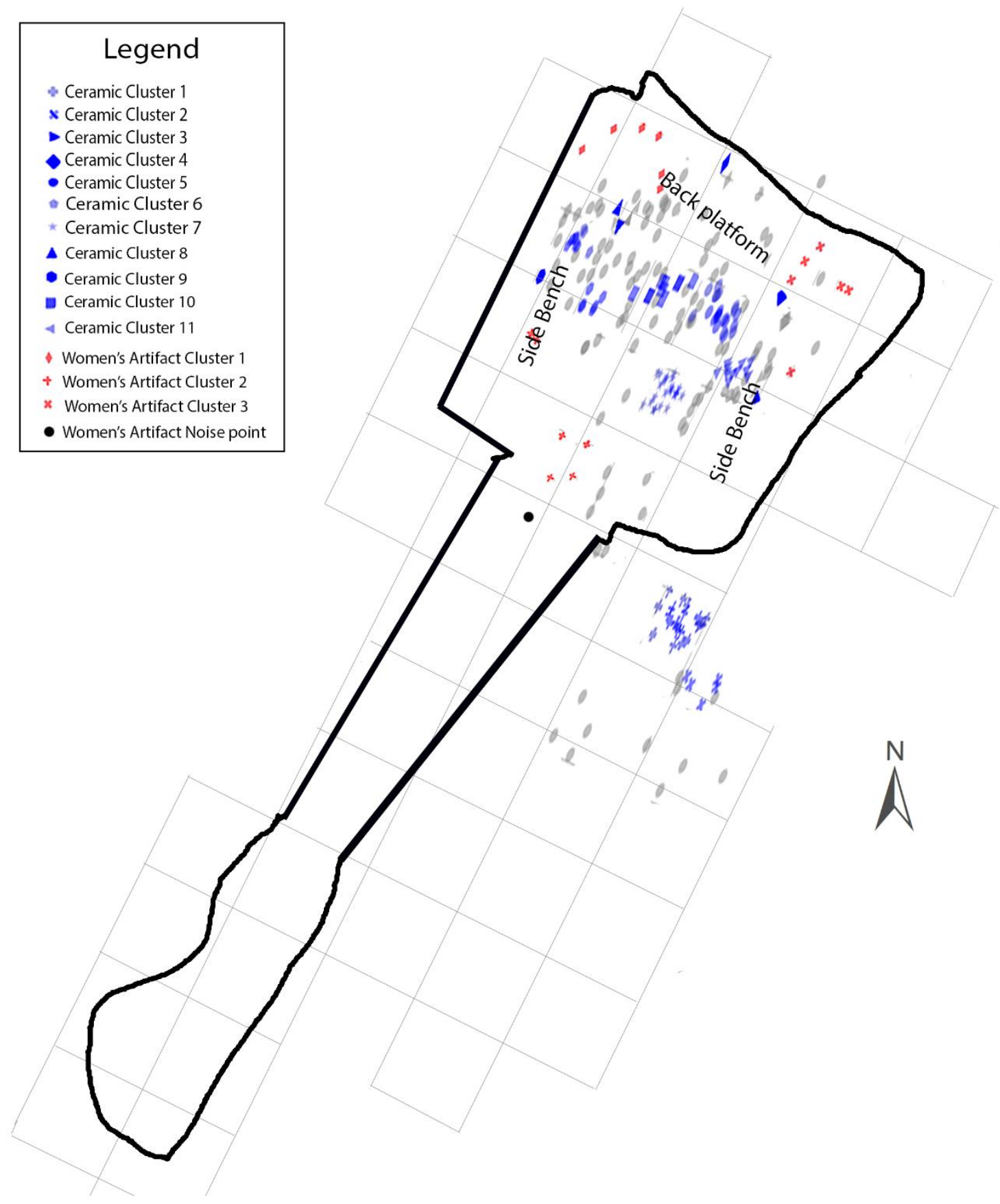

Figure 23. Cluster analysis of all women's artifacts at Feature 87. 


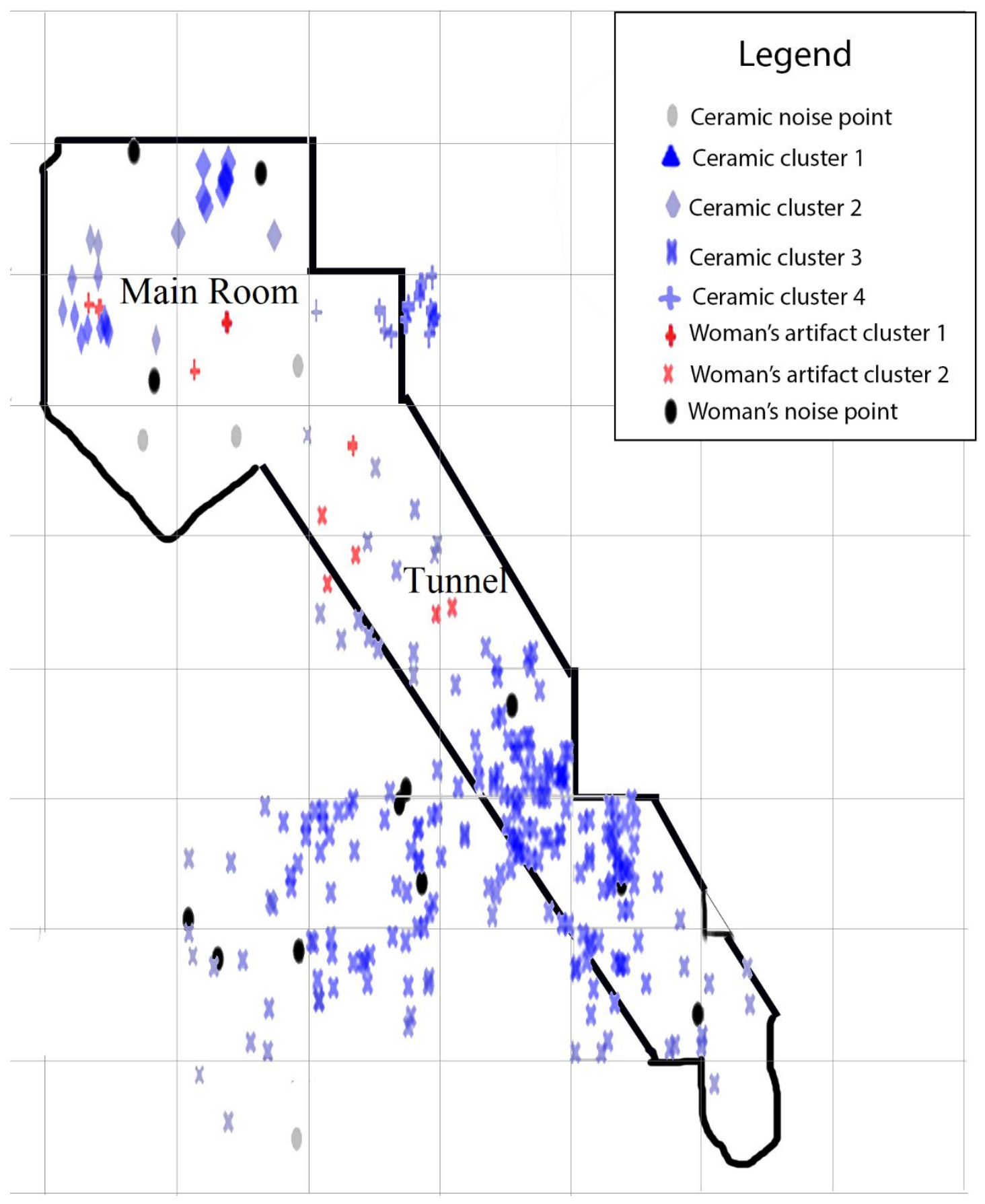

Figure 24. Cluster analysis of all women's artifacts at Feature 68A. 
Similar to the female artifacts, the male artifacts showed little clustering. Only Features 21 and 87 (Figures 25 and 26) showed any clustering of male artifacts, and both were ephemeral clusters (unlikely to persist over other distance scales). Features 68B, 68A and 33 showed no clustering. It is worth nothing that for all the features, there were few male artifacts compared to the female artifacts (Table 7). Because of the overall small sample size of identifiable men's artifacts throughout all the features, this finding should be treated cautiously. One of the possible reasons why the sample of identifiable men's artifacts is so low in Cape Espenberg is that my conservative method of identifying could have eliminated a large number of men's artifacts. I excluded anything labeled "worked bone/antler/ivory" even though it was more likely to be a male artifact than a female one. 


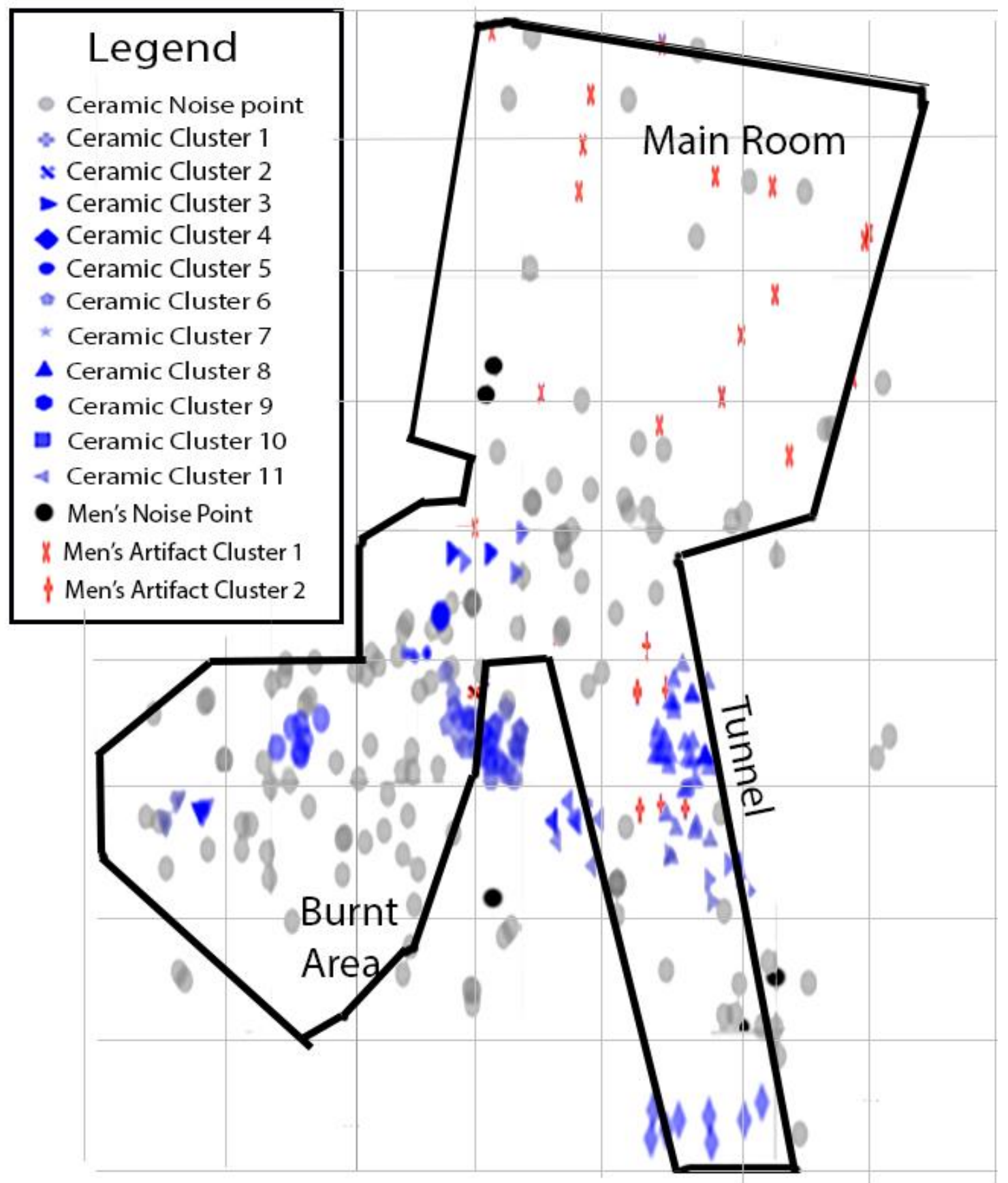

Figure 25. Cluster analysis of men's artifacts at Feature 21. 


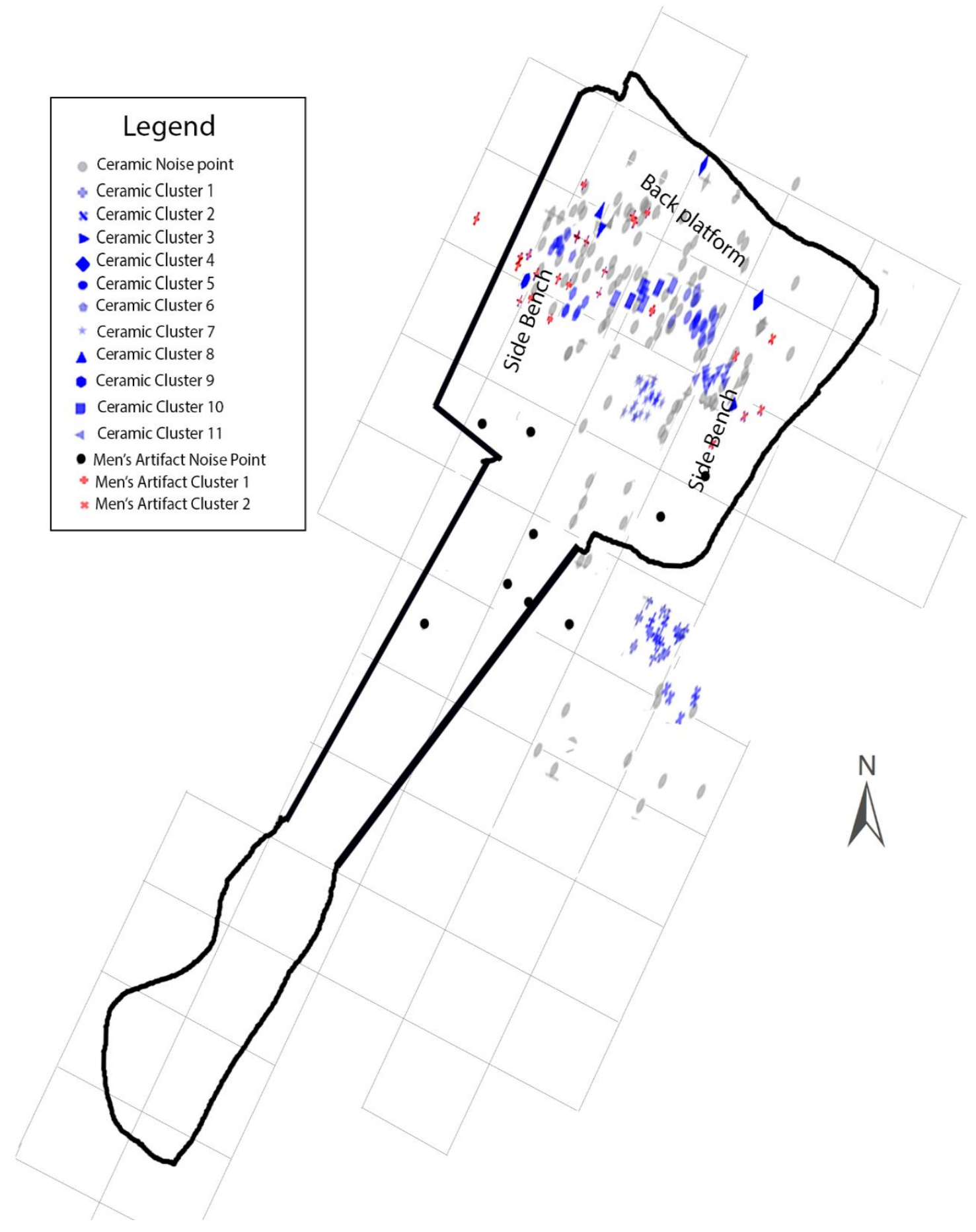

Figure 26. Cluster analysis of all men's artifacts at Feature 87. 
The gender-neutral artifacts showed the least amount of clustering, with clustering limited to two clusters in Feature 21 (Table 11, Figure 27). The other features did not cluster. Like the male artifacts, there were few gender-neutral artifacts present throughout the features.

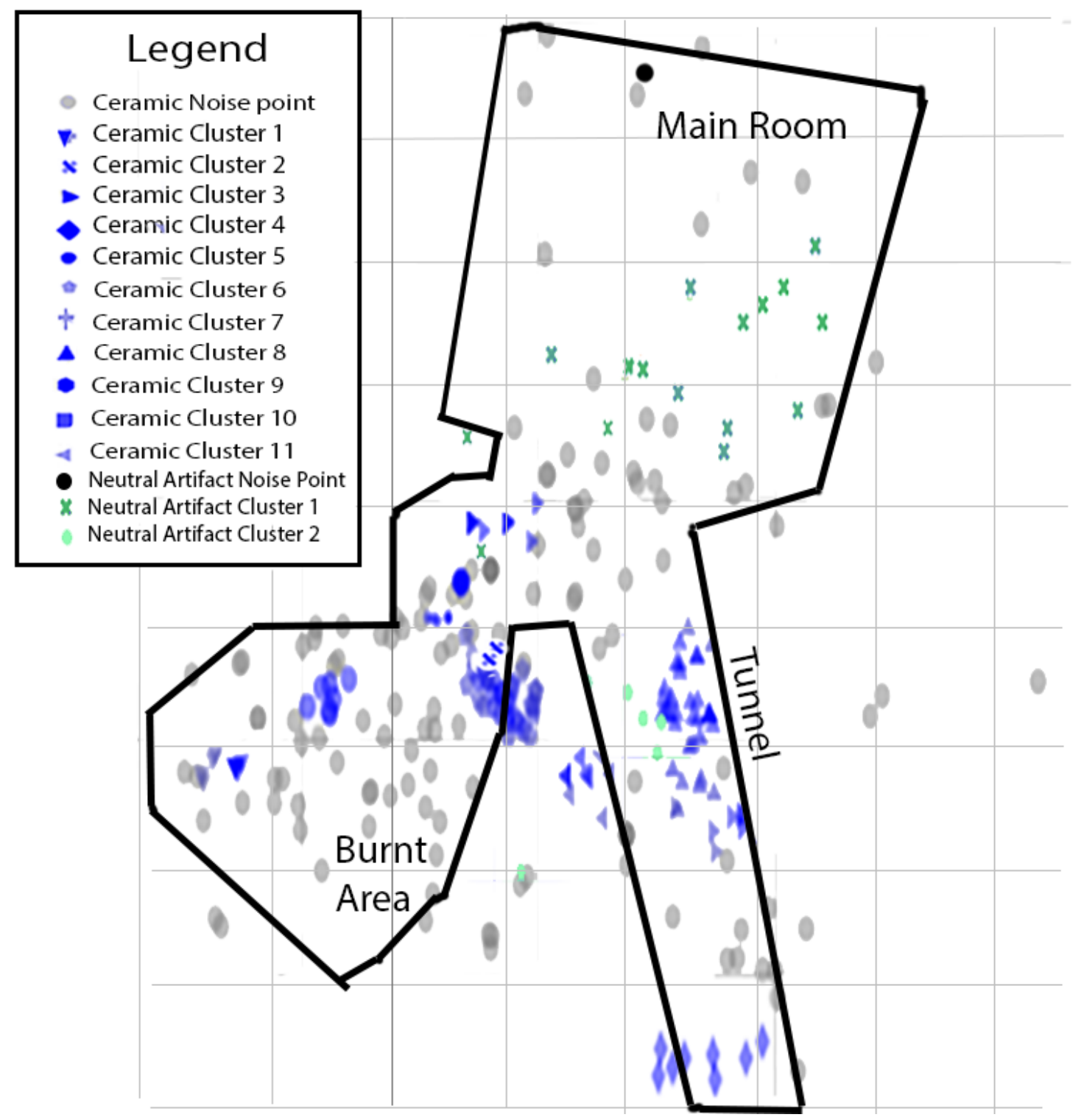

Figure 27. Cluster analysis of neutral artifacts at Feature 21. 


\section{Chapter 5: Discussion and Conclusion}

In this chapter, I will first evaluate my hypotheses and present the interpretation of my results with respect to my original hypotheses. Second, I will present the several confounding factors that may have impacted the interpretation of my results. Finally, I will discuss what I have learned through this spatial analysis and present ideas for future research.

\section{Evaluating Hypotheses}

Hypothesis 1 Results-Evidence of Ceramic Clustering

Hypothesis 1 tested the existence of ceramic clustering. The null hypothesis stated there was no clustering. The alternative stated that ceramics did cluster within the house features. All of the features demonstrated ceramic clustering. The strength of ceramic clusters is variable (Table 11). While features 21 and 87 (Figures 21 and 22) have excellent cluster persistence (1.0, the highest score for a cluster, for all ceramic sherds), Features 68A and 33 (Figures 19 and 20) have slight cluster persistence.

However, there does not appear to be a specific pattern to the clustering; only that it exists. There is no clustering around lamps or features like hearths or benches. I do not see stable clusters that seem to be centered around lamps or hearths. Features 68A and 33 have clusters predominately located within the tunnel. Based on our ethnographic data, it is extremely unlikely that tunnel clusters are the result of primary activity (i.e. ceramic use). The clustering of artifacts in the tunnel is most likely the result of either sweeping/cleaning activity or storage. The fragmentation information shows that the 
ceramics are not more affected by trampling in the tunnel (Figures 15-18). Feature 87 is the only feature where there is significant clustering within the main room of the house; all of this clustering occurs near the back platform.

Hypothesis 2 Results-Clustering of Ceramics with Other Women's Artifacts

I tested whether or not other women's artifacts clustered with ceramics. Ceramics are clustered with the other women's artifacts in most of the features where there is clustering present (Table 11). The women's artifacts have similar cluster persistence scores as the ceramics do in each feature (Figures 20 and 21, Table 11). Feature 33 is the exception to this. The women's artifacts are found in the house, not in the tunnel where the ceramics are found in Feature 33. Unlike the ceramic artifacts, which are robust data sets, the non-ceramic women's artifacts are small sample sizes (Table 7). Because of the low artifact numbers, these results should be treated cautiously.

\section{Men's Artifacts}

An alternative for Hypothesis 2 was that ceramics may cluster with men's artifacts (e.g. harpoon points, adzes, bola weights). The men's artifacts do not consistently cluster with either the ceramics or the other women's artifacts. While the women's artifacts consistently tended to cluster, the men's artifacts did so only rarely. The men's artifacts only clustered in Features 21 and 87 (Figures 24 and 25), and with low cluster persistence (Table 11). Their presence in the house was generally similar to women's artifacts, but the men's artifacts did not fall in specific areas, and nothing so certain as to determine a 
man's workspace or a woman's workspace. One possibility of the low number of male artifacts is that the men were working primarily in a qargi, and their artifacts would remain there. Based on the spatial analysis, I do not believe that any of the features I have analyzed are qargis. None of the features are overly large and they all contain ceramics, something that archaeological qargis rarely have (Larson 1995, Lutz 1972, Van Stone 1970).

Table 12. Summary of spatial analysis

\section{Feature 21 Feature 87 Feature 68A $\quad$ Feature 33}

\begin{tabular}{ccccc}
\hline Clustered ceramics & Yes & Yes & Yes & Yes \\
\hline $\begin{array}{c}\text { Clustered women's } \\
\text { artifacts with ceramics }\end{array}$ & Yes & Yes & Yes & No \\
\hline $\begin{array}{c}\text { Evidence of gendered use } \\
\text { of space }\end{array}$ & No & No & No & No \\
\hline Existence of activity areas & No & Yes & No & No \\
\hline $\begin{array}{c}\text { Primary/Secondary } \\
\text { deposition (sweeping or } \\
\text { cleaning) }\end{array}$ & Yes & No & Yes & Yes
\end{tabular}

\section{Interpretations of Results}

The ultimate goal of this project was to test intrasite ceramic spatial patterning within Northwest Alaskan archaeological sites and to evaluate the existence of a gender specific use of space in pre-contact Northwest Alaska. A secondary goal was to uncover discrete activity spaces. Based on these findings, I cannot say that I found any evidence that gender specific use of space existed among pre-contact Northwest Alaska coast people, nor did I find evidence of specific activity areas within the houses. I do not believe that the ceramic clusters necessarily designate separate activity spaces. It would be unlikely, 
for instance, that Feature 21 had 18 separate spaces for activities. In addition, while there was clustering, few of the clusters centered around areas I would expect primary activities to occur, like a hearth or a lamp.

The exception to the overall pattern is Feature 87, which had ceramics, as well as the other female artifacts and male artifacts, cluster around the back platform of the house; there is no gender segregation of clusters. The ceramic clusters and other female artifact clusters all have a cluster persistence score of 1.0, the strongest possible score. Does this mean the back platform was a shared work area? Possibly, although there are other cultural explanations for this, such as storage. In the ethnographic literature, benches were used for storage and for sleeping (Nelson 1899). This spatial pattern could reflect storage under and near the benches.

In addition to activity spaces, the clustering could be caused by cleaning patterns or storage patterns. The clusters present in my analysis could have been caused by any or all of these behaviors. Only Feature 87 showed possibly primary deposition of ceramics and other formed tools.

$68 \mathrm{~A}$ also showed some evidence of clusters associated with activity areas. There was one cluster centered around the outdoor activity area. This could be an activity area, or a production area, but the cluster is small and there is not enough evidence to say anything definitive about use of the outdoor area. This area could also be an example of secondary deposition of ceramics and other artifacts. 


\section{Data Limitations and Confounding Factors}

There are several reasons, apart from a gender-integrated model of behavior, for why I did not identify evidence of gender segregated use of space, or activity areas.

One data limiting factor is the issue of excavated volume. As discussed in chapter 3, the larger the excavated volume of the floor, the larger the sample size. Houses with higher excavated volumes generally had larger sample sizes. This problem is unavoidable in any analysis that relies on counts. Features 87 and 21 had the highest excavated volumes and sample sizes, and also the most amounts of clusters. This means that my analysis could have been biased toward features with a larger sample size, and therefore larger excavated volume. However, Feature 68A had a similar excavated volume to Features 87 and 21 and had a smaller sample size and a fewer number of clusters. Ultimately, more house features would have to be excavated to see if excavated volume of the floors really correlates to sample size, or if my three features are a larger indication of this trend.

The issue of volume leads to another confounding factor. The sample sizes of the nonceramic artifacts are small. This is a major constraint on doing a spatial analysis of the non-ceramic artifacts. While my cluster analysis for the ceramic sherds is robust, and the features have hundreds of samples, the non-ceramic artifacts have less than fifty samples each. It is possible that my method of classification was too conservative, especially for male-related artifacts. Because I did not have access to the actual artifacts, I had to rely 
on catalog information. Rather than possibly assigning artifacts to the wrong gender, I chose to exclude them all together.

A non-methodological reason why I did not see any gendered use of space is the practicality of using space. In chapter two, I described the spatial syntax, which views space as a social mechanism, and one of the primary ways in which society is constructed and reinforced (Ferguson 1996, Giddens 1984). However, ideas of space do not always link to the performative. As mentioned earlier, the house features excavated at Cape Espenberg are not very large. The main room of Feature 87 is only $3.5 \mathrm{~m}$ wide by $4 \mathrm{~m}$ long (Norman et al. 2017). From a purely functional perspective, two or more adults working in the main room, that also has a back platform and side benches, would likely overlap in their daily activities, even if there were socially constructed ideas about space (see Reinhardt 2002 for a similar discussion). While there is ethnographic evidence of similarly sized houses expressing gendered use of space (Burch 2006, Giffen 1930, Graburn and Strong 1973), it is also possible that gendered ideas of space may not be archaeologically expressed.

One very large confounding factor is primary versus secondary deposition of the artifacts. Secondary behaviors could have obscured the primary behaviors that I was initially interested in investigated (i.e. gendered use of space/activity areas). As previously mentioned, the features themselves proved highly variable with the location and strength of clusters. Two of the five features (Features 33 and 68A) showed strong evidence of cleaning, with over $50 \%$ of the ceramic pieces and other artifacts in the tunnel (Figure 16, Figure 17, Figure 19, Figure 20). In Feature 87 there are no floor-level 
ceramics in the tunnel, and in Feature 21, only $10 \%$ of the ceramics are located within the tunnel. This suggests no sweeping or cleaning.

One possible explanation for the lack of ceramic sherds on the main room floor is cleaning and recovery. Very large to medium sized sherds (which are more likely to be recovered by archaeologists) are usually swept away from the living and work space (Fontana 1998). Very small fragments are usually left behind and these are less likely to be recovered (Orton and Hughes 2013). However, this was not demonstrated in the Cape Espenberg features. It does appear that there is some cleaning happening in Features 33 and 68A, based on the relative percentage of ceramics in the tunnel. As mentioned in chapter 4, debris was regularly swept away from the main floor of the house. Broken tools, broken pots, and any other debris would be swept away from the floors and into the tunnel or around the house. Most of the ceramics (58\%) are smaller than $40 \mathrm{~mm}$. It is possible that larger ceramic pieces were swept out into the tunnel, where they were then trampled on, but data are inconclusive

In contrast to Features 33 and 68A, Features 21 and 87 had very few ceramics or other artifacts in the tunnel. There appears to be no sweeping of debris or artifacts into the tunnel. This is not necessarily an indication that there was no cleaning. It is possible that the tunnel itself was cleaned and emptied into a midden, which would happen periodically, especially in houses that were lived in for more than a few seasons (Burch 2006, Giddings 1952). This would explain the lack of floor level ceramics and artifacts in the tunnel of Feature 87. Because Features 21 and 87 had no evidence of artifacts being swept into the tunnel, I can assume one of two scenarios. First, the artifacts and ceramics 
left in the main rooms were either stored or used in that room. Second, the artifacts and ceramics were removed from the house or tunnel and placed into a midden, or another secondary deposition site. However, there are few medium and large sherds present within the data set. Most of the ceramics (58\%) are smaller than $40 \mathrm{~mm}$. It is possible that larger ceramic pieces were swept out into the tunnel, where they were then trampled on, but data are inconclusive. In Feature 87 alone, there were $8.77 \mathrm{~kg}$ of ceramic fragments less than $20 \mathrm{~mm}$ in any direction. The high fragmentation rate of the ceramics in Feature 87 is also present in other artifacts and debris. The fragmentation analysis done on the zooarchaeological remains of Feature 87 shows a high level of fragmentation in the kitchen, especially as compared to the rest of the house (Norman et. al 2017). This could indicate a high rate of trampling, or other secondary or post-depositional factors fragmenting the ceramics and the faunal material. Adding analysis on other fragmentable material like fauna or lithics can make our interpretations of spatial analysis much more robust, or reveal depositional patterns or activity spaces that were not as visible before adding this data.

\section{Conclusions}

Using ceramics as my proxy for women's activity, and comparing the clusters against ethnographically defined male or female artifacts, I have demonstrated that there is no clear evidence for gender-segregated use of space, at least at Cape Espenberg. Additionally, I did not find evidence of any specific activity areas. This does not mean that gender-segregated use of space or activity areas does not exist: I simply did not find 
evidence supporting it due at least in part to issues of sample size, house size, and the role of secondary and post deposition processes in shaping the ceramic assemblage and distribution.

Using a density-based clustering algorithm, I analyzed four features and found that while ceramics did cluster, they mostly clustered in the tunnel and/or had low cluster persistence. I also found that other women's artifacts, as well as men's artifacts, were not spatially segregated. Women's artifacts were slightly more likely to cluster than men's artifacts. Both sets of artifacts were usually in the same vicinity as the ceramics. Artifacts were not any more likely to be near the hearth than they were near whale bones or fired clay features. In Feature 87, it appears that my results are similar to Hennebury's (1999) spatial analysis of the Eastern Thule, despite the differences among people and our differing methodologies. However, Feature 87 could also be an anomaly, or the result of idiosyncratic behavior, and it is only one feature. I cannot put forth any interpretation of gendered use of space using data from one feature.

However, my analysis identified several other interesting patterns of behavior, especially regarding site formation processes. It also points to the criticality of a systematic and comprehensive ceramic collection strategy, a consideration of the problem of ceramic fragmentation, and the relationship between sample sizes and excavated volumes. Furthermore, my work illustrates the potential of Python for conducting archaeological spatial analysis. 


\section{Site Formation Processes and Need for Systematic Ceramic Collection}

One of these key site formation processes that emerged through the spatial analysis is the role of secondary and post-depositional processes in shaping the ceramic assemblage and the spatial distribution of the assemblage. Although my original intent was to only study the spatial analysis, and not site formation processes, the spatial analysis revealed quite a bit about trampling, secondary disposal, and post-depositional activity. Like the archaeological presentation of gender, post-depositional activities have not been studied in detail in Alaska. In Features 33 and 68A, there is strong evidence of house cleaning. Collecting artifacts at a higher spatial resolution can allow these patterns of house cleaning, or other cultural post-depositional activities, to emerge. The ceramic spatial research was only possible because of the collection protocol. Instead of only collecting large sherds, the recent excavations of Cape Espenberg collected all fragments larger than a 1/8th inch screen. This is important not only because it gives a more accurate interpretation of how many ceramics were at a site, but it also gives information for site formation processes. Furthermore, this study shows that very large sample sizes are needed to conduct spatial analysis; even with the large scale of the excavation at Espenberg, there were not enough ceramics collected to disregard potential sample size effects on the results of spatial analysis. Additionally, large scale excavation of houses in the Arctic is necessary to further address questions about spatial analysis. 


\section{Spatial Analysis: Methodological Contributions}

While the primary goal of this thesis was a gendered interpretation of spatial analysis, a secondary goal of this thesis was to use a relatively new methodology for spatial analysis (Sun 2012), and one that has rarely been used in archaeology. This project also shows the benefits of using HDBSCAN, as well as using Python in archaeological applications. While I could have probably achieved similar results using ArcGIS or R, Python is a valuable tool that should be used more by the broader archaeological community, especially for those interested in modeling.

Perhaps the most important aspect of using Python in spatial analysis is the reproducibility. Because it is automated by a script, any person could take my raw data, run my code, and produce the same results. While this is equally as easy to do in $\mathrm{R}$, it is much harder to create the same level of reproducible data in ArcGIS or MatLab. Python, using packages like Scikit Learn (which is part of the library that includes HDBSCAN) (Pedregosa et al. 2011) and Matplotlib (which created the density plots), is fast, free, relatively easy to learn, and is supported by a strong, dedicated community. Throughout the analysis process, any problems I encountered with coding were usually already answered in forums, or could be answered within a few days or even hours. The language and the associated packages are constantly being developed, updated, revamped, and retooled to fit user needs. Python has an incredible breadth of packages available for spatial analysis, or other types of data analysis. It is especially suited for very large data 
sets, like looking at zooarchaeology remains. This vibrancy and mutability makes it an ideal tool to tailor to specific modeling tests.

\section{Future Research}

To draw more solidified conclusions about the nature of pre-contact gendered use in space in Northwest Alaska, there, perhaps obviously, needs to be more samples and more data sets to analyze. The features at Cape Espenberg are simply not a large enough data set to say much about gendered use of space with any amount of confidence. There are only four analyzed features and the number of artifacts tested was small as well. HDBSCAN and other density mapping tools retain their accuracy to well past ten thousand samples, and in fact, they only become more accurate the more data are added. One way to make the tests more robust is to have a less conservative method of identifying gendered use of tools. Adding manufacturing debitage, or being able to ascertain the gender of more artifacts, would have added hundreds more samples to the HDBSCAN. Additional work can either support or reject our ethnographically based assumptions on gendered use of space among Thule and Birnirk culture-bearing people. This method should ideally be used on house features, with a wide variety of ages, in order to capture the nuances of space usage and activity areas over time. While HDBSCAN could be implemented to include areas of activities around the house, it would need to be a more sophisticated code than the one I implemented. HDBSCAN would not automatically respect the boundaries of a house: it could easily make a cluster out of artifacts that are partially in a house feature and partially outside. 
HDBSCAN could easily be used for other archaeological spatial analyses as well. Density maps of manufacturing debris, especially of stone or bone tools, would be useful in determining the existence and boundaries of activity spaces.

While I did not find evidence of gendered use of space, this study is still an important contribution to addressing questions of gender in the Arctic. It also adds more to the also scanty literature surrounding primary, secondary, and post-depositional activities that form sites. This study also introduces using both HDBSCAN and Python in archaeological contexts. Through these innovations, we can further our knowledge, not only of gender and site formation processes in the Northwest Alaska, but also of human behavior on the microscale in the Arctic. 


\section{References Cited}

Ackerman, Robert E

1982 The Neolithic-Bronze Age Cultures of Asia and the Norton Phase of Alaskan Prehistory. Arctic Anthropology 19(2): 11-38

Adovasio James, Olga Soffer and Jake Page

2007 The Invisible Sex: Uncovering the True Roles of Women in Prehistory. HarperCollins, New York.

Ager, Lynn Price

1980 The Economic Role of Women in Alaskan Eskimo Society. In A World of Women: Anthropological Studies of Women in the Societies of the World., edited by Erika Bourguignon, Praeger Publishers, New York. Pp. 305-318.

Albers, Patricia and Beatrice Medicine,

1993 The Hidden Half: Studies of Plains Indian Women. Washington D.C. University Press of America

Anderson, Shelby

2011 From Tundra to Forest: Ceramic Distribution and Social Interaction in Northwest Alaska. PhD dissertation, Department of Anthropology, University of Washington.

2016 A clay source provenance survey in Northwest Alaska: Late Holocene ceramic production in the Arctic. Journal of Field Archaeology 41(3): 1-17.

Anderson, Shelby L., Matthew T. Boulanger, and Michael D. Glascock

2011 A new perspective on Late Holocene social interaction in Northwest Alaska: results of a preliminary ceramic sourcing study. Journal of Archaeological Science 38(5): 943-955.

Anderson, Shelby and Adam K. Freeburg

2013 A High-Resolution Chronology for the Cape Krusenstern Site Complex, Northwest Alaska. Arctic Anthropology 50(1): 49-71.

Anderson, Shelby L., Matthew T. Boulanger, Michael D. Glascock, and R. Benjamin Perkins

2016 Geochemical investigation of late pre-contact ceramic production patterns in Northwest Alaska. Journal of Archaeological Science: Reports 6: 200-210.

Anderson, Shelby L., Shannon Tushingham, and Tammy Y. Buonasera 2017 Aquatic Adaptations and the Adoption of Arctic Pottery Technology: Results of Residue Analysis. American Antiquity 82(3): 452-479. 
Argote-Espino, Denisse, Jesus Sole, Pedro Lopez-Garcia, and Osvaldo Sterpone 2012 Obsidian Subsource Identification in the Sierra de Pachuca and Otumba Volcanic Regions, Central Mexico, by ICP-MS and DBSCAN Statistical Analysis. Geoarchaeology 27(1): 48-62.

Allison, Penelope M.

1999Introduction. In The Archaeology of Household Activities. Edited by Penelope M. Allison. Routledge, London.

Ardener, Shirley

1981Ground Rules and Social Maps for Women: An Introduction. In Women and Space., edited by Shirely Ardener. Oxford University Press, Oxford pp. 11-32.

Arnold, Charles and Carole Stimmell

1983 An Analysis of Thule Pottery. Canadian Journal of Archaeology. 7(1): 1-21

Barker, James H.

1993 Always Getting Ready Upeterrlainarluta: Yup'ik Eskimo Subsistence in Southwest Alaska. University of Washington Press, Seattle.

Baxter, M.J.

2009 Archaeological Data Analysis and Fuzzy Clustering. Archaeometry 56(6): 10351054.

Beck, Margaret

2006 Midden Ceramic Assemblage Formation: A Case Study from Kalinga, Philippines. American Antiquity 71(1): 27-51

Benedict, J.

1970 Downslope soil movement in a Colorado alpine region: Rates, processes, and climatic significance. Arctic and Alpine Research 2: 165-226.

Betz, Virginia

2009 Sampling, Sample Size, and Artifact Assemblage Size and Richness in Oregon Coast Archaeological Sites. In Prehistory of the Oregon Coast: The Effects of Excavation Strategies and Assemblage Size on Archaeological Inquiry. Edited by R. Lee Lyman. Left Coast Press, Walnut Creek, CA. pp. 60-63.

Billson, Janet Mancini and Kyra Mancini

2007 Inuit Women: Their Powerful Spirit in a Century of Change. Rowman \& Littlefield Publishers, Inc. Plymouth, UK. 
Binford, Lewis

1967 Smudge Pits and Hide Smoking: The Use of Analogy in Archaeological Reasoning. American Antiquity 32(1): 1-12.

1972 Archaeological reasoning and smudge pits — revisited. In An Archeological Perspective, Seminar Press, New York pp. 52-58.

1978 Nunamiut Ethnoarchaeology. Academic Press, New York.

Birket-Smith, Kaj

1929 The Caribou Eskimos-Report on the Fifth Thule Expedition 19211924. Gyldendalske, Copenhagen

Bockstoce, John

1979 The Archaeology of Cape Nome, Alaska. University Museum Monograph No. 38. University of Pennsylvania Press, Philadelphia.

Boismier, William A.

1991 Site formation among sub-arctic peoples: an ethnohistorical approach." Ethnoarchaeological Approaches to Mobile Campsites: HunterGatherer and Pastoralist Case Studies, edited by Clive Gamble and William A. Boismer, pp. 189-214 International Monographs in Prehistory, Ann Arbor, MI.

Bolger, Diane

2013a Gender, Labor, and Pottery Production in Prehistory. In Companions to Anthropology: Companion to Gender Prehistory., edited by Diane Bolger. Wiley-Blackwell, Somerset, NJ.

2013b Companions to Anthropology: Companion to Gender Prehistory. Ed. Diane Bolger. Wiley-Blackwell, Somerset, NJ.

Briggs, Jean L.

1974 Eskimo Women: Makers of Men. In Many Sisters: Women in Cross-Cultural Perspective, edited by Carolyn J. Matthiasson. The Free Press, New York pp. 261-304.

Bronstein Mikhail and Kyrill Dneprovsky

2002 The Northeastern Chukchi Peninsula during the Birnirk and Early Punuk Periods. In Archaeology in the Bering Strait Region: Research on Two Continents, edited by D Dumond and R Bland, University of Oregon Anthropological Papers, 59, Eugene. pp 153-165. 
Brown, J. A.

1989 The Beginnings of Pottery as an Economic Process. In What's New? A Closer Look at the Process of Innovation, edited by S. E. van der Leeuw and R. Torrence, pp. 203-224. Unwin Hyman, London.

Brumfiel Elizabeth

2006 Methods in Feminist and Gender Archaeology: A Feeling for Difference-and Likeness. In Handbook for Gender Archaeology, edited by Sarah Nelson. AltaMira Press, Lanham, MD, pp 31-58.

Burch, Ernest S.

2006 Social Life in Northwest Alaska: The Structure of Iñupiaq Eskimo Nations. University of Alaska Press, Fairbanks.

Butler, Judith

1993 Bodies That Matter: On the Discursive Limits of "Sex", Routledge, New York.

Cannon, Michael

2013 NISP, Bone Fragmentation and the Measurement of Taxonomic Abundance. Journal of Archaeological Method and Theory 20(3): 397-419.

Carr, Christopher

1984 The Nature and Organization of Intrasite Archaeological Records and Spatial Analytic Approaches to their Investigation. In Advances in Archaeological Method and Theory., edited by Michael B. Shiffer. Academic Press, New York pp. 103-222.

Clark, Graham

1954 Excavations at Starr Carr. Cambridge University Press, Cambridge.

Colaninno, Carol, Carla Hadden, and Alexandra Emmons

2015 Testing archaeofaunal collections for differential fragmentation. Journal of Archaeological Science 61(3): 17-24.

Collins, Henry B.

1937 Archeological Excavations at Bering Strait. In Explorations and Field- Work of the Smithsonian Institution in 1931, pp. 63-68. Smithsonian Institution Press, Washington, DC.

1964 The Arctic and Subarctic. In Prehistoric Man in the New World, edited by J.D. Jennings and E. Norbeck, pp. 84-114. University of Chicago Press, Chicago. 
Conkey, Margaret W., and Joan M. Gero

1991 Tensions, Pluralities and Engendering Archaeology: An Introduction to Women and Prehistory. In Engendering archaeology edited by Joan Gero and Margaret Conkey, Oxford and Cambridge, MA pp. 3-30

1997Programme to Practice: Gender and Feminism in Archaeology. Annual Review of Anthropology 26(1): 411-437.

Cooper, H. Kory, Owen Mason, Victor Mair, John Hoffecker and Robert Speakman

2016 Evidence of Eurasian metal alloys on the Alaskan coast in prehistory. Journal of Archaeological Science 74: 176-183.

Currie, Adrian

2016 Ethnographic analogy, the comparative method, and archaeological special pleading. Studies in History and Philosophy of Science 55: 84-94

Damas, David

1972 Central Eskimo systems of food sharing. Ethnology 11(3): 220-240.

Darwent, John, Owen K. Mason, John F. Hoffecker, and Christyann M. Darwent 20131,000 Years of House Change at Cape Espenberg, Alaska: A Case Study in Horizontal Stratigraphy. American Antiquity 78(3): 433-455.

Darwent, Christyann M. and John Darwent

2016 The Enigmatic Choris and Old Whaling "Cultures" of the Western Arctic. In Handbook of Arctic Archaeology, edited by Owen K. Mason and T. Max Friesen, pp.371-394. Oxford University Press, Oxford.

Dawson, Peter C.

1995 "Unsympathetic Users": An Ethnoarchaeological Examination of Inuit Responses to the Changing Nature of the Built Environment. Arctic 48:71-80.

Dawson, Peter, Richard Levy, Don Gardner and Matthew Walls

2007 Simulating the behaviour of light inside Arctic dwellings: implications for assessing the role of vision in task performance. World Archeology 39(1): 1735. 
Dumond, Don E.

1982 Trends and traditions in Alaskan prehistory: the place of Norton culture. Arctic Anthropology 19(2): 39-51.

1987 A Reexamination of Eskimo-Aleut Prehistory. American Anthropologist 89(1):32-56.

2000 The Norton Tradition. Arctic Anthropology 37(2): 1-22.

Enloe, James G., Francine David, and Timothy S. Hare

1994 Patterns of Faunal Processing at Section 27 of Pincevent: The Use of Spatial Analysis and Ethnoarchaeological Data in the Interpretation of Archaeological Site Structure. Journal of Anthropological Archaeology 13: 105-124.

Esdale, Julie A., Raymond J. Le Blanc, and Jacques Cinq-Mars

2001 Periglacial Geoarchaeology at the Dog Creek Site, Northern Yukon. Geoarchaeology - An International Journal 16(2): 151-176.

Ester, Martin, Hans P Kriegel, Jorg Sander, and Xiaowei Xu

1996 A Density-Based Algorithm for Discovering Clusters in Large Spatial Databases with Noise. Proceedings of the 2nd International Conference on Knowledge Discovery and Data Mining: 226-231.

Estioko-Griffin, Agnes, and P. Bion Griffin

1981 Woman the Hunter: The Agta. In Woman the Gatherer. Frances Dahlberg, ed. Pp. 121-151. New Haven, CT: Yale University Press.

Fausto-Sterling, Anne

2000 Sexing the Body: Gender Politics and the Construction of Sexuality Basic Books, New York.

Ferguson, TJ

1996 Historic Zuni Architecture and Society: An Archaeological Application of Space Syntax. Anthropological Papers of the University of Arizona, no. 60. University of Arizon Press, Tuscon.

Fienup-Riordan, Ann

1983 The Nelson Island Eskimo: Social Structure and Ritual Distribution. Alaska Pacific University Press, Anchorage.

Friedl, Ernestine

1975 Women and Men: An Anthropological View. Holt, Reinhart, and Winston, New York. 
Frink, Lisa, Rita S. Shepard and Gregory A. Reinhardt

2002 Many Faces: An Introduction to Gender Research in Indigenous Northern North America. In Many Faces of Gender: Roles and Relationships through Time in Indigenous Northern Communities. Edited by Lisa Frink, Rita Shepard and Gregory Reinhardt University of Colorado, Boulder pp. 1-12.

Frink, Lisa, and Karen G Harry

2008 The Beauty of "Ugly" Eskimo Cooking Pots. American Antiquity 73(1): 103120.

Fontana, Valentina

1998 Procedures to Analyse Intra-Site Pottery Distribution, Applied to the Neolithic Site of Fimon, Molino Casarotto (Italy), Housesite No. 3. Journal of Archaeological Science(3): 1067-1072.

Fortescue, Michael

1988 Eskimo Orientation Systems, Meddelelser om Grønland, Man and Society 11, Copenhagen.

Fowler, Kent D.

2011 Ceramic discard and the use of space at Early Iron Age Ndondondwane, South Africa. Journal of Field Archaeology 36(2): 151-166.

Galanidou, Nena

2000 Patterns in caves: foragers, horticulturalists and the use of space. Journal of Anthropological Archaeology 19: 243-275.

Giddens, Anthony

1984 The Constitution of Society: Outline of the Theory of Structuration. Polity Press, Cambridge.

Giddings, J. Louis

1952 The Arctic woodland culture of the Kobuk River. University Museum Monograph. University of Pennsylvania, Philadelphia.

1961 Kobuk River People. Studies of Northern Peoples 1.

1964 The Archaeology of Cape Denbigh. Brown University Press, Providence.

Giddings, J. Louis and Douglas D. Anderson

1986 Beach Ridge Archaeology of Cape Krusenstern. Publications in Archaeology No. 20, National Park Service, Anchorage. 
Giffen, Naomi

1930 The Roles of Men and Women in Eskimo Culture. Amis Press. New York.

Gifford-Gonzalez, Diane

1993 Gaps in Zooarchaeological Analyses of Butchery: Is Gender an Issue?” In From Bones to Behavior, edited by Jim Hudson, pp. 181-199. Southern Illinois University Press, Carbondale IL.

Goebel, Ted, Heather L. Smith, Lyndsay DiPietro, Michael R.Waters, Bryan Hockett, Kelly E. Graf, Robert Gal, Sergei B. Slobodin, Robert J. Speakman, Steven G. Driese, and David Rhode

2013 Serpentine Hot Springs, Alaska: Results of Excavations and Implications for the Age and Significance of Northern Fluted Points. Journal of Archaeological Science 40(12): 4222-4233.

Gould, Richard and Patty Jo Watson

1982 A Dialogue on the Meaning and Use of Analogy in Ethnoarchaeological Reasoning. Journal of Anthropological Archaeology 1: 355-381.

Graburn, Nelson H. and B. Stephen Strong

1973 Circumpolar Peoples: An Anthropological Perspective. Goodyear Publishing Company. Pacific Palisades, California.

Gregg, Susan A., Keith W. Kintigh, and Robert Whallon

1991 Linking Ethnoarchaeological Interpretation and Archaeological Data: The Sensitivity of Spatial Analytical Methods to Postdepositional Disturbance. In The Interpretation of Archaeological Spatial Patterning, edited by Ellen M. Kroll and T. Douglas Price, pp. 148-198. Plenum Press, New York.

Hall, Edwin S.

1988 Post-Depositional Factors Affecting the Formation of the Utqiagvik Site. In The 1981 Excavations at the Utqiagvik Archaeological Site, Barrow, Alaska, edited by Edwin. S. Hall, Jr. and L. Fullerton, pp. 401-407. North Slope Borough Commission on Iñupiat History, Language and Culture, Barrow.

Hall, Edwin S and Lynne Fullerton

1990 The Utqiagvik Excavations: Volume 3. Excavation of a Prehistoric Catastrophe: A Preserved Household from the Utqiagvik Village, Barrow, Alaska. The North Slope Borough Commission on Iñupiat History, Language and Culture, Barrow

Hanson, Julienne

1998 Decoding Houses and Homes. Cambridge University Press, Cambridge. 
Harritt, Roger

1994 Eskimo Prehistory on the Seward Peninsula, Alaska. National Park Service, Anchorage.

2013 Toward an Archaeology of Late Prehistoric Eskimo bands in Coastal Northwest Alaska. Journal of Anthropological Archaeology. 32(4): 659-674

Harry, Karen, and Liam Frink

2009 The Arctic Cooking Pot: Why Was It Adopted? American Anthropologist 111(3): 330-343.

Harry, Karen G, Lisa Frink, Brendan O'Toole, and Andreas Charest

2009 How to Make an Unfired Clay Cooking Pot: Understanding the Technological Choices Made by Arctic Potters. Journal of Archaeological Method and Theory 16(1): 33-50.

Hawkes, Kristen, James F. O'Connell, and Nicholas G. Blurton Jones

1997 Hadza Women's Time Allocation, Offspring Provisioning, and the Evolution of Long Postmenopausal Life Spans. Current Anthropology 38(4):551-577.

Hennebury, Christine C.

1999 Gender and Spatial Analysis: An Eastern Thule Example. Master's Thesis, Department of Anthropology, University of Manitoba.

Hietla, Harold J.

1984 Intrasite Spatial Analysis: A Brief Overview. In Intrasite spatial analysis in archaeology. Edited by Harold Hietala, pp. 1-4. Cambridge University Press.

Hill, Erica

1998 Gender-informed archaeology: the priority of definition, the use of analogy, and the multivariate approach. Journal of Archaeological Method and Theory 5:99-128.

Hillier, Bill

1996 Space is the Machine. Cambridge University Press, Cambridge.

Hillier, Bill and Julienne Hanson

1984 The Social Logic of Space. Cambridge University Press, Cambridge.

Hilton, Michael R.

2003 Quantifying Postdepositional Redistribution of the Archaeological Record Produced by Freeze-Thaw and Other Mechanisms: An Experimental Approach. Journal of Archaeological Method and Theory 10(3): 165-202. 
Hodder, Ian.

1982 Symbols in action: Ethnoarchaeological studies of material culture. Cambridge University Press, New York.

Hodder, Ian and Clive Orton

1976 Spatial Analysis in Archaeology. Cambridge University Press, New York

Hodson, F. R.

1970 Cluster analysis and archaeology: Some new developments and applications. World Archaeology 1(3): 299-320.

Hoffecker, John and Scott Elias

2007 Human Ecology of Berengia. Columbia University Press, New York.

Hoffecker, John and Owen Mason

2010 Human Response to Climate Change at Cape Espenberg: AD 800-1400: Field Investigations at Cape Espenberg 2010. Preliminary Report. Institute of Arctic and Alpine Research, University of Colorado, Boulder.

2011 Human Response to Climate Change at Cape Espenberg: AD 800-1400: Field Investigations at Cape Espenberg 2011. Annual Report. Institute of Arctic and Alpine Research, University of Colorado, Boulder.

Hoffman, Brian. W.

2002 Broken Eyes and Simple Grooves: Understanding Eastern Aleut Needle Technology through Experimental Manufacture and Use of Bone Needles. In Many Faces of Gender: Roles and Relationships through Time in Indigenous Northern Communities. Edited by Lisa Frink, Rita Shepard and Gregory Reinhardt, pp. 151-164. University of Colorado Press, Boulder.

Hoopes, J. W. and W. K. Barnett

1995 The Shape of Early Pottery Studies. In The Emergence of Pottery: Technology and Innovation in Ancient Societies, edited by W. K. Barnett and J. W. Hoopes, pp. 1- 7. Smithsonian Institution Press, Washington.

Hutson, Scott R, Travis W Stanton, Aline Magnoni, Richard Terry, and Jason Craner 2007 Beyond the Buildings: Formation Processes of Ancient Maya Houselots and Methods for the Study of Non-Architectural Space. Journal of Anthropological Archaeology 26:442-473.

Irving, William

19621961 field work in the western Brooks Range, Alaska: Preliminary report. Arctic Anthropology 1:76-83. 
Jarvenpa, Robert, and Hetty Jo Brumbach

2006 Circumpolar lives and livelihood: a comparative ethnoarchaeology of gender and subsistence. University of Nebraska Press, Lincoln

2008 Revisiting the Sexual Division of Labor: Thoughts on Ethnoarchaeology and Gender. Archeological Papers of the American Anthropological Association 16(1): 97-107.

Jenness, Diamond

1922 The Life of the Copper Eskimos. Report of the Canadian Arctic Expedition, 1913-1918.

Jensen, Anne M.

2009 Nuvuk, Point Barrow, Alaska: The Thule Cemetery and Ipiutak Occupation. PhD dissertation, Department of Anthropology, Bryn Mawr College. University of Michigan, Ann Arbor.

Johnson, Matthew

2010 Archaeological Theory: An Introduction. 2nd Edition. Wiley-Blackwell Press, Oxford.

Jones, Anore

2010 Plants that We Eat: Nauriat Nigiñaqtuat, From the traditional wisdom of the Iñuiat Elders of Northwest Alaska. $2^{\text {nd }}$ Edition. University of Alaska Press, Fairbanks.

Jones, B. M., K. M. Hinkel, C. D. Arp, and W. R. Eisner

2008 Modern erosion rates and loss of coastal features and sites, Beaufort Sea coast, Alaska, Arctic 61: 361-372.

Jones, B.M. C. D. Arp, M. T. Jorgenson, K. M. Hinkel, J. A. Schmutz and P. L. Flint 2009 Increase in the rate and uniformity of coastline erosion in Arctic Alaska. Geophysical Research Letters, 36(3).

Jordan, Peter and Marek Zvelebil

2009 Ex Oriente Lux: The Prehistory of Hunter-Gatherer Ceramic Dispersals. In Ceramics before Farming: The Dispersal of Pottery among Prehistoric Eurasian Hunter-Gatherers, edited by Peter Jordan and Marek Zvelebil, pp: 3389, Left Coast Press, Walnut Creek, CA. 
Kehoe, Alice

1995 Blackfoot Persons. In Women and Power in Native North America. Laura F. Klein and Lillian A. Ackerman, eds. Pp. 113-125. Norman: University of Oklahoma Press

2005 Expedient Angled-Tang Endscrapers: Glimpsing Women's Work in the Archaeological Record. In Gender and Hide Production, edited by Lisa Frink and Kathryn Weedman, pp. 133-142. AltaMira Press. Walnut Creek, CA.

Kent, Susan

1990 Activity Areas and Architecture: An Interdisciplinary View of the Relationship Between Use of Space and Domestic Built Environments.

In Domestic Architecture and the Use of Space: An Interdisciplinary CrossCultural Study, edited by Susan Kent, pp: 1-8. Cambridge University Press, New York.

1995 Does Sedentarization Promote Gender Inequality? A Case Study from the Kalahari. The Journal of the Royal Anthropological Institute 1(3): 513-536.

Kinder, Jesse and Philip Nelson

2015 A Student's Guide to Python for Physical Modeling. Princeton University Press, Princeton, NJ.

Kintigh, Keith W, and Albert J Ammerman

1982 Heuristic Approaches to Spatial Analysis in Archaeology. American Archaeology 47(1): 31-63.

Kumar, Mahesh K., and A. Rama Mohan Reddy

2016 A fast DBSCAN clustering algorithm by accelerating neighbor searching using Groups method. Pattern Recognition 58: 39-48.

Koetje, Todd

1992 The simulation and recovery of archaeologically meaningful levels. In Archaeology and the Information Age: A Global Perspective, edited by Paul Reilly and Sebastian Rahtz, pp. 177-187. Routledge, London.

Kroll, Ellen and T. Douglas Price

1991 Introduction. In The Interpretation of Archaeological Spatial Patterning, edited by Ellen M. Kroll and T. Douglas Price, pp.1-7. Plenum Press, New York.

LaMotta Vincent M. and Michael B. Schiffer

1999 Formation Processes of House Floor Assemblages. In The Archaeology of Household Activities. Edited by Penelope M. Allison Routledge, London. 
Lang, Sabine

1998 Men as Women, Women as Men: Changing Genders in Native American Cultures. University of Texas Press, Austin.

Lane, Paul

2005 Barbarous Tribes and Unrewarding Gyration? The Changing Role of Ethnographic Imagination in African Archaeology. In African Archaeology: A Critical Introduction. Edited by Ann Stahl, pp. 24-54. Blackwell, Oxford.

Larsen, Helge

2001 Deering: A Men's House from Seward Peninsula, Alaska. National Museum Department of Ethnography: SILA - Greenland Research Centre, Copenhagen.

Larsen, Helge, and Froelich Rainey

1948 Ipiutak and the Arctic Whale Hunting Culture. Anthropological Papers of the American Museum of Natural History, New York.

Larson, Mary Ann

1991 Determining the function of a "men's house". In The Archaeology of Gender, proceedings of the Twenty-second Annual Conference of the Archaeological Association of the University of Calgary, edited by Dale Wade and Noreen Willows, pp. 165-175, University of Calgary Press, Calgary.

1995 And then there were none: the 'disappearance' of the Qargi in Northern Alaska. In Hunting the largest animals: Native whaling in the western Arctic and Subarctic, edited by Allen McCartney, pp. 33-50, Canadian Circumpolar Institute, University of Alberta.

2004 The Evolution of the Qalgi in Post-epidemic Point Hope, Alaska. Ph.D dissertation, Department of Anthropology, Brown University.

Lee, Molly and Gregory A. Reinhardt

2003 Eskimo Architecture: Dwelling and Structure in the Early Historic Period. University of Alaska Press, Fairbanks.

Lemoine, Genevieve

2003 Woman of the House: Gender, Architecture and Ideology in Dorset Prehistory. Arctic Anthropology 40(1): 121-138.

Li Lingjuan and Yang Xi

2011 Research on Clustering Algorithm and Its Parallelization Strategy. 2011 International Conference on Computational and Information Sciences, pp. 325328. Chengdu, China. 
Lutz, Bruce

1973 An Archaeological Karigi at the Site of UngaLaqLiq, Western Alaska. Arctic Anthropology 10(1): 111-118.

Lyman, R. Lee and Michael O'Brien

1987 Plow-zone Zooarchaeology: Fragmentation and Identifiability Journal of Field Archaeology 14(4): 493-498.

Lyons, Diane E.

1992 Men's Houses, Women's Spaces: An Ethnoarchaeological Study of Gender and Household Design in Dela, North Cameroon. Ph.D Dissertation, Department of Anthropology, Simon Fraser University.

Markus, Thomas

1993 Buildings and Power: Freedom and Control in the Origin of Modern Building Types. Routledge, London.

Marom, Nimrod

2016 Fragmentation in zooarchaeological assemblages: The role of equifinal, random process. Journal of Archaeological Science: Reports 8: 11-14.

Mason, Otis

1890 The Ulo or Women's Knife of the Eskimo. Annual Report of Board of Regents of Smithsonian Institution for year ending June 30, 1890.

Mason, Owen

1998 The Contest between the Ipiutak, Old Bering Sea, and Birnirk Polities and the Origin of Whaling During the First Millennium A.D. Along Bering Strait. Journal of Anthropological Archaeology 17(3):240-325.

2009 "The Multiplication of Forms;" Bering Strait Harpoon Heads as a Demic and Macroevolutionary Proxy. In Macroevolution in Human Prehistory: Evolutionary Theory and Processual Archaeology, edited by Anna Prentiss, Ian Kuijt and James Chatters, pp. 73-107. Springer, New York.

Mason, Owen and S. Craig Gerlach

1995 The Archaeological Imagination, Zooarchaeological Data, the Origins of Whaling in the Western Arctic, and "Old Whaling" and Choris Cultures. In Hunting the Largest Animals, edited by A. P. McCartney, pp. 1-31. Studies in Whaling No. 3, Occasional Publication No. 36. The Canadian Circumpolar Institute, Calgary. 
Mason, Owen K, David M Hopkins, and Lawrence Plug

1997 Chronology and Paleoclimate of Storm-Induced Erosion and Episodic Growth across Cape Espenberg Spit, Alaska, USA. Journal of Coastal Research 13(3): 770-797.

Mellars, Paul

1996 The Neanderthal Legacy: An Archaeological Perspective from Western Europe. Princeton University Press, Princeton, NJ.

Moss, Madonna

1993 Shellfish, Gender, and Status on the Northwest Coast: Reconciling Archeological, Ethnographic, and Ethnohistorical Records of the Tlingit. American Anthropologist 95(3): 631-652

Murray, Stephen

1994 On Subordinating Native American Cosmologies to the Empire of Gender. Current Anthropology 35(1): 59-61.

Nelson, Edward

1899 The Eskimo About Bering Strait. Smithsonian Institution Press, Washington, DC.

Norman, Lauren

2015 Ethnography, Analogy, and Arctic Archaeofaunas: Assessing the Limits of Zooarchaeological Interpretation. PhD dissertation, Department of Anthropology, University of Toronto, Toronto, ON.

Norman, Lauren, T. Max Friesen, Claire Alix, Michael J. E. O'Rourke, and Owen K. Mason

2017 An Early Inupiaq Occupation: Observations on a Thule House From Cape Espenberg, Alaska. Open Archaeology, 3(1): 17-48.

Nuttall, Mark

1992 Arctic Homeland: Kinship, Community and Development in Northwest Greenland. University of Toronto Press, Toronto.

Ortner, Sherry B.

1974 Is Female to Male as Nature Is to Culture? In Woman, Culture, and Society, edited by M.Z. Rosaldo and L. Lamphere, pp. 68-87. Stanford, CA: Stanford University Press, Stanford, CA.

Orton, Clive, and Mike Hughes.

2013 Pottery in archaeology. $2^{\text {nd }}$ edition Cambridge University Press, Cambridge. 
Papageorgiou, Ioulia, MJ Baxter, and Ma Cau

2001 Model based Cluster Analysis of Artefact Compositional

Data. Archaeometry 43(4): 571-588.

Park, Robert W.

2010 Frozen coasts and the development of Inuit culture in the North American Arctic. In Landscapes and Societies - Selected Cases, edited by I. P. Martini and W. Chesworth, pp. 407-421. Springer, Dordrecht, Netherlands.

Pettit, Paul B.

1997 High resolution Neanderthals? Interpreting Middle Palaeolithic intrasite spatial data. World Archaeology 29(2): 208-224

Pierce, Christopher

1999 Explaining corrugated pottery in the American Southwest: an evolutionary approach. Ph.D dissertation, Department of Anthropology, University of Washington.

Pinder, David, Izumi Shimada, and David Gregory

1979 The Nearest-Neighbor Statistic: Archaeological Application and New Developments. American Antiquity 44(3): 430-445.

Ponkratova, I.

2006 Pottery industries in the North of the Russian Far East. In Archaeology in Northeast Asia: on the pathway to Bering Strait, edited by D Dumond and R. Bland. Museum of Natural and Cultural History and Department of Anthropology, University of Oregon, Eugene, pp. 129-158.

Powers, W. Roger and Richard H. Jordan

1990 Human Biogeography and Climate Change in Siberia and Arctic North America in the Fourth and Fifth Millennia BP. Philosophical Transactions of the Royal Society of London. Series A. Mathematical and Physical Sciences 330(1615):665-670. 
Raghavan, Maanasa, Michael DeGiorgio, Anders Albrechtsen, Ida Moltke, Pontus

Skoglund, Thorfinn S. Korneliussen, Bjarne Grønnow, Martin Appelt, Hans

Christian Gulløv, T. Max Friesen, William Fitzhugh, Helena Malmström, Simon

Rasmussen, Jesper Olsen, Linea Melchior, Benjamin T. Fuller, Simon M. Fahrni, Thomas

Stafford, Vaughan Grimes, M. A. Priscilla Renouf, Jerome Cybulski, Niels Lynnerup,

Marta Mirazon Lahr, Kate Britton, Rick Knecht, Jette Arneborg, Mait Metspalu, Omar E. Cornejo, Anna-Sapfo Malaspinas, Yong Wang, Morten Rasmussen, Vibha Raghavan, Thomas V. O. Hansen, Elza Khusnutdinova, Tracey Pierre, Kirill Dneprovsky, Claus Andreasen, Hans Lange, M. Geoffrey Hayes, Joan Coltrain, Victor A. Spitsyn, Anders Götherström, Ludovic Orlando, Toomas Kivisild, Richard Villems, Michael H. Crawford, Finn C. Nielsen, Jørgen Dissing, Jan Heinemeier, Morten Meldgaard, Carlos Bustamante, Dennis H. O’Rourke, Mattias Jakobsson, M. Thomas P. Gilbert, Rasmus Nielsen, and Eske Willerslev

2014 The Genetic Prehistory of the New World Arctic. Science 345(6200): DOI: $10.1126 /$ science. 1255832 .

Rasmussen, Knud

1921 Greenland by the Polar Sea- the story of the Thule Expedition from Melville Bay to Cape Morris Jesup. William Heinemann, London.

Ray, Dorothy J.

1964 Nineteenth Century Settlement and Subsistence Patterns in Bering Strait. Arctic Anthropology 2(2):61 -94.

1975 The Eskimos of Bering Strait, 1650-1898. University of Washington Press, Seattle.

1983 Ethnohistory in the Arctic: the Bering Strait Eskimo. Limestone Press, Kingston, Ontario.

Reinhardt, Gregory

2002 Puzzling Out Gender-Specific "Sides" to a Prehistoric House in Barrow, Alaska. In Many Faces of Gender: Roles and Relationships through Time in Indigenous Northern Communities. Edited by Lisa Frink, Rita Shepard and Gregory Reinhardt, pp. 121-150. University of Colorado Press, Boulder.

Reynolds, Georgeanne Lewis

1995 Cultural and Environmental Formation Processes: Distortion of the Archaeological Record in Northern Alaska. Arctic Anthropology 32(1): 138146.

Roscoe, William

1991 The Zuni Man-Woman. University of New Mexico Press, Albuquerque. 
Rosenwig, Robert

2009 Early Mesoamerican garbage: Ceramic and daub discard patterns from Cuauhtémoc, Soconusco, Mexico. Journal of Archaeological Method and Theory 16(1): 1-32.

Schaaf, Jeanne

1988 The Bering Land Bridge National Preserve: an Archaeological Survey, Volumes I and II. National Park Service Resource/Research Management Report AR-14. US Department of the Interior, Washington D.C.

Schiffer, Michael

1987 Formation Processes of the Archaeological Record. University of New Mexico Press, Albuquerque.

Schweger, C.

1985 Geoarchaeology of Northern Regions: Lessons from Cryoturbation at Onion Portage, Alaska. In Archaeological Sediments in Context, edited by J. K. Stein and W. R. Farrand, pp. 127-141. Center for the Study of Early Man, Institute for Quaternary Studies, University of Maine, Orono.

Siebert, Jeffrey

2006 Introduction. In Space and Spatial Analysis in Archaeology, edited by Elizabeth Robertson, Jeffrey Seibert, Deepika Fernandez and Marc Zender, pp. xiii-xxiv. University of Calgary Press, Calgary.

Simek, J.F.

1984 A K-means approach to the Analysis of Spatial Structure in Upper Paleolithic Habitation Sites: Le Flagolet I and Pincevent Section 36. British Archaeological Reports, International Series. 20S, Oxford.

Sørensen, Marie Louise Stig

2000 Gender Archaeology. Polity Press, Cambridge

Spector, Janet D.

1993 What This Awl Means: Feminist Archaeology at a Wahpeton Dakota Village. Minnesota Historical Society Press, St. Paul.

Spencer, Richard

1959 The North Alaskan Eskimo: A Study in Ecology and Society. Bureau of American Ethnology Bulletin 171. Washington, D.C.

Stefansson, Vilhjalmur

1919 Stefansson-Anderson Arctic Expedition. Anthropological Papers of the American Museum of Natural History. Volume 14, Part I. 
Stewart, Henry

2002 Kipijuituq in Netsilik Society: Changing Patterns of Gender and Patterns of Changing Gender.In Many Faces of Gender: Roles and Relationships through Time in Indigenous Northern Communities. Edited by Lisa Frink, Rita Shepard and Gregory Reinhardt, pp. 121-150. University of Colorado Press, Boulder.

Stutz, Aaron Jonas, and George F. Estabrook

2004 Computationally intensive multivariate statistics and relative frequency distributions in archaeology (with an application to the Early Epipaleolithic of the Levant). Journal of Archaeological Science 31(12): 1643-1658.

Sun, Zhiwei

2012 A hierarchical clustering algorithm based on density for data stratification 2012 International Conference on Systems and Informatics pp. 2208-2211.

Taylor, Walter

1948 A Study of Archaeology. American Anthropological Association Memoir 69. American Anthropological Association, Menasha, Wisconsin.

Tomášková, Silvia

2011 Landscape for a good feminist. An archaeological review. Archaeological Dialogues 18(01): 109-136.

Tran, Thanh N., Klaudia Drab, and Michal Daszykowski

2013 Revised DBSCAN algorithm to cluster data with dense adjacent clusters. Chemometrics and Intelligent Laboratory Systems 120(January 2013): 92-96.

Tremayne, Andrew

2011 An Analysis of Faunal Remains from a Denbigh Flint Complex Camp at Matcharak Lake, Alaska. Arctic Anthropology 48(1):35-55.

2015 The Design of Arctic Small Tool Tradition Toolkits: An Example from Matcharak Lake, Alaska. North American Archaeologist 36:1-31.

Trigger, Bruce

2006 A History of Archaeological Thought. Cambridge University Press, Cambridge.

Tringham, Ruth

1991 Households with Faces: The Challenge of Gender in Prehistoric Architectural Remains in Engendering Archaeology: Women in Prehistory edited by Joan Gero and Margaret Conkey, pp 93-131. Blackwell Publishers, Oxford. 
Valentine, Benjamin, George D. Kamenov, Jonathan Mark Kenoyer, Vasant Shinde, Veena Mushrif-Tripathy, Erik Otarola-Castillo, and John Krigbaum

2015 Evidence for patterns of selective urban migration in the greater Indus Valley (2600-1900 BC): A lead and strontium isotope mortuary analysis. PLoS ONE 10(4): 1-20.

Van Stone, James

1970 Akulivikchuk: A nineteenth century Eskimo village on the Nushagak River, Alaska. Fieldiana: Anthropology 60: 1-123.

Voorrips, Albertus, and John M O'Shea

1987 Conditional Spatial Patterning: Beyond the Nearest Neighbor. American Antiquity 52(3): 500-521.

Waguespack, Nicole

2005 The Organization of Male and Female Labor in Foraging Societies : Implications for Early Paleoindian Archaeology. American Anthropologist 107(4): 666-676

Weisstein, Eric

2017 Bonferroni correction. Electronic Document. http://mathworld.wolfram.com/BonferroniCorrection.html, accessed November 12, 2017.

Willey, Gordon

1948 A Functional Analysis of "Horizon Styles" in Peruvian Archaeology. In A Reappraisal of Peruvian Archaeology, edited by W.C. Bennett, pp. 8-15. Society for American Archaeology Memoir 4. Society for American Archaeology, Menasha, Wisconsin.

Whelan, Carly, Adrian Whitaker, Jeffrey Rosenthal and Eric Wohlgemuth 2013 Hunter-Gatherer Storage, Settlement, and the Opportunity Costs of Women's Foraging. American Antiquity 78(4): 662-678.

Whelen, Mary K.

1995 Beyond Hearth and Home on the Range: Feminist Approaches to Plains Archaeology. In Beyond Subsistence: Plains Archaeology and the Postprocessual Critique. Edited by Philip Duke and Michael C. Wilson, pp. 46-65. University of Alabama Press, Tuscaloosa. 
Whitridge, Peter

1999 The Construction of Social Difference in a Prehistoric Inuit Whaling Community. PhD Dissertation, Department of Anthropology, Arizona State University.

2002 Gender, households, and the material construction of social difference: Metal consumption at a classic Thule whaling village. In Many Faces of Gender: Roles and Relationships through Time in Indigenous Northern Communities. Edited by Lisa Frink, Rita Shepard and Gregory Reinhardt, pp. 165-194. University of Colorado Press, Boulder.

2004 Landscapes, Houses, Bodies, Things: "Place" and the Archaeology of Inuit Imaginaries. Journal of Archaeological Method and Theory 11(2): 213-250.

Woodhouse-Beyer, Katharine

2001 Gender Relations and Socio-economic Change in Russian America: An Archaeological Study of the Kodiak Archipelago, Alaska, 1741-1867 AD. Ph.D. Dissertation, Department of Anthropology, Brown University, Providence.

Wylie, Alison

1982a An Analogy by Any Other Name is Just as Analogical: A Commentary on the Gould-Watson Dialogue. Journal of Anthropological Archaeology 1: 382401.

1982b Epistemological Issues Raised by a Structuralist Archaeology. in Symbolic and Structural Archaeology, edited by Ian Hodder, pp. 39-46. Cambridge University Press, Cambridge.

1985 The Reaction Against Analogy. Advances in Archaeological Method and Theory 8: 63-111.

1991 Gender Theory and the Archaeological Record: Why Is There No Archaeology of Gender? In Engendering archaeology edited by Joan Gero and Margaret Conkey, Oxford and Cambridge, MA pp. 31-56 


\section{Appendix: Code for HDBSCAN}

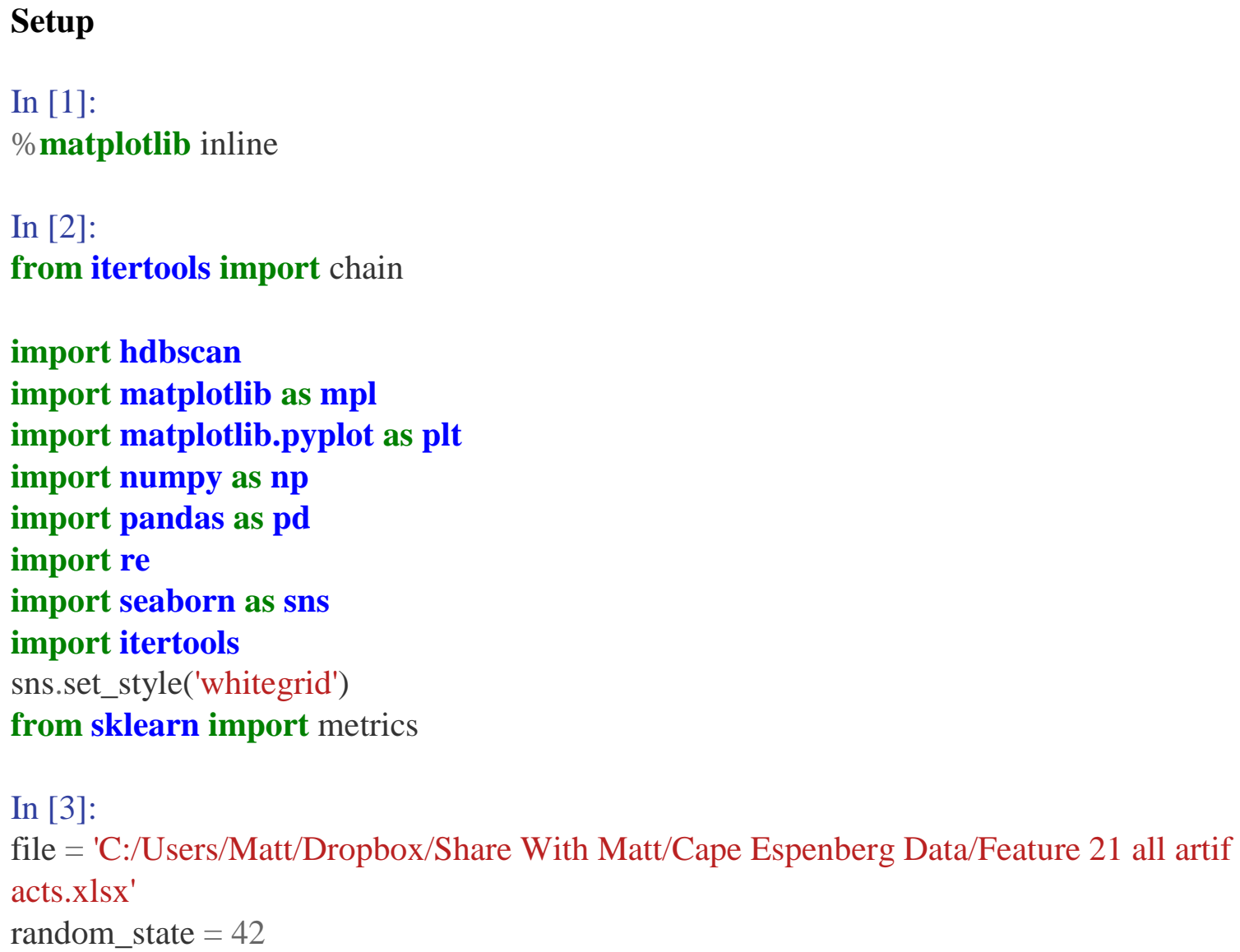

\section{Read and Clean Data}

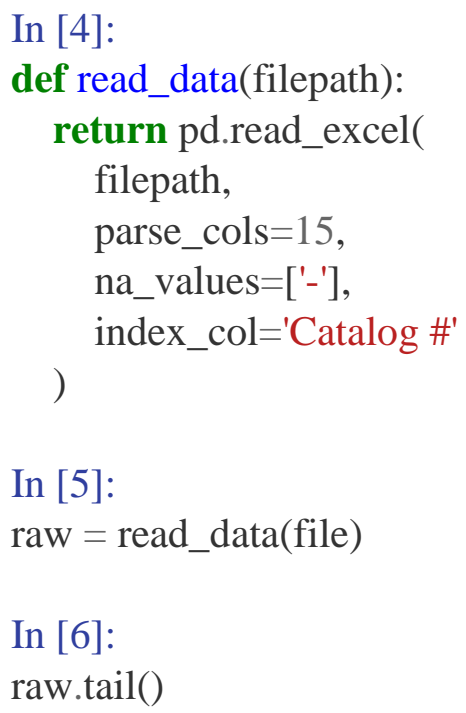




\section{Get unit number}

In [7]:

def extract_unit(series):

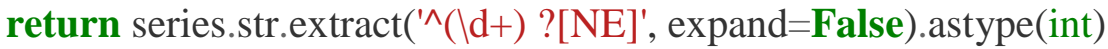

\section{Expand}

In [8]:

def apply_weights(df):

"'"'Duplicate rows by weight.""'"

def duplicate(df):

for index, row in df.reset_index().iterrows():

yield [row] * row['True Item count']

return pd.concat(chain.from_iterable(df.pipe(duplicate)), axis=1, ignore_index=True) . T

\section{Make points}

In [9]:

def quad_to_point_simple(quad):

"'"'Converts quandrant data to point data.

Currently uses midpoint of quad. Will be probabalistic in future.

"'"'"

mapping $=\{$

'N': 75,

'S': 25,

'W': 25,

'E': 75

\}

\# Split the quad into northing and easting.

north, east $=(\mathrm{x}$ for $\mathrm{x}$ in quad $)$

return mapping[north], mapping[east]

In [10]:

def quad_to_point(quad):

"'"'Converts quadrant data to point data.

The point chosen is drawn from a Uniform distribution.

"'"'"

mapping $=\{$ 


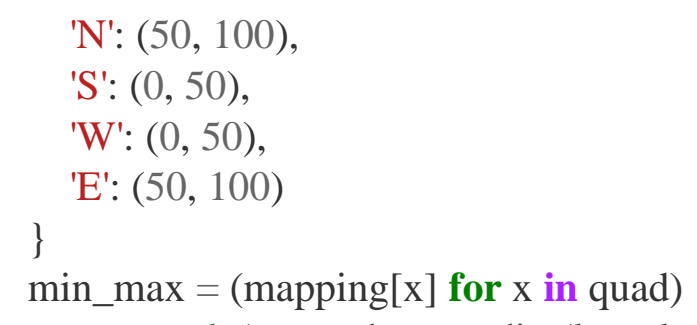

return tuple(np.random.randint(low=low, high=high) for low, high in min_max)

In [11]:

def make_points(row, method='simple'):

"'"'Returns a north-easting normalized to the entire site.

If the record has point data, use it.

Otherwise, convert the quadrant data.

"'"'"

funcs $=\{$ 'simple': quad_to_point_simple, 'probabilistic': quad_to_point $\}$

func $=$ funcs $[$ method $]$

if any(pd.isnull(row $[\mathrm{x}])$ for $\mathrm{x}$ in ('N cm', 'E cm')):

north, east $=$ func(row.Quad)

else:

north, east $=\left(\operatorname{int}(\mathrm{x})\right.$ for $\mathrm{x}$ in $\left.\left(\operatorname{row}\left[\mathrm{N} \mathrm{cm}^{\prime}\right], \operatorname{row}[\mathrm{E} \mathrm{cm} ']\right)\right)$

\# Each unit is $100 \mathrm{~cm}$

data $=($ row.unit_north $* 100+$ north, row.unit_east $* 100+$ east $)$

return pd.Series(data, index $=($ 'north', 'east') $)$

\section{Putting it together}

In [12]:

def clean_data(raw):

\# Drop observations that are missing key variables. Also drop last (bs) column

$\mathrm{df}=$ raw.dropna(how='all', subset=['Quad', 'N cm', 'E cm']).copy()

\# Add unit_north and unit_east

df['unit_north'] = df['Unit North'].pipe(extract_unit)

df['unit_east'] = df['Unit East'].pipe(extract_unit)

\# Split records containing multiple artifacts into separate observations

$\mathrm{df}=$ df.pipe(apply_weights)

\# Make points 
$\mathrm{df}=\mathrm{df} . j \operatorname{join}(\mathrm{df}$.apply$($ make_points, axis=1, args=('probabilistic', $)))$

return $\mathrm{df}$

In [13]:

df $=$ raw.pipe (clean_data)

In [14]:

df.head()

\section{Are there clusters?}

In [15]:

data1 $=\mathrm{df}[[$ 'east', 'north']].copy()

In [16]:

def base_plot(df):

return plt. scatter(df.east, df.north, $s=50$, linewidth $=0, c=' k$ ', alpha $=0.25$ )

In [17]:

data1.pipe(base_plot);

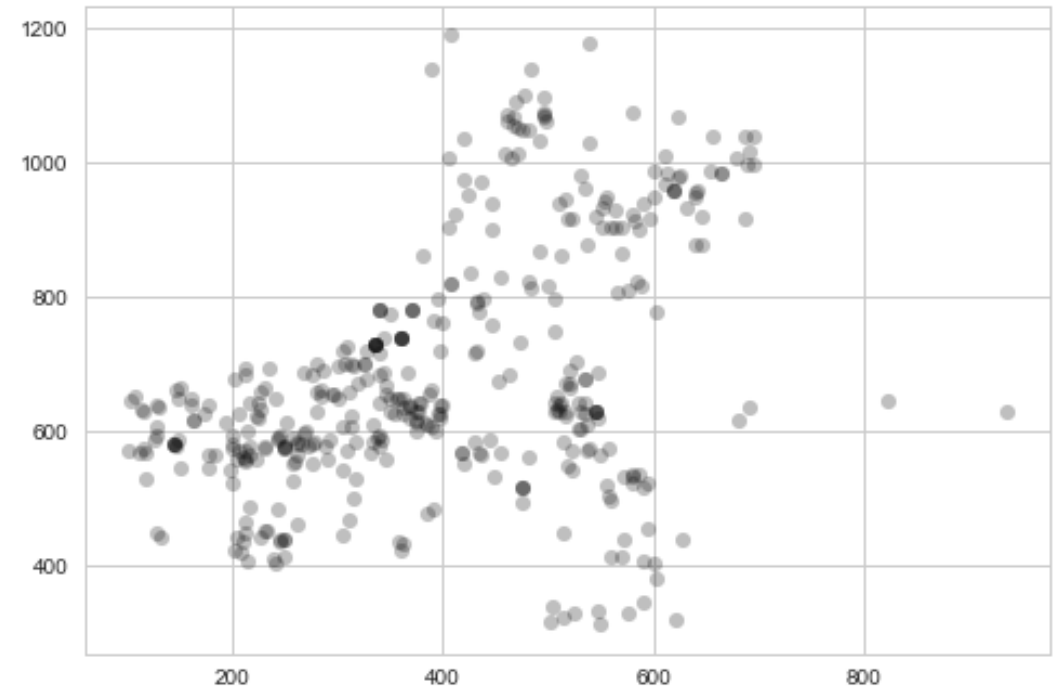

\section{HDBSCAN}

In [18]:

def model(df):

clusterer $=$ hdbscan.HDBSCAN(min_cluster_size =5)

clusterer.fit(df) 
return clusterer

In [19]:

clusterer $=$ data1.pipe $($ model $)$

\section{Plot}

In [20]:

def model_plot(df, clusterer):

with sns.color_palette('Set2', len(clusterer.labels_)) as color_palette:

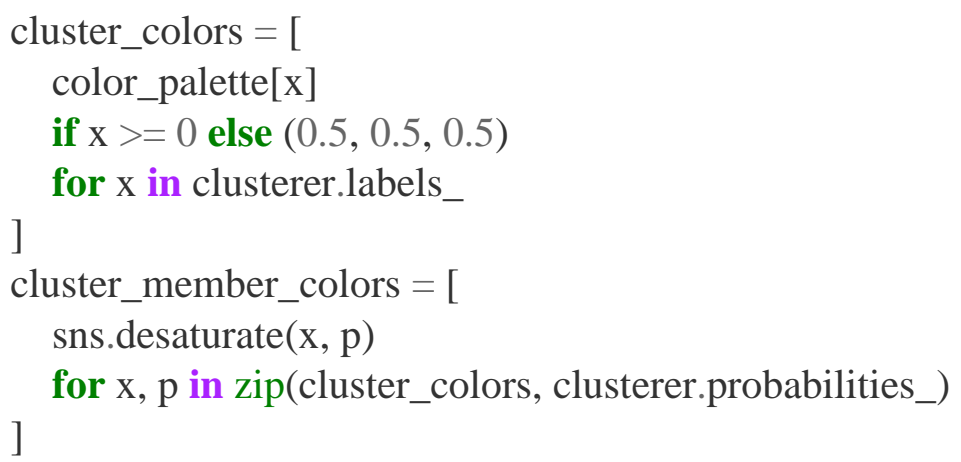

return plt.scatter(df['east'], df['north'], $\mathrm{s}=50$, linewidth=0, c=cluster_member_colors , alpha=0.5)

In [21]:

def get_markers(labels):

\# Get the list of available point types

unique_markers $=$ [marker for marker in mpl.markers.MarkerStyle.markers if marker ! $=$ 'o']

\# Make it a Series

markers $=$ pd.Series(unique_markers)

\# Add point as -1

markers $=$ markers.append $\left(p d . \operatorname{Series}\left(\left\{-1\right.\right.\right.$ : $\left.\left.\left.^{\prime}{ }^{\prime}\right\}\right)\right)$

\# Return the thing

return markers

In [22]:

def plot(raw, clusterer):

markers $=$ get_markers(clusterer.labels_)

colors $=[$

sns.desaturate('k', p) 
for $p$ in clusterer.probabilities

]

$\mathrm{df}=\operatorname{raw} \cdot \operatorname{copy}()$

df['labels_'] = clusterer.labels_

df['probabilities_'] = clusterer.probabilities_

groups $=$ df.groupby('labels_')

fig, ax = plt.subplots ()

for cluster, group in groups:

colors $=$ [sns.desaturate('b', p) for $\mathrm{p}$ in group['probabilities_'] $]$

ax.scatter(group['east'], group['north'], s=50, c=colors, linewidth=0, marker=markers [cluster], alpha $=0.5$ )

In [23]:

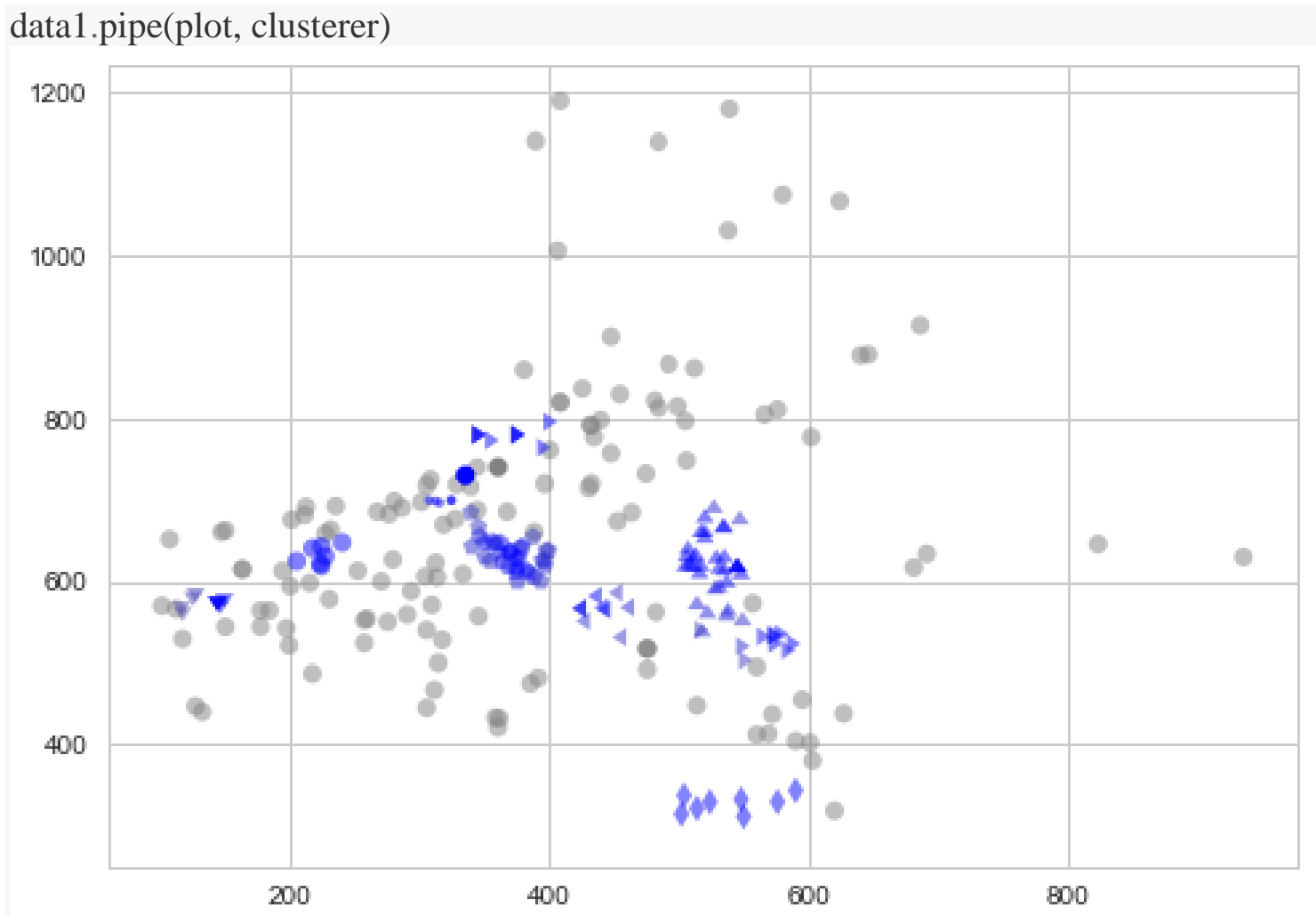

data1.pipe(model_plot, clusterer) 


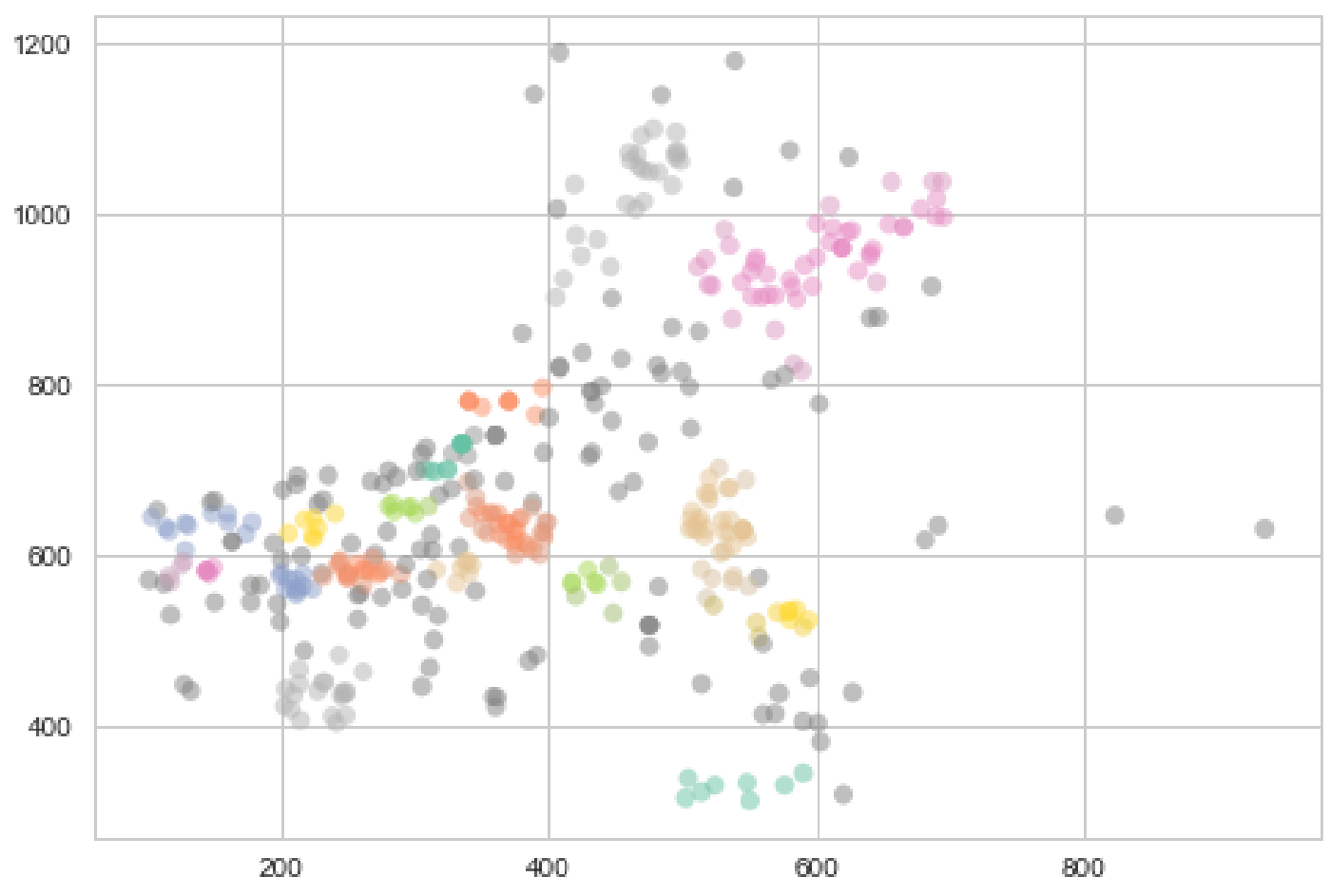

132 